\title{
Capital allocation and non-cooperative behavior in diversified firms
}

Citation for published version (APA):

André, J. F. (2011). Capital allocation and non-cooperative behavior in diversified firms. [Doctoral Thesis, Maastricht University]. Datawyse / Universitaire Pers Maastricht. https://doi.org/10.26481/dis.20110429ja

Document status and date:

Published: 01/01/2011

DOI:

10.26481/dis.20110429ja

Document Version:

Publisher's PDF, also known as Version of record

\section{Please check the document version of this publication:}

- A submitted manuscript is the version of the article upon submission and before peer-review. There can be important differences between the submitted version and the official published version of record.

People interested in the research are advised to contact the author for the final version of the publication, or visit the DOI to the publisher's website.

- The final author version and the galley proof are versions of the publication after peer review.

- The final published version features the final layout of the paper including the volume, issue and page numbers.

Link to publication

\footnotetext{
General rights rights.

- You may freely distribute the URL identifying the publication in the public portal. please follow below link for the End User Agreement:

www.umlib.nl/taverne-license

Take down policy

If you believe that this document breaches copyright please contact us at:

repository@maastrichtuniversity.nl

providing details and we will investigate your claim.
}

Copyright and moral rights for the publications made accessible in the public portal are retained by the authors and/or other copyright owners and it is a condition of accessing publications that users recognise and abide by the legal requirements associated with these

- Users may download and print one copy of any publication from the public portal for the purpose of private study or research.

- You may not further distribute the material or use it for any profit-making activity or commercial gain

If the publication is distributed under the terms of Article $25 \mathrm{fa}$ of the Dutch Copyright Act, indicated by the "Taverne" license above, 


\section{Capital Allocation and Non-Cooperative Behavior in Diversified Firms}


(C) Julius André, 2011

All rights reserved. No part of this publication may be reproduced, stored in a retrieval system, or transmitted in any form or by any means, electronic, mechanical, photocopying, recording or otherwise, without the prior permission in writing from the author.

\section{ISBN 9789461590466}

Cover: Julius André

Printed by: Datawyse bv, Universitaire Pers Maastricht 


\title{
Capital Allocation and Non-Cooperative Behavior in Diversified Firms
}

\author{
PROEFSCHRIFT \\ ter verkrijging van de graad van doctor \\ aan de Universiteit Maastricht, \\ op gezag van de Rector Magnificus, \\ Prof. mr. G.P.M.F. Mols \\ volgens het besluit van het College van Decanen, \\ in het openbaar te verdedigen \\ op vrijdag 29 april 2011 om 12.00 uur
}

door

Julius Frédéric André

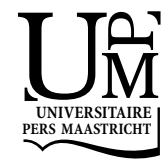




\section{Promotor}

Prof. dr. F. Moers

\section{Copromotor}

Dr. A. Brüggen

\section{Beoordelingscommissie}

Prof. dr. A. Vanstraelen (voorzitter)

Prof. dr. R.M.M.J. Bauer

Prof. dr. E. Peek (Erasmus University Rotterdam) 


\section{Acknowledgements}

One of the crucial documents in the pursuit of a $\mathrm{PhD}$ is without doubt the first research proposal. Not necessarily to actually carry out this research idea, an admittedly unlikely case, but to keep it and read it again once you have finished your doctorate. There is certainly no better way to remind you that without a host of people you would most likely still be stuck with that first proposal rather than a defendable dissertation. I am grateful to all those that have helped me reach the point that I can write these lines to thank them for their influence in completing my PhD studies.

First, I would like to thank my advisor Frank Moers for his invaluable insights into research, his support and his critical evaluation of my work. I have learned a lot from his abstract way of thinking and his enthusiasm for research was truly motivating. Also, I would like to thank my daily supervisor Alexander Brüggen for his input, feedback and encouragement over the last years. I much enjoyed working with Alexander and Frank and I am grateful to them both for the very pleasant and uncomplicated working atmosphere. I also extend my gratitude to Ann Vanstraelen, Rob Bauer and Erik Peek for their evaluation of my dissertation and their approval.

The time at the Wharton School at the University of Pennsylvania has been a very important element in my doctoral studies and I would like to thank Chris Ittner for the opportunity to join his department as a visiting scholar and for his reflections on my research. I would also like to thank the faculty and $\mathrm{PhD}$ students of the Accounting Department and other institutes at the Wharton School for their insightful comments on my work and for making my stay a truly memorable experience.

I also thank my colleagues at the Department of Accounting and Information Management at Maastricht University for a very enjoyable working environment. In particular, I would like to thank Caren Schelleman and Eddy Vaessen who gave me the idea and opportunity to join the department as a PhD student, Mark Vluggen for the knowledge transfer from senior to junior staff, Jeroen van Raak for being a much-appreciated roommate and Thomas Thijssens for highly sophisticated jokes and for proofreading the Dutch summary. I am also indebted to Peter Sampers for his professional contacts and his interest in my work as well as to Léon Pluim for his detailed explanations: Their cooperation has been invaluable during my research. Working in the PhD committee of the School of Business and Economics has been very enjoyable and I extend my gratitude towards Daniela Osterrieder, Daniela Snaphaan, Stefan Kühn, Nina Belei and Erik Pot. Erik has also provided much appreciated mathematical feedback. I am moreover grateful to the community of $\mathrm{PhD}$ students at the School of Governance, to Zina Nimeh and Yasser Mohy El-Din, Daniel Hann as well as to Frank Medefindt for making life in Maastricht outside the university walls much more enjoyable. 
A special thank you goes out to Clemens Köhler and Robin Braun. Together we have gone through the ups and downs of the entire $\mathrm{PhD}$ track not only in Maastricht but also overseas and I am happy to have shared this time and a lot of memorable moments with them.

After Arthur Schopenhauer had been awarded a $\mathrm{PhD}$ with the dissertation "On the Fourfold Root of the Principle of Sufficient Reason", his mother raised an eyebrow when looking at the title and remarked that this piece of work is most likely something for pharmacists. Quite in contrast, I feel very fortunate to have enjoyed tremendous support from my mother, father and sister and I am deeply grateful for all their trust and understanding throughout my time in Maastricht. Finally, I would like to thank Clara for her unconditional encouragement and her presence that has filled the last months of this work with so much sunlight.

Maastricht, February 2011

Julius André 


\section{Table of contents}

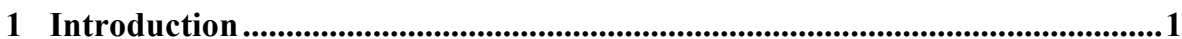

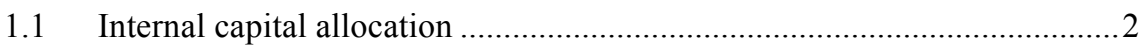

1.2 Divisional rent-seeking, stock options and the quality of internal capital allocations

1.3 Organizational design and the efficiency of internal capital allocations in

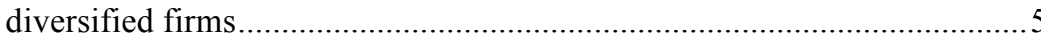

1.4 Capital budget renegotiations and the adverse consequences of delegating investment decision rights

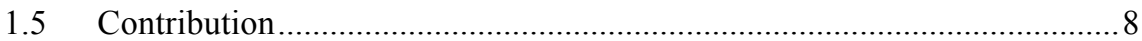

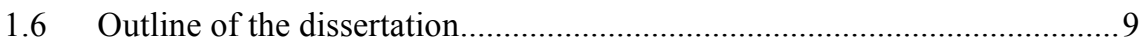

2 Divisional rent-seeking, stock options and the quality of internal capital

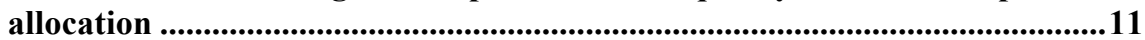

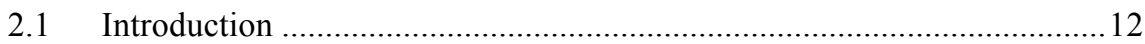

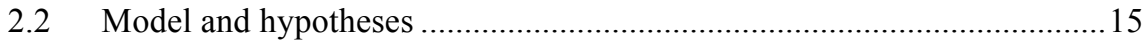

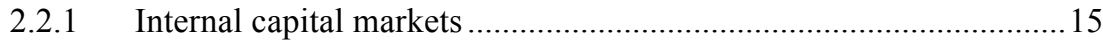

2.2.2 The Scharfstein and Stein (2000) model ........................................ 15

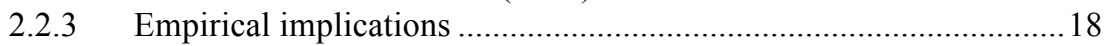

2.3 Sample, data, and econometric design....................................................20

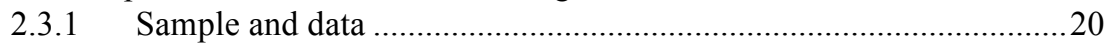

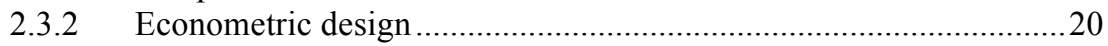

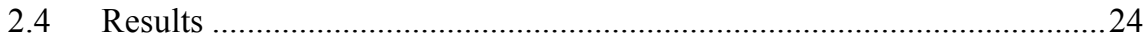

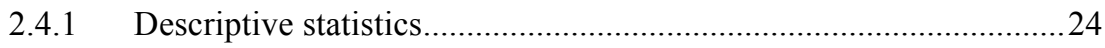

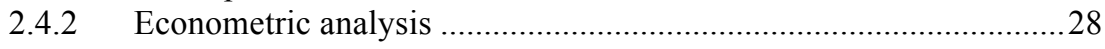

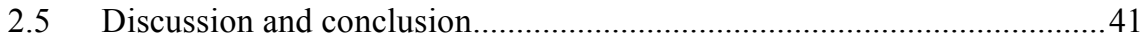

3 Organizational design and the efficiency of internal capital allocations in diversified firms ........................................................................................43

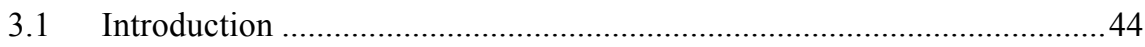

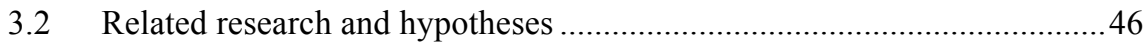

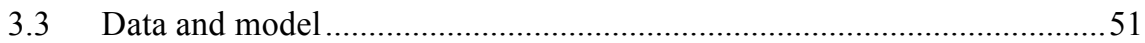

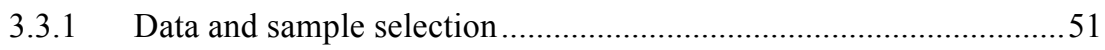


3.3.2 Model and variable construction ....................................................5

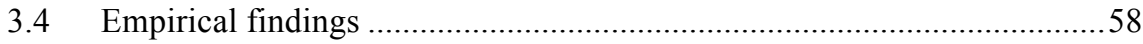

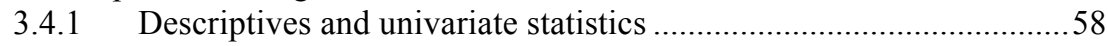

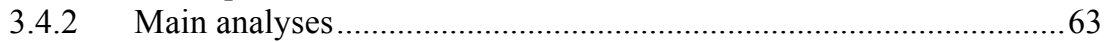

3.4.3 Additional analyses and robustness tests .....................................69

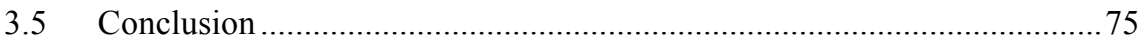

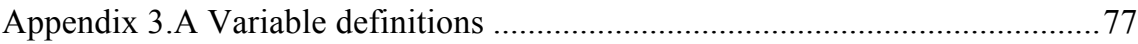

4 Capital budget renegotiations and the adverse consequences of delegating

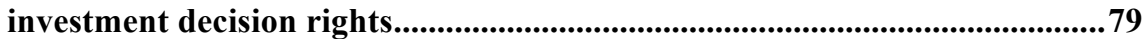

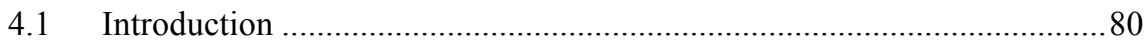

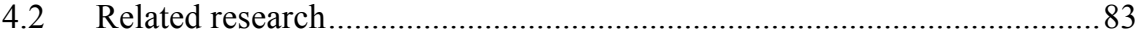

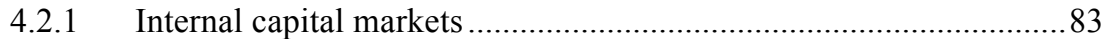

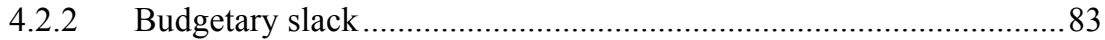

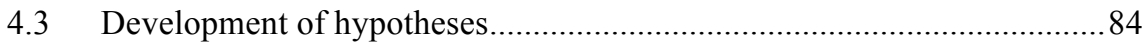

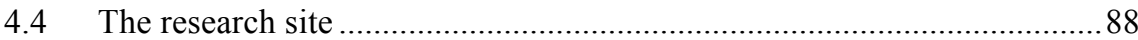

4.5 Nature of the data and descriptive statistics ........................................ 90

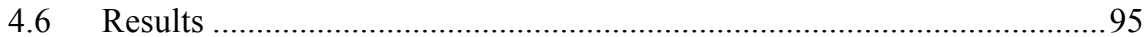

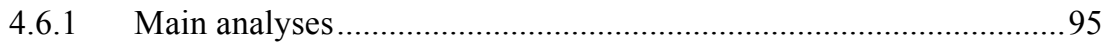

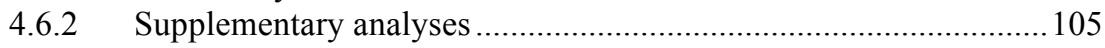

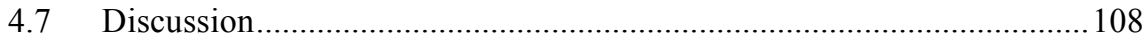

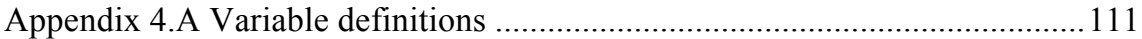

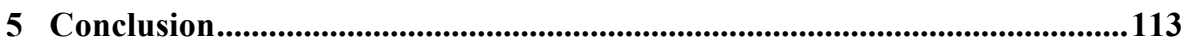

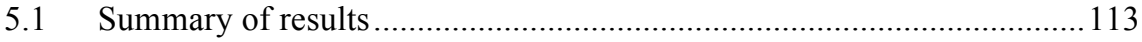

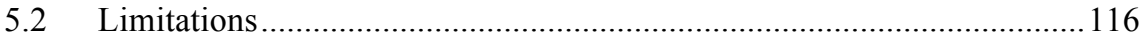

5.3 Implications and recommendations for future research ....................... 117

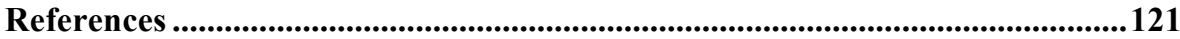

Summary in Dutch (Nederlandse samenvatting) ..........................................127

Summary in German (Deutsche Zusammenfassung) ...................................133

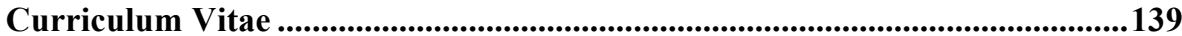




\section{Chapter 1}

\section{Introduction}

Over the last decades, worldwide economic activity and interaction have been considerably increasing to unprecedented levels. The consequence has not only been an overall growth in the number of firms but also an expansion of their respective operational perimeter. A look at the development of the average size of all USbased, non-financial companies listed in COMPUSTAT as measured by total assets, revenues and the number of employees in figure 1.1 clearly confirms this trend ${ }^{1}$. Between the beginning of the 1980s and middle of the 1990s, total assets and revenues remained at almost the same level before markedly increasing until 2009 by $136 \%$ and $110 \%$, respectively. With some decline in the $1980 \mathrm{~s}$, the number of employees underwent a closely comparable development, increasing by $67 \%$ between the mid 1990s and 2009. An end to this upward trend is not yet in sight.

As firms expand, the need to set up and operate well-functioning internal management structures to support the organization increases. Procedures to internally allocate financial resources within the firm for capital investments in fixed assets are of particular importance: Corbett and Jenkinson (1997) indicate that from 1970 to 1994 between $70 \%$ and $96 \%$ of new physical investments in the United Kingdom, Germany, Japan and the United States were financed out of internal funds instead of tapping external debt or equity markets. The recent crisis in the financial sector peeking in 2008-2009 further stresses the importance of internal financing, as firms were facing a sharp decline in the liquidity of external sources of finance. Indeed, Kuppuswamy and Villalonga (2010) find evidence that firms with the capacity to efficiently finance investments internally have gained more in value during this crisis than comparable firms that are more dependent on the external financial market. In this dissertation I analyze these internal financing structures, how inefficiencies can arise in these processes and how they can be resolved.

\footnotetext{
${ }^{1}$ Total assets and revenues are adjusted for inflation and fixed at the average consumer price index level of 1982-1984.
} 


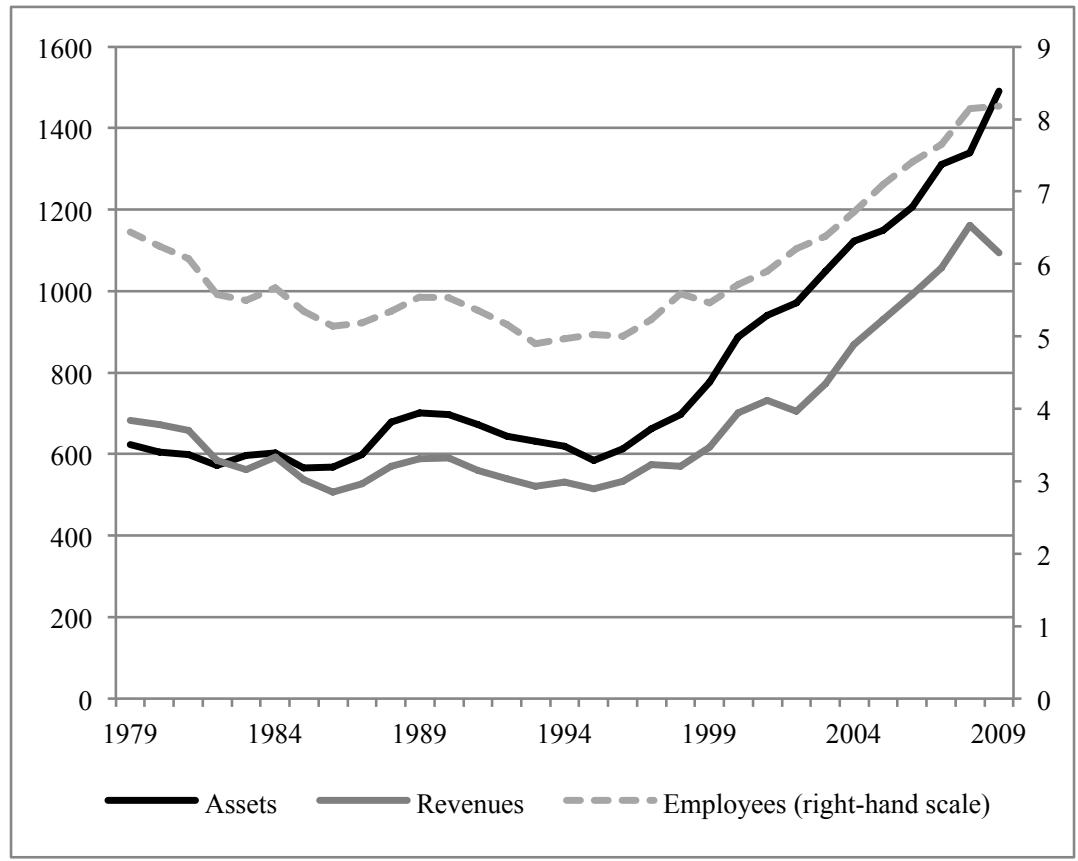

Figure 1.1 Development between 1979 and 2009 of assets and revenues (in million USD) as well as employees (in '000) of US firms as listed in the COMPUSTAT database, excluding the financial sector.

\subsection{Internal capital allocation}

Internal financing processes are of particular interest in firms that hold a diversified portfolio of distinct business units. In these firms, corporate headquarters are typically the sole interface with the external financial market, such as banks or the stock market, to raise capital for investment within the firm. Headquarters also centrally collect the funds that each of the firm's units generates and then decide how both external and internal funds are allocated among the business units. This capital allocation process can be used as part of the firm's cash management, ensuring that each unit is endowed with the financial means to meet its short-term liquidity requirements. Such cash pooling transactions are frequently automated and constitute only a small portion of the capital transfers between units. The larger, and more important share of capital allocations concerns the financing of investment projects in fixed assets that each business unit proposes.

A continuing debate among both practitioners and academics revolves around the benefits and drawbacks of these allocation processes to finance capital investments, also referred to as internal capital markets. This debate addresses not only the efficiency of the allocation process itself, but also the implications for the 
value of the entire diversified firm. Central to this discussion is the role of information asymmetry during investment decisions. Proponents of internal capital allocation processes argue that corporate management can more efficiently allocate capital to its units than an external provider of capital because management has inside information about the prospects of a unit, i.e. faces lower information asymmetries (Stein 1997). Raising external funds centrally for internal distribution can also be less costly compared to each unit contracting individually with the external financial market. Moreover, internal capital allocation can be particularly valuable when external capital is costly due to weak financial market conditions. Firstly, this can be the case if an established financial market is severely disrupted as in the recent financial crisis (Kuppuswamy \& Villalonga 2010). Secondly, it can be the case in emerging economies that lack an established financial market and a legal system that ensures reliable financial contracting. Several studies indeed show that diversified firms with the capacity to efficiently reallocate capital are more valuable in less-developed economies (cf. Khanna \& Palepu 2000; Fauver, Houston \& Naranjo 2003).

Contrasting these advantages, various arguments have been raised that internal capital allocations are bound to be inefficient and reduce corporate value. The common denominator of these arguments is the fact that even though allocations in diversified firms are referred to as internal capital markets, they lack the market component. More specifically, it is not a price mechanism, but the discretion of corporate management that determines the distribution of capital within the firm. Given that business units have an interest to execute as many of their investment projects as possible, they have an incentive to influence corporate management to lobby for a more favorable allocation of capital beyond the economic optimum (Rajan et al. 2000; Scharfstein \& Stein 2000). These self-interested influence activities are costly for the firm for at least three reasons. Firstly, capital is not necessarily reaching the unit that holds the best investment projects but that is most successful in lobbying. Secondly, managers spend time on lobbying rather than their assigned productive activities. Thirdly, a business unit that starts lobbying for more capital can provoke more lobbying from other units that would otherwise refrain from doing so. The lobbying process can therefore be self-reinforcing. Berger and Ofek (1995) show that diversified firms on average trade at a discount compared to the sum of their individually valued business units. This finding is frequently referred to as a consequence of the inefficiency of internal allocations.

More recent studies have contested this conclusion, showing that diversification is not necessarily related to a discount of the firm's value when controlling for endogeneity (Campa \& Kedia 2002) or when using more detailed data that allow to more precisely value business units of diversified firms (Villalonga 2004). However, regardless of whether diversified firms trade on average at a more or less pronounced discount, the preceding arguments illustrate 
that internal capital allocation processes not always operate efficiently. Given that firms face potential inefficiencies, it is interesting to note that the majority of the existing literature is silent on how firms can react to contain these inefficiencies. These reactions are analyzed in the first and the second study of this dissertation. More specifically, the first study considers adjustments to the firm-wide compensation structure, whereas the focus of the second study is on changes in the organizational design of diversified firms to reduce inefficient allocations. The first two studies are based on publicly available financial data of a cross-section of firms. This is the predominant approach that authors of related studies have taken, but this method has clear limitations when trying to more thoroughly examine the mechanics of internal capital allocations. The third study of this dissertation addresses this shortcoming and analyzes detailed data from the capital allocation process of a large diversified company. The third study specifically focuses on how delegating authority over investment projects within the firm affects the way in which managers renegotiate the initially requested capital budget to their own advantage. All three studies of this dissertation provide new insights about internal capital allocations that have not yet been addressed in the existing literature. The following sections provide a more detailed overview of each of these studies.

\subsection{Divisional rent-seeking, stock options and the quality of internal capital allocations}

The first study of this dissertation in chapter 2 investigates how capital misallocation problems can arise in diversified, multi-divisional firms and how compensation contract design can help to reduce these inefficient allocations. Inefficient allocations are triggered by division managers that attempt to obtain more capital than would be economically justified by the performance and outlook of the division they are heading. This lobbying for money is possible because the allocation of capital is largely a discretionary decision taken by the CEO, rather than driven by a market mechanism between two independent parties. Information asymmetries within diversified firms furthermore facilitate lobbying because division managers typically have better, more detailed knowledge about their investment prospects than the CEO. Division managers exploit this information asymmetry to obtain excess allocations because their goals do not necessarily coincide with those of the firm, as they are primarily concerned with their own division rather than the entire firm. Additionally, the information asymmetry as well as the specificity of tasks require the $\mathrm{CEO}$ to delegate and hire division managers. Due to the necessity to delegate the CEO cannot simply ignore influence activities or centralize all activities but has to make concessions, as division managers could otherwise threaten to leave the firm. 
The CEO faces two alternatives how to react to this type of lobbying within the firm. One response is to allocate more capital to the lobbying division, at the cost of foregoing more profitable investments elsewhere within the firm. Alternatively, the CEO can increase the lobbying manager's compensation and pay him directly to refrain from his influence activities. Directly paying the division manager is less costly for the firm because the capital budget is not distorted, but it reduces the firm's funds that the CEO could otherwise spend on perquisites to his personal benefit $^{2}$. The CEO will consequently rather distort the capital budget to the detriment of capital allocation efficiency instead of reducing his own consumption. Excess allocations should therefore be inversely related to a division manager's total compensation and coincide with a decline in allocation efficiency. Scharfstein and Stein (2000) describe this two-stage agency conflict between divisional managers, CEO and the owners of the firm but do not discuss how firms can respond to resolve this conflict. Adjusting the compensation contracts of the involved agents by tying their personal pay-off function closer to the value of the firm can in fact help to resolve this problem as any value-reducing behavior consequently affects their personal wealth. Issuing equity incentives should therefore be associated with a higher quality of internal capital allocations.

The expected positive relation between incentives and allocation quality as well as the inverse relation between compensation and allocation are tested using public financial reporting data of US firms and their segments from 1998 to 2004, augmented with hand-collected data on equity compensation as published in $10-\mathrm{k}$ forms filed with the SEC. The sample starts in 1998 because US reporting rules require financial segments to be reported according to the internal divisional structure from that year onwards, which is important to correctly estimate allocation efficiencies among divisions. The results confirm the predictions developed in this study. Excess allocations are found to decrease the capital allocation quality and are indeed inversely related to division manager compensation, i.e. the CEO resorts to the capital budget to pay lobbying managers rather than directly raising their compensation. The findings furthermore indicate that these excess allocations are lower when more firm-wide equity incentives are issued to employees within the firms. The results continue to hold under various robustness checks.

\subsection{Organizational design and the efficiency of internal capital allocations in diversified firms}

Whereas the first study of this dissertation considers compensation contracts to contain misallocations, the second study in chapter 3 analyzes whether changes in

\footnotetext{
${ }^{2}$ To a certain degree, this aspect can be illustrated with loss-making, government-subsidized farming: paying the farmer a wage directly is cheaper than indirectly subsidizing his farming activities.
} 
the organizational design of firms are an alternative response to misallocations in internal capital markets. Several theoretical papers on the causes of inefficiencies in internal capital allocations argue that division managers engage in non-cooperative lobbying for excess allocations as a result of the economic profile of the division that they are in charge of. For instance, Scharfstein and Stein (2000) present arguments that the extent to which a manager engages in non-cooperative behavior to obtain excess resources is defined by the relative returns of productive and lobbying activities. A division manager will thus be more likely to spend time on lobbying when returns from his division are comparatively low. In addition, Rajan et al. (2000) conjecture that the degree of non-cooperative behavior leading to misallocations is an increasing function of the diversity of the relative returns of each division within a firm. The underlying rationale is that divisions are less willing to generate profits when they know in advance that they have to cede part of their surplus to worse performing divisions in the same firm. In consequence, the CEO reallocates funds between divisions in an effort to reduce return discrepancies. While this can stimulate divisions to refrain from non-cooperative behavior, these cross-subsidies are costly because of the lost returns that the diverted funds would have generated with the first-best investment among the portfolio of divisions.

In equilibrium, firms have set up an optimal divisional organization in line with their operating environment that keeps non-cooperative behavior causing misallocations as low as possible. The operating environment is however subject to changes over time, as markets expand and shrink. The economic profile of each division can therefore develop differently over time, changing the division managers' incentives to engage in lobbying and changing the extent of misallocations within the firm. To reduce increasing misallocations, firms can adjust the divisional layout of the firm to alter the economic profile, considering that the latter is the root cause of inefficient allocations. More specifically, firms can change the composition of operations that each division manager supervises, i.e. adjusting their decision rights, so that their portfolio of operations reduces the incentive for non-cooperative actions. For instance, a strong and a low performing division may be combined to be supervised by one division manager so that the joint return of both units is closer to that of other divisions in the same firm. Misallocations among firms that change their divisional layout in an attempt to increase efficiency should therefore be more pronounced than among comparable firms without such changes. Furthermore, allocation efficiencies should improve among firms that change their organizational design, if this is indeed the intended purpose.

These expectations are tested using a sample of US multi-divisional firms in the period 1998-2007. Similar to the first study of this dissertation, this paper exploits the fact that the reported financial segments have to be aligned to the internal divisional structure in this time frame. Changes in the financial segments can thus be an indication that the divisional layout has been modified. 10-k forms 
filed with the SEC are used to verify that this is indeed the case, as companies report the underlying reasons for any segment change in these forms. This verification procedure therefore filters out unrelated reasons for segment changes such as mergers, acquisitions or divestments. The resulting sample provides evidence that confirms the expectations developed in this study. Firms are indeed more likely to adjust their organizational design when capital allocations in prior years have been relatively inefficient. Furthermore, the findings indicate that both allocation efficiency and shareholder wealth improve after the organizational layout is adjusted. Various additional robustness tests reinforce the evidence obtained in the main analysis.

\subsection{Capital budget renegotiations and the adverse consequences of delegating investment decision rights}

Almost all empirical studies on internal capital markets and the associated allocation problems resort to externally reported financial data, which requires approximating capital allocations that are not directly observable, rather than studying data from the capital budget process directly. One of the reasons for using publicly available reports is that many firms do not wish to provide access to internal allocation data for reasons of confidentiality. In the light of the limitations that external data imposes, many questions about the actual allocation process and the factors surrounding inefficient capital allocations remain unanswered.

Using a proprietary dataset on the capital budgeting process of a large diversified firm, the third study of this dissertation in chapter 4 aims in this direction and specifically focuses on budgetary slack that is incorporated during capital allocations in multidivisional firms. Slack is the share of capital allocated by a principal to a requesting agent beyond the necessary amount an investment in fact requires. It arises when the agent's motivation is to obtain excess allocations for private, perquisite consumption (Antle \& Eppen 1985), similar to lobbying for higher capital budgets as described in the internal capital markets literature. Incorporating slack is possible when an information asymmetry between principal and agent renders it too costly for the former to verify the exact nature of the proposed project.

Most studies on budgetary slack are based on either experimental or analytical settings with a single negotiation round between principal and agent during which the latter incorporates slack (e.g. Chow et al. 1988; Arya et al. 2000). Actual budgeting processes however frequently offer the agent the possibility to renegotiate part of the allocated budget due to the longer-term nature and inherent uncertainty about exact costs of most capital investments that span several investment periods. For instance, an agent may request more funds if contingencies arise throughout the 
project that the initial proposal and allocation did not cover. Moreover, the decision if and how much capital each proposed investment is being allocated is in many cases not entirely centralized as processing constraints would make it impossible for the principal to decide on all projects entirely himself. Instead, some of these investment decision rights are decentralized, reducing the workload for the principal but also lowering the control of the decisions taken.

The third study of this dissertation investigates the effect of decentralizing these decision rights on budgetary slack when agents have the possibility to renegotiate budgets. One of the predictions is that agents exploit the renegotiation possibility to incorporate more slack when the principal's control is lower, i.e. when the decision rights on an investment project are more decentralized. Furthermore, investment projects are uncertain and may develop differently than even the agent expected. The agent may therefore wish to discretionally reallocate the already incorporated slack between the project's different investment periods to fit his consumption preferences, i.e. postpone slack to a later period or conversely advance future slack for more immediate consumption. Consequently, another prediction of this study is that agents use renegotiations to shift slack between a project's investment periods to a higher extent when the delegation of decision rights is comparatively high, i.e. when the principal's control is low.

The predictions are tested with a detailed, internal dataset directly obtained from the capital allocation process of a globally operating, multidivisional firm that is listed in the index of a major European stock exchange. The findings confirm that incorporating and shifting slack are more pronounced the more the decision rights of a project are delegated. The results also show that agents tend to incorporate more slack when it is more difficult for the principal to detect these excess allocations. Shifting of slack is additionally found to be more pronounced when the agent faces less uncertainty about how a project will develop, i.e. when the agent is more able to adjust slack to his consumption preferences. These results hold under various robustness checks.

\subsection{Contribution}

The first study of this dissertation in chapter 2 contributes in several ways. The first contribution is of methodological nature: Most existing measures to estimate allocation efficiencies are based on only very few factors and heavily rely on a presumed comparability of a division in a diversified firm with single-segment firms in the same industry. While validated against these measures, this study offers a new approach that jointly takes more factors into consideration, is less reliant on the comparability assumption and offers a simple way to determine over- and underallocations. Second, this study is the first to provide empirical evidence that 
allocation and division manager compensation are indeed substitutes. Third, the results show that providing firm-wide equity incentives can be useful even when there are few operational interdependencies between divisions. Fourth, Oyer and Schaeffer (2005) propose that stock options issued to employees below top executive level are not used for incentive purposes. In line with Gerakos et al. (2007), this study shows that firm-wide equity plans do have incentive effects that realign the goals of division managers and CEO with those of the owners of the firm.

The contribution of the second study in chapter 3 is twofold. First, the literature on internal capital markets is to a large part defined by analyses of static, cross-sectional allocation settings. In contrast, this study focuses on the dynamic dimension of misallocations, illustrating a yet undocumented way in which firms contain inefficient allocations. Second, the majority of the literature on organizational design focuses on the question when decisions are delegated (e.g. Baiman et al. 1995; Moers 2006). Mookherjee (2006) notes however that very few studies analyze the determinants of the horizontal scope of authority within firms once the decision to delegate has already been taken. This study aims in this direction, providing evidence that internal capital allocations affect the divisional layout, i.e. the way that investment decision rights are repartitioned among division managers.

The third study in chapter 4 contributes firstly by investigating how agents exploit budget renegotiations in order to increase excess allocations under varying degrees of delegation, which has not been studied empirically in the extant literature on budgetary slack. Secondly, this chapter provides unique evidence that agents use renegotiations to shift slack between budget periods, which has not been explicitly analyzed before. Thirdly, this study contributes to the literature on internal capital markets, offering a more detailed perspective on how agents operate to obtain more capital during the allocation process. It shows that allocation quality varies not only between but also within companies since budgetary control is not necessarily the same for all investment projects. Fourth, this research stresses the importance to be aware of the multi-period nature of investment projects as agents change their behavior to obtain excess funds depending on the stage of an investment, which should affect how firms implement control in their capital budget processes.

\subsection{Outline of the dissertation}

Each of the following chapters describes one of the aforementioned three studies of this dissertation in detail. The autonomous structure of each chapter allows the three studies to be read separately or in different order than presented in this book. Chapter 2 presents the effect of firm-wide equity incentives on internal allocation 
quality, whereas chapter 3 illustrates the role of organizational design to contain allocation inefficiencies. Chapter 4 focuses on a more specific aspect of these internal allocation processes, namely how agents take advantage of budget renegotiations during multi-period investments to obtain and discretionally shift excess capital allocations to their own benefit. Chapter 5 summarizes the main findings of all three studies, discusses their implications and provides directions how future research can extend these results. 


\title{
Chapter 2
}

\section{Divisional rent-seeking, stock options and the quality of internal capital allocation ${ }^{3}$}

\begin{abstract}
We empirically investigate to what extent firms' resource allocation decisions are affected by the CEOs' response to division-managers' rent-seeking activities and whether equity incentives throughout the firm, i.e., Employee Stock Option Plans (ESOPs), can mitigate this problem. We argue that the CEO is herself an agent and prefers to use the capital budget as a substitute for increased take-home pay to compensate the division manager for his influence activities. Consistent with this argument, we empirically find that excess capital allocation is negatively associated with division-managers' take-home pay. We further argue and find that equity incentives throughout the firm alleviate this problem by increasing the quality of internal capital allocation.
\end{abstract}

\footnotetext{
${ }^{3}$ This chapter is based on a working paper co-authored with Frank Moers and Alexander Brüggen.
} 


\subsection{Introduction}

The allocation of resources within a firm is one of the most important decisions made by its management. Examples of such decisions are the allocation of funds for capital expenditures and $R \& D$ expenditures at the divisional level. These allocations are organized in so-called internal capital markets; individual divisions of a firm generate cash, which is transferred to the firm's headquarters, who then decides if and how to allocate the funds back to individual divisions. ${ }^{4}$ An important question with respect to internal capital markets is how resource allocation decisions that are taken internally differ from those taken in a marketplace. Both Alchian (1969) and Williamson (1975) indicate that the benefit of allocating capital internally is that investment projects are less troubled by information and incentive problems than would be the case with external financing. The main reason for this is that a firm's headquarters does a better job of monitoring and information production, which is driven by headquarters having all the 'control rights' (Stein 1997). The literature on the diversification discount, however, critically questions the efficiency of internal capital markets. In this paper, we empirically examine to what extent potential inefficiencies are driven by the CEO misusing the capital budget to respond to division-managers' rent-seeking activities and whether equity incentives alleviate this behavior.

Economic theory states that, for the allocation of capital to be efficient, the marginal return to investment should be equal across every investment project. However, efficient capital allocation gets undermined as soon as there are information asymmetry and agency problems. For example, investors in the external capital market are aware of the informational advantages and divergent preferences of CEOs, which leads to more costly financing and thus reduced efficiency. Similarly, division managers in an internal capital market have better information about divisional prospects and have preferences that do not necessarily coincide with those of the firm. Previous research shows that internal capital allocation has socialist tendencies, where weaker divisions get cross-subsidized by stronger ones. Following Scharfstein and Stein (2000) we focus on one explanation for this "socialism", being that the CEO is herself an agent and the distortion in internal capital allocation is the result of division-managers' successful rent-seeking behavior.

Division managers have an incentive to rent-seek as soon as the benefits of this outweigh the costs of directing time away from productive effort. Managers of highproductive divisions are thus less likely to engage in rent-seeking than managers of low-productive divisions because of the costs of this effort reallocation. If rentseeking occurs, then the CEO can respond to these activities by increasing the division manager's take-home pay or by allocating a larger share of a fixed capital

\footnotetext{
${ }^{4}$ Note that we use the terms 'division' and 'segment' interchangeably throughout this paper.
} 
budget to the division manager's division. Increasing take-home pay leaves the efficiency of internal capital allocation unaffected, but reduces the resources available to the CEO. In contrast, using the capital budget to pay rents allows the CEO to 'keep' the resources for her own consumption, but distorts the internal allocation of capital and thus investment decisions. The CEO thus faces a trade-off in which he sees the capital budget and take-home pay as substitutes. Given that the outcome of this trade-off is very likely to vary in a cross-section, the empirical implication is that we should observe this substitution in a cross-section. We therefore expect that a division's 'excess' capital allocation is negatively associated with the division manager's total pay.

Firm-wide equity incentives can play an important role in the efficiency of internal capital markets. These incentives not only affect the outcome of the above described trade-off, but also the necessity of making the trade-off. Equity incentives for the CEO increase the attention of the CEO to firm value, which makes the option to distort the capital budget less attractive. Further, a wider use of equity incentives for division managers helps division managers to internalize the impact of their actions on other divisions. In addition, since firm-wide equity incentives have retention effects, they make it more costly for the division manager to "threaten to leave". Unproductive efforts, such as rent-seeking, thus become less attractive, which decreases the need for the CEO to respond and distort the capital budget. Consequentially, we expect firm-wide equity incentives to increase the quality of a firm's internal capital allocation.

To test our expectations, we use segment data from the COMPUSTAT segment filings, compensation data from EXECUCOMP, and hand collected data on Employee Stock Option Plans (ESOPs) from 10-K forms, all over the time period 1998-2004. We choose fiscal year 1998 as the starting point of our sample period because this is the first fiscal year in which FASB Statement No. 131, Disclosure about Segments of an Enterprise and Related Information (SFAS 131) became effective (FASB 1997). SFAS 131 requires firms to report disaggregated information in a way consistent with the way management internally evaluates the performance of individual operating segments, which allows users to make the same assessments. Previous research shows that SFAS 131 has led to a significant improvement in the information environment (e.g., Berger \& Hann 2003) and we exploit this improvement in our sample selection.

Our empirical analysis proceeds in four steps. First, we estimate a benchmark model of within-firm capital allocation in which the allocation of capital to division $i$ in year $t$ is based on the division's relative size, profitability, and growth opportunities in year $t-1$. We extract the division-year specific residual from this model to proxy for a division's excess capital allocation; then take the firm-year specific variance of the residuals to proxy for the quality of a firm's internal capital allocation. Second, we validate the benchmark model by showing that the proxy for 
the quality of a firm's internal capital allocation is positively associated with a firmlevel proxy of ex-post internal capital market efficiency. Third, we show that, at the divisional level, excess capital allocations are negatively associated with division managers' total pay, after controlling for standard economic determinants of total pay. We interpret this finding as evidence of the CEO using the capital budget as a substitute for increased take-home pay to compensate rent-seeking divisional managers, which is consistent with our expectations. Fourth, we show that, at the firm level, the incentives provided by ESOPs are positively associated with the quality of internal capital allocation, also consistent with our expectations. Finally, we re-run our analyses using numerous alternative specifications and also test the robustness of our results to sample selection problems and endogeneity concerns. We find that our results are robust to all these tests.

Our paper contributes to the literature in several ways. First, we provide evidence that inefficiencies in internal capital markets are, at least in part, driven by a two-layer agency problem (cf. Scharfstein \& Stein 2000). We find that, on average, CEOs distort internal capital allocation by using the capital budget as a substitute for increased take-home pay to adjust the overall compensation package of rent-seeking divisional managers. Second, we show that the design of incentive systems can mitigate the problem of misallocation. Although Wulf (2002) finds results consistent with firms designing firm-level incentives in an attempt to reduce influence activities, she acknowledges that her results are also consistent with arguments unrelated to issues of rent-seeking in internal capital markets. We contribute to the literature by empirically making an explicit link between the use of employee stock option incentives and the quality of internal capital allocations and show that ESOPs are used to align the interests of employees with those of the firm. Third, while the informativeness principle has been used to predict that firm-level incentives for divisional managers are less useful when there are few operational interdependencies between divisions (e.g., Bushman et al. 1995), we show that these incentives can actually be beneficial in these settings once investment decisions and issues of rent-seeking are taken into account. Finally, we add to the literature on whether stock options for employees other than the top executives have incentive effects. While Oyer and Schaeffer (2005) reject the incentive purpose of employee stock options in favor of the retention purpose, Gerakos et al. (2007) find that broadbased equity plans are used by firms whose compensation objective is incentives. Whatever the intended purpose, our model predicts that "on the job behavior" will be affected by these plans, either directly (incentives) or indirectly (retention), and consistent with this we provide empirical evidence that employee stock options increase the quality of an internal capital market.

Our paper proceeds as follows. In the next section we develop our theory and derive hypotheses. In section 2.3 , we describe our research method, and in section 
2.4, we describe the results of our empirical models. We discuss the results and conclude this study in section 2.5 .

\subsection{Model and hypotheses}

\subsubsection{Internal capital markets}

Building on Grossman and Hart (1986), Stein (1997) shows that internal capital markets can be superior to external capital markets and centralized financing (bank lending). In contrast to a bank or an external shareholder, the CEO has all the control rights and thus the rights to decide on how to allocate capital internally. These control rights, which are absent in external (centralized) financing, provide the CEO with greater incentives to monitor and engage in a process called "winnerpicking". That is, the CEO can actively shift capital from one division to another based on the expected returns of the divisions. The internal capital market can be more efficient than the external capital market because of this reallocative power of the CEO.

Despite the benefits of internal capital markets versus external capital markets, there is a huge debate in both the academic and more practice-oriented literature about the value of diversified firms (e.g., Villalonga 2004; Lins \& Servaes 1999; Rajan et al. 2000; Stowe \& Xing 2006). Several studies have investigated the use and effects of diversification of a firm and in particular the question whether internal capital markets are efficient. Studies by, for example, Lang and Stulz (1994), Berger and Ofek (1995), and Servaes (1996) find that diversified firms trade at a discount relative to non-diversified firms. Although recent studies claim that this diversification discount is the result of measurement error and biased samples (e.g., Whited 2001; Villalonga 2004), a more fundamental question is why internal capital markets would be inefficient.

The main reason why an internal capital market might be inefficient is related to the same reason why it might be efficient, i.e., the reallocative power of the CEO. The CEO of a diversified firm might do a poor job in allocating the funds that are generated by some divisions. Scharfstein and Stein (2000) argue that such inefficiencies are driven by a two-layer agency problem where the CEO might misuse the capital budget to compensate a division manager for his rent-seeking activities. To explain the argument more fully, we repeat the main features of their model and use it to develop a number of cross-sectional empirical implications.

\subsubsection{The Scharfstein and Stein (2000) model}

The model is a two-period model with periods labeled 1 and 2. At time 1, the CEO of a two-division firm hires two new managers, each of whom manages the assets in place of one division. The division manager can spend time on productive effort $e_{i}$ 
and/or on non-productive, rent-seeking activities $r_{i}$. He does, however, need to allocate his time, given that he has a time constraint of $h=e_{i}+r_{i}$. The productive effort translates into output of the division at time 1 of $\theta_{i} f\left(h-r_{i}\right)$, where $\theta_{i}$ is a measure of productivity and $f(\cdot)$ is an increasing concave function. The division manager receives private benefits from the output of his own division of $\gamma \theta_{i} f\left(h-r_{i}\right)$ and the CEO receives private benefits of $\phi \theta_{i} f\left(h-r_{i}\right)$ from each division.

Any rent-seeking activities by the division manager are personally costly at time 1, as they direct time away from productive effort and reduce output. Specifically, the costs amount to $\gamma \theta_{i}\left[f(h)-f\left(h-r_{i}\right)\right]$. The benefit of the rent-seeking activities is, however, an increase in his outside options at time 2 equal to $g\left(r_{i}\right)$, where $g(\cdot)$ is an increasing concave function with $g(0)=0$. Note that, for simplicity, the outside options for the division managers at time 1 are normalized at zero.

At time 2, all assets are depreciated and production depends solely on newly invested capital. The CEO decides on the allocation of a fixed capital budget $\left(\bar{I}=I_{1}+I_{2}\right)$ and any wages $\left(w_{i}\right)$ to be paid by her to the division manager. If the division manager remains on the job, then output at time 2 equals $\theta_{i} f\left(I_{i}\right)$, where $k(\cdot)$ is an increasing concave function with $k^{\prime}(0)=\infty$. If the division manager is replaced, then the CEO incurs replacement costs of $X$ and output will drop to $\theta_{i} k\left(I_{i}\right)-X$. $^{5}$ The private benefits at time 2 for the division manager remain $\gamma$ times the output of his own division and that of the CEO $\phi$ times the output of each division. It is assumed that the CEO has all the bargaining power at time 2 and that she is always better off retaining the division manager (formally, $\phi X>g\left(r_{i}\right)$ ).

Before examining the impact of rent-seeking on the allocation of capital, it is important to first examine what happens in a first-best scenario. The first-best allocation of capital $\left(I_{i}=I_{i}^{*}\right)$, labeled "efficient allocation", is achieved when the marginal return to investment is equal across every investment project, which in this case implies

$$
\theta_{1} k^{\prime}\left(I_{1}^{*}\right)=\theta_{2} k^{\prime}\left(I_{2}^{*}\right)
$$

Based on this characterization of efficient capital allocation and the set-up described above, we can now analyze when rent-seeking occurs and what impact it has on the efficiency of capital allocation. In particular, the above implies that a division manager rent-seeks if

$$
g\left(r_{i}\right)>\gamma \theta_{i}\left[k\left(I_{i}^{*}\right)+f(h)-f\left(h-r_{i}\right)\right] .
$$

That is, any benefits from a rise in outside options due to rent-seeking must be higher than the private benefits received from an efficient allocation of capital plus

\footnotetext{
${ }^{5}$ The replacement costs are caused by, for example, valuable acquired firm-specific capital leaving the firm.
} 
the cost of rent-seeking. ${ }^{6}$ The rent-seeking condition thus shows that, even though all division managers have the opportunity to rent-seek, not all of them will do so because some are so productive that they incur too much cost from directing time away from productive effort and/or derive sufficient utility from the efficient allocation of capital at time 2 .

If the rent-seeking condition holds, then the equilibrium amount of rentseeking is given by

$$
g^{\prime}\left(r_{i}^{*}\right)=\gamma \theta_{i} f^{\prime}\left(h-r_{i}^{*}\right) .
$$

If the rent-seeking condition does not hold, then the division manager does not rent-seek at all. In summary form, the equilibrium level of rent-seeking is thus given by

$$
\hat{r}_{i} \begin{cases}r_{i}^{*} & \text { if } g\left(r_{i}^{*}\right)>\gamma \theta_{i}\left[k\left(I_{i}^{*}\right)+f(h)-f\left(h-r_{i}^{*}\right)\right] \\ 0 & \text { otherwise }\end{cases}
$$

To determine the optimal wage and allocation of capital, we maximize the CEO's utility over $I_{i}$ and $w_{i}$, subject to the division managers' retention constraints. That is,

$$
\begin{array}{ll}
\max _{I_{1}, w_{i}} & \phi \theta_{1} k\left(I_{1}\right)-w_{1}+\phi \theta_{2} k\left(\bar{I}-I_{1}\right)-w_{2} \\
\text { s.t. } & w_{1}+\gamma \theta_{1} k\left(I_{1}\right) \geq g\left(r_{1}\right) \\
& w_{2}+\gamma \theta_{2} k\left(\bar{I}-I_{1}\right) \geq g\left(r_{2}\right)
\end{array}
$$

We solve this model for the setting that best reflects the essence of the story, which is a setting where the manager of division 1 always rent-seeks, while the manager of division 2 never rent-seeks even though he knows that the manager of division 1 will. $^{7}$ The relevant first-order conditions of the Lagrangian in this setting are:

$$
\begin{aligned}
& \frac{\partial L}{\partial w_{1}}=-1+\lambda_{1} \leq 0 \\
& \frac{\partial L}{\partial I_{1}}=\phi\left[\theta_{1} k^{\prime}\left(I_{1}\right)-\theta_{2} k^{\prime}\left(\bar{I}-I_{1}\right)\right]+\lambda_{1} \gamma \theta_{1} k^{\prime}\left(I_{1}\right)=0
\end{aligned}
$$

where $\lambda_{1}$ is the Lagrange multiplier for the retention constraint of division manager $1 .^{8}$ Equation (2.9) shows that there will always be some distortion in the

\footnotetext{
${ }^{6}$ Alternatively, any net benefits of rent-seeking should be higher than the private benefits associated with the efficient allocation of capital, i.e.,$$
g\left(r_{i}\right)-\gamma \theta_{i}\left[f(h)-f\left(h-r_{i}\right)\right]>\gamma \theta k\left(I_{i}^{*}\right) .
$$

${ }^{7}$ Technically, we assume

$$
\begin{aligned}
& g\left(r_{1}^{*}\right)>\gamma \theta_{1}\left[k\left(I_{1}^{*}\right)+f(h)-f\left(h-r_{1}^{*}\right)\right] \\
& g\left(r_{2}^{*}\right) \leq \gamma \theta_{2}\left[k\left(I_{2}\left(r_{1}^{*}\right)\right)+f(h)-f\left(h-r_{2}^{*}\right)\right]
\end{aligned}
$$
${ }^{8}$ The Lagrange multiplier for the retention constraint of division manager $2, \lambda_{2}$, equals 0 , since it is never
binding.
} 
optimal allocation of capital. Given that $\lambda_{1} \theta_{1} k^{\prime}\left(I_{1}\right)$ is strictly positive, $\phi\left[\theta_{1} k^{\prime}\left(I_{1}\right)-\theta_{2} k^{\prime}\left(\bar{I}-I_{1}\right)\right]$ must be strictly negative, which implies that $I_{1}>I_{1}^{*}$.

Even though there will always be some misallocation, the extent of misallocation depends on how much the CEO prefers to use the fixed capital budget as opposed to wages to compensate the rent-seeking division manager. Specifically, it depends on whether the marginal cost of distortion to the CEO is outweighed by the marginal reduction in wage made possible by an increase in $I_{1}$, i.e.,

$$
\phi\left[\theta_{2} k^{\prime}\left(\bar{I}-I_{1}\right)-\theta_{1} k^{\prime}\left(I_{1}\right)\right]<\gamma \theta_{1} k^{\prime}\left(I_{1}\right)
$$

Assume that there is a capital allocation $I_{1}=I_{1}^{A}$ that solves the retention constraint of division manager 1 with $w_{1}=0$, i.e.,

$$
\gamma \theta_{1} k\left(I_{1}^{A}\right)=g\left(r_{1}^{*}\right)
$$

If equation (2.10) holds for $I_{1}=I_{1}^{A}$, then the optimal wages and allocation of capital are: $w_{1}^{A}=w_{2}^{A}=0 ; I_{1}^{A}>I_{1}^{*} ; I_{2}^{A}<I_{2}^{*} \cdot{ }^{10}$ If equation (2.10) does not hold for $I_{1}=I_{1}^{A}$, then a reduction in $I_{1}$ is necessary to make it hold (due to concavity of $f(\cdot)$ ), which leads to $I_{1}=I_{1}^{B}$ with $I_{1}^{A}>I_{1}^{B}$. However, with $I_{1}=I_{1}^{B}<I_{1}^{A}$ the retention constraint (equation (2.11)) is violated and the CEO must thus use the wage to solve the constraint. ${ }^{11}$ In this case, the optimal wages and allocation of capital are: $w_{1}^{B}>0 ; w_{2}^{B}=0 ; I_{1}^{B}>I_{1}^{*} ; I_{2}^{B}<I_{2}^{*}$.

\subsubsection{Empirical implications}

The above analysis indicates two mutually exclusive solutions to the CEO's problem. Assuming that these two solutions are both observed in a cross-section, as well as variation in the extent of the problem per se, then the model has the following cross-sectional empirical implications, where we use subscript $i$ for the division and $j$ for the firm:

i. $\operatorname{Cov}\left(w_{i j}, I_{i j}\right)<0$ for $I_{i j}>I_{i j}^{*}$.

ii. $\operatorname{Cov}\left(w_{i j}, I_{i j}\right)=0$ for $I_{i j}<I_{i j}^{*}$.

iii. $\frac{\partial \sigma_{j}}{\partial \phi_{j}}<0$, where $\sigma_{j}=\sqrt{\sum_{i=1}^{2}\left(I_{i j}-I_{i j}^{*}\right)^{2}} \cdot 12$

\footnotetext{
${ }^{9}$ Remember that the efficient allocation of capital requires that $\theta_{1} k^{\prime}\left(I_{1}^{*}\right)=\theta_{2} k^{\prime}\left(\bar{I}-I_{1}^{*}\right)$ in which case $\delta L / \delta I_{1}$ would be strictly positive.

${ }^{10}$ In this case, $\lambda_{1}<1$ satisfies equation (2.9), which implies $w_{1}=0$.

${ }^{11}$ This implies that $\lambda_{1}=1$.

${ }^{12}$ Note that $\sigma^{A}=\sqrt{\sum_{i=1}^{2}\left(I_{i}^{A}-I_{i}^{*}\right)^{2}}>\sigma^{B}=\sqrt{\sum_{i=1}^{2}\left(I_{i}^{B}-I_{i}^{*}\right)^{2}}$.
} 
iv. $\frac{\partial \sigma_{j}}{\partial\left(\Delta \hat{r}_{j}\right)}>0$, where $\Delta \hat{r}_{j}=\left|\hat{r}_{i j}-\hat{r}_{l \neq i, j}\right|$.

The first two implications lead to the following two hypotheses, respectively:

H1: $\quad$ Ceteris paribus, the extent of overallocation at the divisional level $\left(I_{i j}-I_{i j}^{*}>0\right)$ is negatively associated with division manager's total pay.

H2: $\quad$ Ceteris paribus, the extent of underallocation at the divisional level $\left(I_{i j}-I_{i j}^{*}<0\right)$ is not associated with division manager's total pay.

We interpret the third and fourth implication as a problem of divergent preferences and that incentive mechanisms can potentially mitigate this problem. In particular, equity incentives for division managers can help to reduce inefficiencies of an internal capital market as they focus the attention also on the other division and not only ones own. Consequently, power struggles and lobbying for capital are reduced $\left(\Delta \hat{r}_{j}\right.$ decreases $)$, since the division managers get penalized if they engage in such activities (cf. Milgrom and Roberts (1992)). Furthermore, once equity incentives have retention effects for division managers, as proposed by Oyer (2004), it becomes less likely that the retention constraint is binding and thus $\Delta \hat{r}_{j}$ decreases. In addition, by providing equity incentives to the CEO ( $\phi_{j}$ increases), her marginal cost of distorting capital allocation increases and she is thus less likely to use the capital budget to respond to influence activities. As a result, equity incentives throughout the firm help to increase internal capital market efficiency by improving the quality of the internal allocations. This argument is summarized in the following hypothesis.

H3: Firm-wide equity incentives are positively associated with the quality of a firm's internal capital allocations $\left(-1 \cdot \sigma_{j}\right)$. 


\subsection{Sample, data, and econometric design}

\subsubsection{Sample and data}

The sample of firms for this study is gathered via the COMPUSTAT segment filings from the years 1998 until 2004. We start our sample period in fiscal year 1998 because this is the year in which SFAS 131 became effective. SFAS 131 basically requires firms to disclose disaggregated information in a way consistent with their internal organization. As such, outsiders can make assessments in a way consistent with insiders' assessments, which allows us to make use of segment disclosures to infer the inner workings of the firm.

We use a sampling procedure similar to Berger and Ofek (1995) and Billett and Mauer (2003). Sampled firms are required to have at least two segments as well as two years of subsequent years of data. We exclude firms with segments in the financial sector. Further, sampled firms should have at least \$20 million in consolidated firm sales, and the sum of segment sales (assets) should be within one (25) percent of consolidated firm sales (assets). This data collection procedure results in an initial sample of 297 firms with 1,190 firm-year and 2,474 divisionyear observations over a period of seven years from 1998 until 2004.

We augment this dataset with manually collected data on company-wide stock option compensation plans using 10-k forms filed with the SEC. More specifically, we record details on the number of options outstanding per sample year and the change in outstanding options due to grants, exercises, and forfeitures. Further, we collect the average option price as disclosed in the $10-\mathrm{k}$ forms. In the firm-level models, various missing data reduce the sample to 291 firms with 801 firm-year observations.

To investigate the substitution effect between division manager pay and division capital allocation, we match the segment data with the EXECUCOMP files, which provide details on the compensation of the firms' highest paid executives. Besides CEO, CFO and other corporate-level functions, the job title descriptions at times reveal these executives to be heading one of the firm's divisions. Based on these job title descriptions and the firm's division names, we are able to manually trace 691 division-years (370 division managers) to individual division manager compensation data in EXECUCOMP.

\subsubsection{Econometric design}

The design of our econometric analysis is composed of four steps, which we explain below. First, we discuss the benchmark model that we use to develop our proxy for excess capital allocation at the divisional level $\left(I_{i}\right.$ vs. $\left.I_{i}^{*}\right)$ and the quality of internal capital allocation at the firm level $\left(-1 \cdot \sigma_{j}\right)$. Subsequently, we describe a model validating our proxy for the quality of internal capital allocation. We then describe the model used to test hypotheses 1 and 2, which links a division manager's total 
pay to excess capital allocation. Finally, we present our model that tests hypothesis 3 , which links equity incentives to the quality of internal capital allocation.

\section{Model 1: Benchmark model}

We first estimate a benchmark model to evaluate the transactions taking place within the internal capital markets of our sampled firms. Using insights from standard investment regressions based on q-theory, we specify a model that explains a division's share of a fixed capital budget using variables that reflect the division's relative size and investment opportunities. In particular, we use the following division-level model:

$$
\begin{aligned}
\text { CAPXSHARE }_{i j t}= & \beta_{0}+\beta_{1} \text { NRDIV }_{j t}+\beta_{2} \text { RELSIZE }_{i j, t-1}+\beta_{3} \text { AROA }_{i j, t-1} \\
& +\beta_{4} \text { SIBLINGAROA }_{k j, t-1}+\beta_{5} H_{I G H} G_{i j, t-1} \\
& +\beta_{6} \text { HIGH_GO }_{i j, t-1} * \text { RELSIZE } \\
& + \text { YearControls }+ \text { IndustryControls }+\beta_{7} \text { CAPXSHARE }_{i j, t-1},
\end{aligned}
$$

with CAPXSHARE $E_{i j t}=\frac{C A P X_{i j t}}{\sum_{i=1}^{n} C A P X_{i j t}}, \operatorname{RELSIZE}_{i j, t-1}=\frac{\operatorname{DIVASSETS~}_{i j, t-1}}{\sum_{i=1}^{n} \operatorname{DIVASSETS~}_{i j, t-1}}$, and

$\operatorname{SIBLINGAROA}_{k j, t-1}=\frac{1}{n-1} \sum_{k \neq i}^{n-1} A R O A_{k j, t-1}$.

$C A P X_{i j t}$ is the capital expenditure of segment $i$ in firm $j$ at time $t$, as reported in COMPUSTAT, and $n$ the number of segments in firm $j . N R D I V_{j t}$ signifies the number of segments in firm $j$. As the number of segments increase, the allocation share of each individual segment will, all else equal, decrease by construction and we control for this effect. To adjust for the influence of differences in segment size, we include the relative size of the division $\left(R E L S I Z E_{i j, t-1}\right)$, with DIVASSETS $i j$ being total identifiable segment assets. We adjust segment return on assets (ROA) for the respective (two-digit) industry ROA $\left(A R O A_{i j, t-1}\right)$. A segment with an ROA in excess of its concomitant industry level is expected to be allocated more internal funds and thus to invest more relative to other segments. The inverse holds for the impact of industry-adjusted ROA of the firm $j$ 's all other segments, i.e., siblings: the higher the sibling ROA, the less investment should take place in segment $i$. To incorporate this effect, we include the average industry-adjusted sibling ROA $\left(S I B L I N G A R O A_{k j, t-1}\right)$.

$H I G H \_G O_{i j, t-1}$ is a dichotomous variable equal to 1 if the segment has the highest growth opportunities (lowest book-to-market ratio) of all of a firm's 
segments and equal to 0 otherwise. We expect that segments with the highest growth opportunities receive a larger share of the capital budget to exploit these opportunities. To control for potential size effects in this relationship, we also include the interaction between $H_{I G H} G O_{i j, t-l}$ and $R E L S I Z E_{i j, t-l}$. Since segments are not publicly traded, we impute the book-to-market ratio for each segment using a procedure similar to Billett and Mauer (2003). In particular, we regress the book-tomarket ratio on firm assets, return on assets, and sales-to-assets ratio for a sample of single-segment firms. We separately estimate this regression for every two-digit SIC code for every year. We then fit the book-to-market ratio of each segment in each year using that year's estimated parameters for the industry of interest and the segment's assets, return on assets, and sales-to-assets ratio.

For all variables other than $N R D I V$, we consider values from the preceding period, as allocation decisions are assumed to take place at the beginning of each year on the grounds of preceding end-of-period information. The benchmark model furthermore controls for inter-temporal correlation by including the lagged segment share of the firm's total capital expenditures. The model is specified to control for year and industry fixed effects and corrects for potential within-firm error term correlation.

We use the benchmark model to develop a number of proxies associated with the misallocation of capital that are in line with the theoretical model. First, we use the division-year specific residual $\varepsilon_{i j t}$ as a proxy for $I_{i j t}-I_{i j t}^{*}$, i.e., excess capital allocation at the divisional level in a given year $\left(E X C E S S C A P X_{i j t}\right)$. Second, to test hypotheses 1 and 2 , we separate the overallocation of capital $\left(I_{i j t}>I_{i j t}^{*}\right)$ from the underallocation of capital $\left(I_{i j t}<I_{i j t}^{*}\right)$ by creating two variables based on EXCESSCAPX $_{i j t}$. OVERALLOCATION ${ }_{i j t} \quad\left(\right.$ UNDERALLOCATION $\left._{i j t}\right) \quad$ equals $E X C E S S C A P X_{i j t}\left(-1^{*} E X C E S S C A P X_{i j t}\right)$ if EXCESSCAPX $X_{i j t}$ is positive (negative) and zero otherwise. Finally, we use the firm-year specific standard deviation of the residual of the benchmark model $\operatorname{STD}_{\mathrm{jt}}\left(\varepsilon_{i j t}\right)$, as a proxy for $\sigma_{j t}$, i.e., the (lack of) quality of a firm's internal capital allocation. We multiply this variable with -1 to make sure that higher values are associated with higher quality $\left(I C A \_Q U A L I T Y_{j t}\right)$.

\section{Model 2: Validation}

To validate the proxy for the quality of internal capital allocation identified in the benchmark model $\left(I C A \_Q U A L I T Y_{j t}\right)$, we examine the extent to which this proxy is related to a proxy for the efficiency of the internal capital market after the fact. We define the following firm-level model:

$$
\begin{aligned}
\text { ICM }_{-} \text {EFF }_{j t}= & \delta_{0}+\delta_{1} \text { ICA_QUALITY }_{j t}+\delta_{2} \text { NRDIV }_{j t}+\delta_{3} \text { DIVERSIFICATION }_{j t} \\
& +\delta_{4} \text { DIVERSBTM }_{j t}+\delta_{5} \text { FIRMBTM }_{j t}+\delta_{6} \text { FIRMSIZE }_{j t} \\
& +\delta_{7} \text { GO_EMPL }_{j t}+\text { YearControls }+ \text { IndustryControls }+\eta_{j t},
\end{aligned}
$$


where ICM_EFF $F_{j t}$ is the Billett and Mauer (2003) end-of-the year efficiency measure based on industry-adjusted ROA. We include several additional variables assumed to influence internal capital market efficiency: the number of segments $N R D I V_{j t}$; the degree of diversification, using the entropy measure described in Bushman, Indjejikian and Smith (1995) (DIVERSIFICATION DIt $_{\text {; }}$; the diversity in

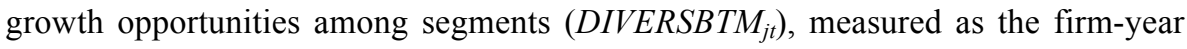
specific standard deviation of the imputed book-to-market ratios of a firm's segments (cf. Rajan et al. 2000); the firm's book-to-market ratio $\left(\right.$ FIRMBTM $\left._{j t}\right)$; firm size, measured as the log of the firm's total assets $\left(F I R M S I Z E_{j t}\right)$; the importance of human capital $\left(G O_{-} E M P L_{j t}\right)$, measured as the firm's growth opportunities per employee, i.e. the difference between the firm's market and book value of equity, divided by the number of employees (cf. Core and Guay 2001); and dichotomous variables for both year as well as type of industry. The model controls for potentially clustered errors at firm level.

\section{Model 3: Hypotheses 1 and 2}

We first specify a division-level model that investigates in how far excess capital allocations explain the overall level of the respective divisional manager's total pay:

$$
\begin{aligned}
L N_{-} \text {TOTALPAY } & = \\
& \alpha_{0}+\alpha_{1} \text { EXCESSCAPX }_{i j t}+\alpha_{2} R O A_{i j t}+\alpha_{3} S_{I Z E_{i j t}} \\
& +\alpha_{4} B T M_{i j t}+\alpha_{5} G O_{-} E M P L_{j t}+\text { YearControls } \\
& + \text { IndustryControls }+v_{i j t}
\end{aligned}
$$

where LN_TOTALPAY $Y_{i j t}$ is the log of the individual segment manager's total (takehome) pay; this pay includes salary, bonus, the total value of both restricted stock, as well as stock options granted using Black-Scholes (1973) valuation, long-term incentive payouts, and all other compensation items such as pension contributions. To specifically test hypotheses 1 and 2, we then run the analysis after replacing $E_{X C E S S C A P X_{i j t}}$ by OVERALLOCATION $N_{i j t}$ and UNDERALLOCATION ${ }_{i j t}$, i.e.,

$$
\begin{aligned}
L_{-} \text {TOTALPAY }_{i j t}= & \alpha_{0}+\alpha_{1 a} \text { OVERALLOCATION }_{i j t} \\
& +\alpha_{1 b} \text { UNDERALLOCATION }_{i j t}+\alpha_{2} \text { ROA }_{i j t} \\
& +\alpha_{3} \text { SIZE }_{i j t}+\alpha_{4} \text { BTM }_{i j t}+\alpha_{5} G_{-} \text {EMPL }_{j t} \\
& + \text { YearControls }+ \text { IndustryControls }+v_{i j t},
\end{aligned}
$$

The rent-seeking argument assumes that providing a rent-seeking manager with additional capital implies a reduction in the capital allocated to a manager that has no incentive to rent-seek. As explained in section 2.2.2, this incentive arises when the pay-off of productive activities is relatively higher than of rent-seeking 
activities. The CEO can therefore reduce the allocation to this manager without having to compensate him for the loss in resources (underallocation). As a result, we expect that the substitution effect between capital and pay takes place with respect to the overallocation of capital, but not the underallocation of capital, i.e., $\alpha_{1 a}<0$ and $\alpha_{1 a}=0$.

Previous compensation research shows that the entity's performance, size, growth opportunities, and importance of human capital have an influence on the total level of pay. We therefore incorporate variables representing segment size as measured by the segment's ROA $\left(R O A_{i j t}\right)$, the log of total segment assets $S I Z E_{i j t}$, imputed book-to-market ratio $\left(B T M_{i j t}\right)$, and growth opportunities per employee $\left(G O_{-} E M P L_{j t}\right)$. Further, we control for year and industry effects as well as potentially clustered errors at the firm level.

\section{Model 4: Hypothesis 3}

Hypothesis 3 states that equity incentives are positively associated with the quality of internal capital allocations. To test this hypothesis, we define the following firmlevel empirical model:

$$
\begin{aligned}
\text { ICA_QUALITY }_{j t}= & \gamma_{0}+\gamma_{1} \text { ESOPINC }_{j t}+\gamma_{2} \text { DIVERSIFICATION }_{j t} \\
& +\gamma_{3} \text { DIVERSBTM }_{j t}+\gamma_{4} \text { FIRMSIZE }_{j t}+\gamma_{5} \text { GO_EMPL }_{j t} \\
& + \text { YearControls }+ \text { IndustryControls }+\mu_{j t},
\end{aligned}
$$

where $E S O P I N C_{j t}$ measures all equity incentives (excluding the ones provided to the CEO) by computing the sensitivity of the firm-wide option plans to a one percent change in stock price, as in Core and Guay (2001). We also replace ESOPINC $j t$ with ESOPINC_ALL $L_{j t}$, which additionally contains CEO stock option incentives, and report results separately. All other variables are defined above. We control for year and industry fixed-effects and correct for errors potentially clustered at the firmlevel.

\section{$2.4 \quad$ Results}

\subsubsection{Descriptive statistics}

Tables 2.1-2.3 present selected summary statistics for divisional and firm level variables. To reduce the effect of outliers, we winsorize the continuous variables at the $1 \%$ and $99 \%$ level. Table 2.1 provides statistics for the entire sample of divisionyear observations $(n=2,474)$. The sample divisions' size in assets (DIVASSETS) ranges from USD 6 million to 10.9 billion with a mean (median) of USD 1.1 billion (USD 407 million). The average division has a return on assets (ROA) and return on assets above industry average $(A R O A)$ of $15.7 \%$ and $6.8 \%$, respectively. 
Divisional rent-seeking, stock options and the quality of internal capital allocation

Table 2.1

Descriptive statistics - Division-year observations

\begin{tabular}{llllll} 
& Mean & Median & Std.dev. & Min & Max \\
\hline CAPXSHARE & 0.343 & 0.262 & 0.287 & 0 & 1 \\
DIVASSETS (\$ millions) & 1,131 & 407 & 1,898 & 6 & 10,920 \\
SIZE & 6.030 & 6.009 & 1.514 & 1.729 & 9.298 \\
ROA & 0.157 & 0.154 & 0.162 & -0.568 & 0.744 \\
AROA & 0.068 & 0.060 & 0.163 & -0.625 & 0.651 \\
SIBLINGAROA & 0.071 & 0.063 & 0.115 & -0.625 & 0.651 \\
BTM & 0.875 & 0.743 & 0.549 & 0.033 & 2.956 \\
\hline
\end{tabular}

This table reports descriptive statistics on all divisions $(\mathrm{n}=2,474)$ across all sampled firms. Divisions are business segments as disclosed according to SFAS No. 131. CAPXSHARE is the division's share of capital expenditures in total firm capital expenditures DIVASSETS are total identifiable segment assets. SIZE is the natural logarithm of DIVASSETS. ROA is the segment's return on assets, calculated as segment net income divided by segment total assets. $A R O A$ is the segment's return on assets less the segment's respective (two-digit) industry return on assets. SIBLINGAROA is the average AROA of all other segments in the same firm. $B T M$ is the segment's book-to-market ratio, with imputed market values based on matching segments to samples of single-segment firms with corresponding two-digit SIC codes.

Table 2.2 displays division level statistics for the subset of division-year observations $(n=691)$ that could be matched to individual compensation data. Average division CEO total pay amounts to USD 1.2 million annually (TOTALPAY), ranging from USD $218 \mathrm{k}$ to USD 6.3 million. A cursory inspection of the key descriptive statistics in table 2.1 and 2.2 reveals that the divisions in the subset are, on average, slightly larger and more profitable in terms of assets and return on assets, respectively, and receive a larger share of the capital budget. In a robustness check, we correct for a potential sample selection bias using a Heckman procedure (see section "2.4.2.4 Robustness checks and additional tests" for details).

The firm-level variables, presented in table 2.3, show that the number of divisions within the sampled firms ranges from 2 to 6 (NRDIV), with 3 divisions for the median firm. The measure for the ex-post efficiency of the internal capital market $\left(I C M \_E F F\right)$ shows that the average firm exhibits inefficiency, while the median firm does not exhibit inefficiency, as in the original study by Billet and Mauer (2003). The sample firms' size in assets (ASSETS) ranges from USD 13 million to 48.3 billion with a mean (median) of USD 3.6 billion (USD 1.4 billion). Further, the mean change in the logarithm of the value of options held by nonexecutives excluding (including) the CEO for a $1 \%$ change in stock prices 
(ESOPINC and ESOPINC_ALL) is 6.152 (6.388), i.e., an average change of USD 470k (USD 595k).

We present Pearson correlations among the independent variables of the division-level models in table 2.4 and 2.5, and the correlations among the independent variables of the firm-level models in table 2.6. From a multicollinearity perspective, only the correlations between the equity incentive variables (ESOPINC and ESOPINC_ALL) and FIRMSIZE are relatively high. Specification tests, however, show that the Variance Inflation Factors are mostly at or below 2.00 with a maximum of 4.97, which indicates that none of our empirical models are troubled by multicollinearity problems.

Table 2.2

Descriptive statistics - Division-year observations with matched compensation data

\begin{tabular}{llllll} 
& Mean & Median & Std.dev. & Min & Max \\
\hline TOTALPAY (\$ 000) & 1,244 & 839 & 1,113 & 218 & 6,285 \\
LN_TOTALPAY & 6.834 & 6.733 & 0.738 & 5.384 & 8.746 \\
CAPXSHARE & 0.439 & 0.408 & 0.288 & 0 & 1 \\
DIVASSETS (\$ millions) & 1,354 & 573 & 2,155 & 6 & 10,920 \\
SIZE & 6.363 & 6.351 & 1.317 & 1.729 & 9.298 \\
ROA & 0.176 & 0.162 & 0.133 & -0.568 & 0.744 \\
AROA & 0.088 & 0.074 & 0.134 & -0.625 & 0.651 \\
SIBLINGAROA & 0.067 & 0.061 & 0.116 & -0.522 & 0.651 \\
BTM & 0.813 & 0.697 & 0.532 & 0.033 & 2.956
\end{tabular}

This table reports descriptive statistics on the subset of divisions across all sampled firms that could be matched to individual compensation data of the responsible division manager. This matching procedure led to a sub-sample of $n=691$ of the entire division-year sample of $n=2,474$. Divisions are business segments as disclosed according to SFAS No. 131. TOTALPAY is the segment manager's total pay, comprising salary, bonus, restricted stock and stock options grants at Black-Scholes (1973) value, longterm incentive payouts, and any other compensation item, e.g. pension contributions. LN_TOTALPAY is the natural logarithm of TOTALPAY. DIVASSETS are total identifiable segment assets. SIZE is the natural logarithm of DIVASSETS. ROA is the segment's return on assets, calculated as segment net income divided by segment total assets. $A R O A$ is the segment's return on assets less the segment's respective (two-digit) industry return on assets. SIBLINGAROA is the average AROA of all other segments in the same firm. $B T M$ is the segment's book-to-market ratio, with imputed market values based on matching segments to samples of single-segment firms with corresponding two-digit SIC codes. 
Table 2.3

Descriptive statistics - Firm-year observations

\begin{tabular}{llllll} 
& Mean & Median & Std.dev. & Min & Max \\
\hline ICM_EFF & -0.004 & 0.000 & 0.016 & -0.112 & 0.002 \\
ICA_QUALITY & -0.117 & -0.090 & 0.095 & -0.497 & -0.005 \\
ESOPINC & 6.152 & 6.194 & 1.938 & 0.000 & 9.888 \\
ESOPINC_ALL & 6.388 & 6.386 & 1.759 & 0.693 & 9.939 \\
NRDIV & 2.886 & 3.000 & 1.003 & 2.000 & 6.000 \\
DIVERSIFICATION & 0.384 & 0.341 & 0.377 & 0.000 & 1.340 \\
DIVERSBTM & 0.283 & 0.233 & 0.204 & 0.009 & 0.936 \\
FIRMBTM & 0.594 & 0.511 & 0.408 & -0.115 & 2.338 \\
ASSETS (\$ millions) & 3,585 & 1,401 & 5,646 & 13 & 48,263 \\
FIRMSIZE & 7.433 & 7.245 & 1.161 & 5.439 & 10.305 \\
GO_EMPL & 157 & 83 & 238 & -106 & 1,293 \\
\hline TIS & & &
\end{tabular}

This table reports descriptive statistics on the firm-level observations $(n=801)$. ICM_EFF is the ex-post internal capital market efficiency measure developed by Billett and Mauer (2003.) ICA_QUALITY proxies the quality of internal capital allocations; it is measured as the standard deviation of the error terms of a benchmark model that distinguishes abnormal capital allocations from those based on economic determinants such as growth opportunities. ESOPINC are the incentives provides by employee stock option plans to all employees but the CEO as in Core and Guay (2001), i.e., the sensitivity of firmwide option plans to a one percent change in stock price. ESOPINC_ALL is measured as ESOPINC and captures the incentives provided to all employees including the CEO. NRDIV is the number of divisions in the firm. DIVERSIFICATION is the entropy measure as in Bushman, Indjejikian, and Smith (1995), capturing the firm's degree of diversification. DIVERSBTM is the diversity in growth opportunities of the firm's segments, based on the standard deviation of the segments' imputed book-to-market ratios. FIRMBTM is the firm's book-to-market ratio. ASSETS are the firm's total assets. FIRMSIZE is the natural logarithm of ASSETS. GO_EMPL captures the importance of human capital and is measured as the difference between the firm's market and book value of equity, divided by the number of employees. 


\subsubsection{Econometric analysis}

\subsubsection{Benchmark model and validation}

Table 2.7 presents the results of our benchmark model. The explanatory power of this benchmark model is very high (Adjusted R-square $=82.54 \%$ ), which indicates that the allocation of internal capital is strongly associated with the variables of our model. In particular, internal capital allocation $\left(C A P X S H A R E_{t}\right)$ is significantly positively associated with lagged relative segment size $\left(R E L S I Z E_{t-1}\right)$, lagged segment industry-adjusted return on assets $\left(A R O A_{t-1}\right)$, lagged highest growth opportunity interacted with lagged relative size $\left(H I G H \_G O_{t-1} * R E L S I Z E_{t-1}\right)$, and lagged internal capital allocation $\left(C A P X S H A R E_{t-1}\right)$. Internal capital allocation is significantly negatively associated with the number of divisions $\left(N R D I V_{t}\right)$ and lagged sibling industry-adjusted return on assets (SIBLINGAROA $\left.A_{t-1}\right)$. All these findings are in line with our expectations. Interestingly, the findings for $A R O A$ and SIBLINGAROA indicate that there is an almost perfect relative performance evaluation, in the sense that the impact of own division performance and sibling performance on capital allocation is symmetric $(0.070, \mathrm{p}<0.01 ;-0.075, \mathrm{p}<0.01$, respectively).

Table 2.4

Pearson correlation statistics among independent variables - Division-year observations

\begin{tabular}{llllll} 
& 1 & 2 & 3 & 4 & 5 \\
\hline 1: NRDIV $_{t}$ & 1 & & & & \\
2: RELSIZE $_{t-1}$ & $-0.401^{* * *}$ & 1 & & & \\
3: AROA $_{t-1}$ & $-0.046^{* *}$ & 0.028 & 1 & & \\
4: SIBLINGAROA & -0.011 & 0.004 & $0.139^{* * *}$ & 1 & \\
5: HIGH_GO $_{t-1}$ & $-0.230^{* * *}$ & $0.195^{* * *}$ & 0.007 & -0.013 & 1 \\
\hline
\end{tabular}

This table reports Pearson correlation statistics across all sampled divisions and years $(n=2,474)$. Divisions are business segments as disclosed according to SFAS No. 131. NRDIV is the number of divisions in the firm. RELSIZE is the division's total identifiable assets divided by total firm assets. $A R O A$ is the segment's return on assets less the segment's respective (two-digit) industry return on assets. SIBLINGAROA is the average AROA of all other segments in the same firm. HIGH_GO is an indicator variable equal to 1 for the division with the lowest imputed book-to-market ratio (highest growth opportunities) within the firm, and 0 otherwise. $* * *, * *$, and $*$ denote significance at $1 \%, 5 \%$, and $10 \%$, respectively. 


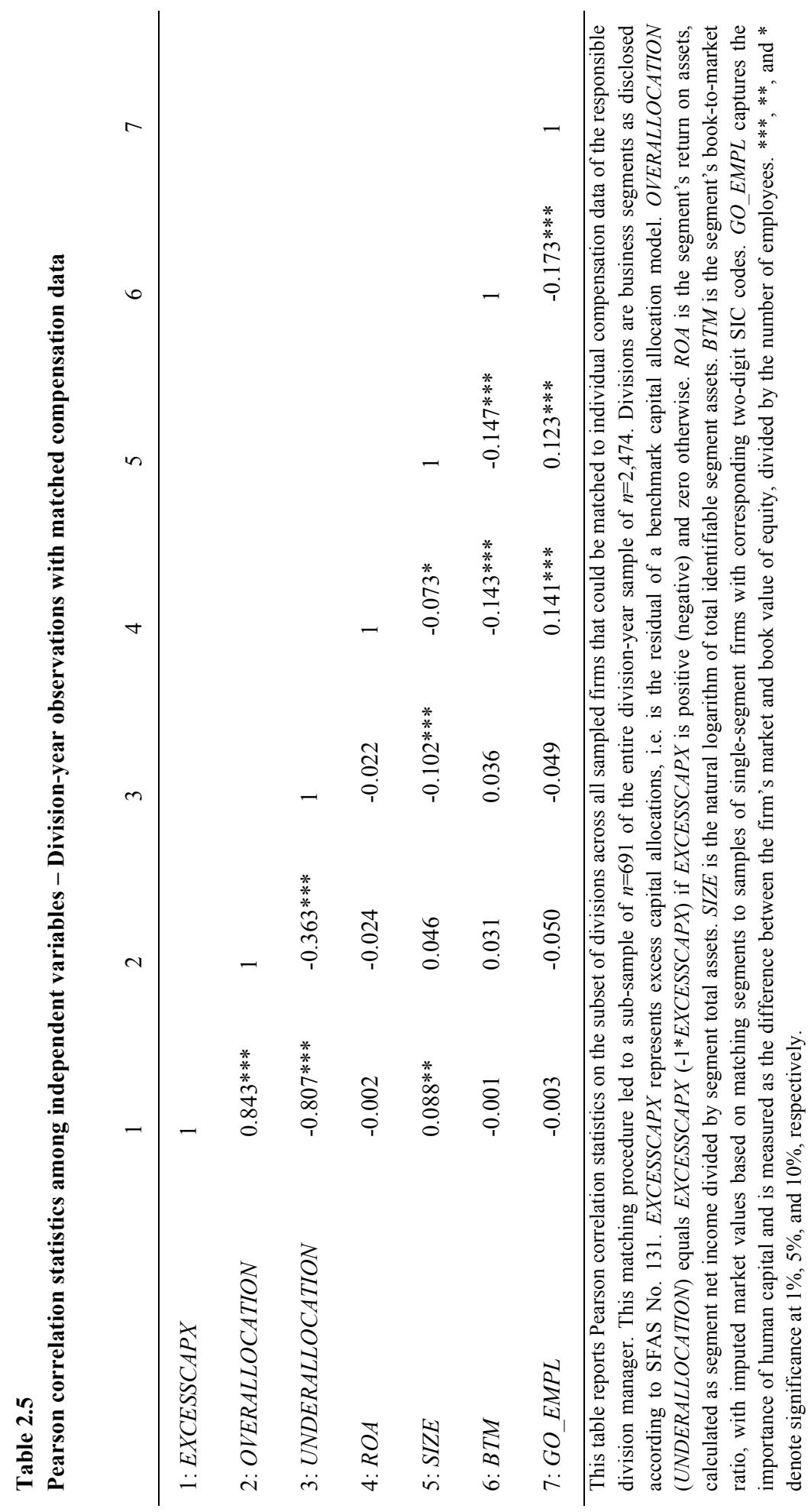




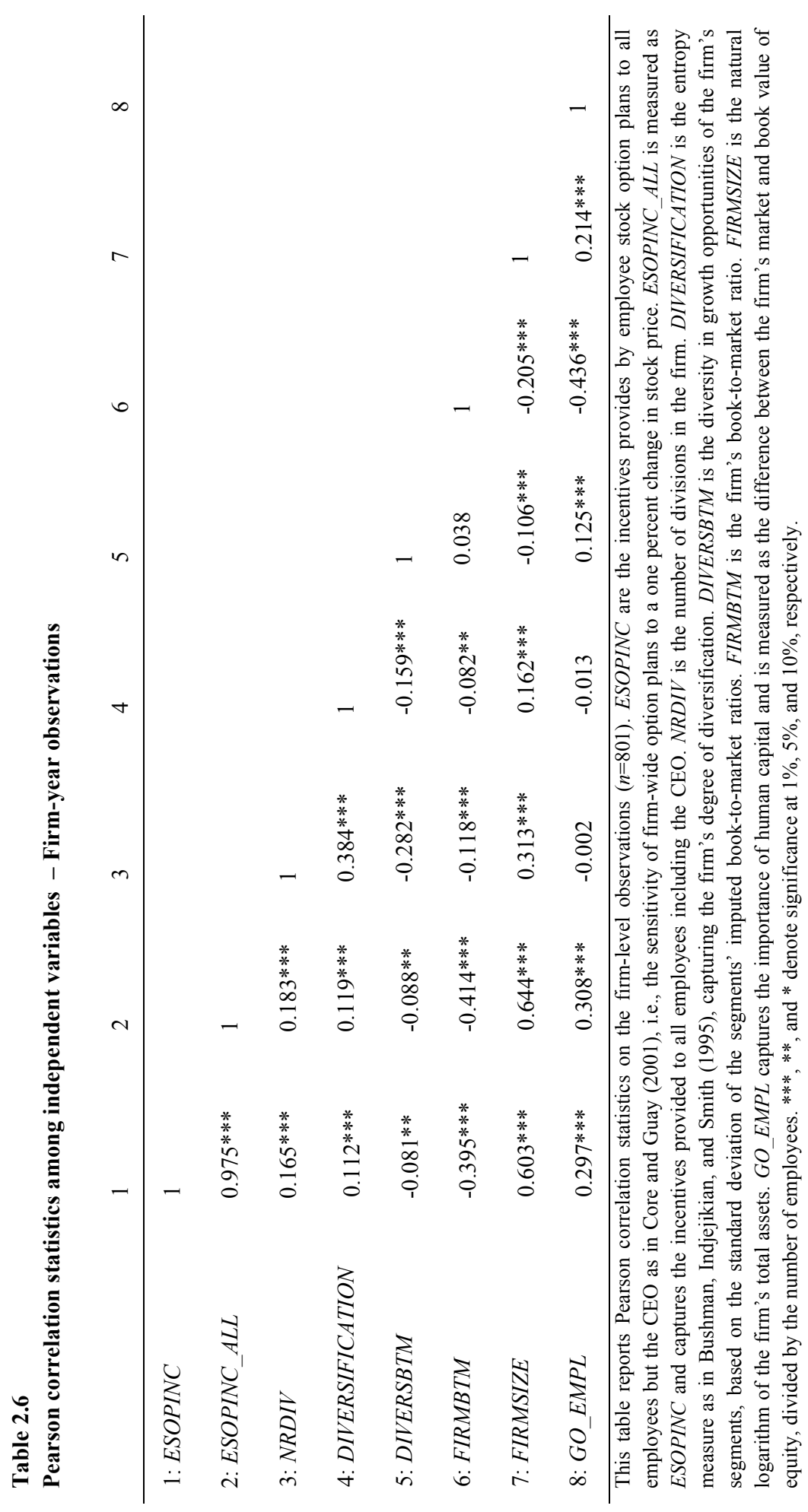


Table 2.7

Benchmark model of internal capital allocation

\begin{tabular}{|c|c|c|c|}
\hline \multirow[b]{2}{*}{ Independent variables } & \multirow[b]{2}{*}{$\begin{array}{l}\text { Predicted } \\
\text { sign }\end{array}$} & \multicolumn{2}{|c|}{$\begin{array}{l}\text { Internal capital allocation } \\
\quad\left(C A P X S H A R E_{t}\right)\end{array}$} \\
\hline & & Marginal effect & Prob. \\
\hline$N R D I V_{t}$ & - & -0.004 & $0.003 * * *$ \\
\hline RELSIZE $E_{t-1}$ & + & 0.300 & $0.000 * * *$ \\
\hline$A R O A_{t-1}$ & + & 0.070 & $0.000 * * *$ \\
\hline SIBLINGAROA $A_{t-I}$ & - & -0.075 & $0.004 * * *$ \\
\hline$H I G H \_G O_{t-1}$ & $?$ & -0.005 & 0.460 \\
\hline$H I G H \_G O_{t-1} * R E L S I Z E_{t-1}$ & + & 0.026 & $0.078 *$ \\
\hline CAPXSHARE $E_{t-1}$ & + & 0.654 & $0.000 * * *$ \\
\hline Adjusted R-square & & 0.825 & \\
\hline Segment-year observations & & 2,474 & \\
\hline
\end{tabular}

This table reports the regression results from estimating the benchmark model of internal capital allocation using $n=2,474$ division-year observations. Divisions are business segments as disclosed according to SFAS No. 131. Intercept, year controls, and industry controls are included but not separately reported. The dependent variable is the division's share of capital expenditures in total firm capital expenditures, CAPXSHARE. Several determinants are specified to explain this share. NRDIV is the number of divisions in the firm. RELSIZE is the division's total identifiable assets divided by total firm assets. $A R O A$ is the segment's return on assets less the segment's respective (two-digit) industry return on assets. SIBLINGAROA is the average AROA of all other segments in the same firm. HIGH_GO is an indicator variable equal to 1 for the division with the lowest imputed book-to-market ratio (highest growth opportunities) within the firm, and 0 otherwise. P-values in parentheses are based on heteroskedasticity-robust, firm-clustered standard errors (one-tailed for predictions, two-tailed otherwise). $* * *, * *$, and $*$ denote significance at $1 \%, 5 \%$, and $10 \%$, respectively.

Before proceeding, we first test whether the assumption of the benchmark model that capital allocation is a linear function of the explanatory variables is empirically valid. For this purpose, we use the regression specification error test (RESET) proposed by Ramsey (1969). The results of this test, whether based on the $F$-test or $L M$-test (see Wooldridge 2002), cannot reject the null-hypothesis that the benchmark model is correctly specified. As a result, there is no evidence of functional form misspecification.

We use the firm-year specific standard deviation of the residual of the benchmark model as a proxy for the quality of a firm's internal capital allocation and multiply this measure, as indicated earlier, by -1 to ensure that higher values are associated with higher quality. Table 2.8 presents the results of our validation test for this measure. The coefficient for ICA_QUALITY is positive and significant $(\mathrm{p}<0.10)$, which provides evidence that the quality of internal capital allocation is positively associated with the efficiency of a firm's internal capital market. Given that the distribution of $I C M \_E F F$ shows clustering of negative and nonnegative values, we also replace this continuous measure of internal capital market efficiency 
Table 2.8

Validation of proxy of quality of internal capital allocation

\begin{tabular}{|c|c|c|c|c|c|}
\hline \multirow[b]{2}{*}{ Independent variables } & \multirow[b]{2}{*}{$\begin{array}{c}\text { Predicted } \\
\text { sign }\end{array}$} & $\begin{array}{l}\text { Ex-po } \\
\text { (1) } \mathrm{O} \\
\text { (ICN }\end{array}$ & $\begin{array}{l}\text { Internal Cay } \\
\text { model } \\
\left.E F F_{t}\right)\end{array}$ & $\begin{array}{r}\text { Market } \mathrm{E} \\
\text { (2) PrC } \\
\text { (ICl }\end{array}$ & $\begin{array}{l}\text { ciency } \\
\text { it model } \\
\left.I N D_{t}\right)\end{array}$ \\
\hline & & $\begin{array}{r}\text { Marginal } \\
\text { effect } \\
\end{array}$ & Prob. & $\begin{array}{r}\text { Marginal } \\
\text { effect } \\
\end{array}$ & Prob. \\
\hline$I C A \_Q U A L I T Y_{t}$ & + & 0.013 & $0.090 *$ & 1.484 & $0.010 * * *$ \\
\hline$N R \overline{D I} V_{t}$ & $?$ & -0.002 & $0.013 * * *$ & -0.498 & $0.000 * * *$ \\
\hline DIVERSIFICATION $_{t}$ & $?$ & 0.003 & $0.058 *$ & 0.375 & $0.048 * *$ \\
\hline DIVERSBTM $_{t}$ & - & -0.009 & $0.025 * *$ & -0.772 & $0.010 * * *$ \\
\hline FIRMBTM $_{t}$ & $?$ & 0.000 & 0.997 & -0.418 & $0.007 * * *$ \\
\hline FIRMSIZE $_{t}$ & $?$ & 0.002 & $0.042 * *$ & 0.145 & $0.029 * *$ \\
\hline$G O \_E M P L_{t}$ & - & -0.007 & 0.114 & 0.019 & 0.476 \\
\hline $\begin{array}{l}\text { Adjusted R-square } \\
\text { Segment-year }\end{array}$ & & 0.076 & & 0.148 & \\
\hline observations & & 801 & & 801 & \\
\hline
\end{tabular}

This table reports the results from the estimation of the model used to validate the measure of internal capital allocation quality. It links internal capital allocation quality with the ex-post internal capital market efficiency measure developed by Billett and Mauer (2003), ICM_EFF, using ordinary least squares. For a Probit version of the model, ICM_EFF is recoded into the binary variable ICM_IND, with 1 for nonnegative values of $I C M_{-} E F F$ and 0 otherwise. Intercept, year controls, and industry controls are included, but not separately reported. Internal capital allocation quality is captured by ICA QUALITY; it is measured as the standard deviation of the error terms of a benchmark model that distinguishes abnormal capital allocations from those based on economic determinants such as growth opportunities. NRDIV is the number of divisions in the firm. DIVERSIFICATION is the entropy measure as in Bushman, Indjejikian, and Smith (1995), capturing the firm's degree of diversification. DIVERSBTM is the diversity in growth opportunities of the firm's segments, based on the standard deviation of the segments' imputed book-to-market ratios. FIRMBTM is the firm's book-to-market ratio. FIRMSIZE is the natural logarithm of the firm's total assets. GO_EMPL captures the importance of human capital and is measured as the difference between the firm's market and book value of equity, divided by the number of employees (coefficient multiplied by 1,000). P-values in parentheses are based on heteroskedasticity-robust, firm-clustered standard errors (one-tailed for predictions, two-tailed otherwise). ${ }^{* * *}, * *$, and $*$ denote significance at $1 \%, 5 \%$, and $10 \%$, respectively.

by an indicator variable. We construct $I C M_{-} I N D$, which equals 1 for nonnegative values of $I C M \_E F F$ (efficient), zero otherwise (inefficient), and run a probit model. The results of this analysis corroborate our findings for the continuous measure and show that the quality of internal capital allocation is positively associated with the probability that the internal capital market is efficient $(p=0.01)$. In sum, both the OLS and probit results provide evidence of the validity of our benchmark model.

Regarding the control variables, we find that the continuous measure of the efficiency of a firm's internal capital market $\left(I C M_{-} E F F\right)$ is positively associated with the level of diversification (DIVERSIFICATON) and the size of the firm (FIRMSIZE) and negatively associated with the number of divisions (NRDIV) and 
Table 2.9

Substitution between excess capital allocation and division manager total compensation

Segment manager's total compensation

(LN TOTALPAY $)$

(1)

\begin{tabular}{|c|c|c|c|c|c|}
\hline Independent variables & $\begin{array}{c}\text { Predicted } \\
\text { sign }\end{array}$ & $\begin{array}{r}\text { Marginal } \\
\text { effect }\end{array}$ & Prob. & $\begin{array}{r}\text { Marginal } \\
\text { effect }\end{array}$ & Prob. \\
\hline EXCESSCAPX $X_{t}$ & - & -0.409 & $0.002 * * *$ & & \\
\hline OVERALLOCATION $_{t}$ & - & & & -0.840 & $0.001 * * *$ \\
\hline UNDERALLOCATION $_{t}$ & $?$ & & & -0.088 & 0.787 \\
\hline$R O A_{t}$ & + & 0.622 & $0.004 * * *$ & 0.616 & $0.004 * * *$ \\
\hline$S I Z E_{t}$ & + & 0.362 & $0.000 * * *$ & 0.360 & $0.000 * * *$ \\
\hline$B T M_{t}$ & - & -0.107 & $0.057 *$ & -0.106 & $0.060 *$ \\
\hline$G O_{-} E M P L_{t}$ & + & 0.408 & $0.039 * *$ & 0.390 & $0.046 * *$ \\
\hline Adjusted R-square & & 0.504 & & 0.506 & \\
\hline $\begin{array}{l}\text { Segment-year } \\
\text { observations }\end{array}$ & & 691 & & 691 & \\
\hline
\end{tabular}

This table provides the estimates from a model examining the substitution effect between capital allocation and division manager total compensation. The model is applied to 691 observations of a full sample of $n=2,474$ division-years that could be matched to data on division manager compensation. Intercept, year controls, and industry controls are included but not separately reported. LN_TOTALPAY is the natural logarithm of the segment manager's total pay, comprising salary, bonus, restricted stock and stock options grants at Black-Scholes (1973) value, long-term incentive payouts, and any other compensation item, e.g. pension contributions. EXCESSCAPX represents excess capital allocations, i.e. is the residual of a benchmark capital allocation model. EXCESSCAPX is used as a determinant in Model 1. In Model 2, EXCESSCAPX is replaced by OVERALLOCATION and UNDERALLOCATION, where OVERALLOCATION (UNDERALLOCATION) equals EXCESSCAPX $\left(-1^{*} E X C E S S C A P X\right)$ if EXCESSCAPX is positive (negative) and zero otherwise. ROA is the segment's return on assets, calculated as segment net income divided by segment total assets. SIZE is the natural logarithm of total identifiable segment assets. BTM is the segment's book-to-market ratio, with imputed market values based on matching segments to samples of single-segment firms with corresponding two-digit SIC codes. GO_EMPL captures the importance of human capital and is measured as the difference between the firm's market and book value of equity, divided by the number of employees (coefficient multiplied by 1,000). P-values in parentheses are based on heteroskedasticity-robust, firm-clustered standard errors (one-tailed for predictions, two-tailed otherwise). ***,**, and * denote significance at $1 \%, 5 \%$, and $10 \%$, respectively.

the diversity in divisions' growth opportunities (DIVERSBTM). Similar results are found for the probability of efficiency, with the exception that also firm growth opportunities are negatively associated with the probability of efficiency.

\subsubsection{Hypotheses 1 and 2}

Table 2.9 presents the results of our model that links excess capital allocation at the divisional level to division manager's total pay. The coefficient for the variable 
Table 2.10

Firm-wide equity incentives and the quality of internal capital allocation

Internal capital allocation quality

(1)

\begin{tabular}{|c|c|c|c|c|c|}
\hline Independent variables & $\begin{array}{c}\text { Predicted } \\
\text { sign }\end{array}$ & $\begin{array}{r}\text { Marginal } \\
\text { effect }\end{array}$ & Prob. & $\begin{array}{r}\text { Marginal } \\
\text { effect }\end{array}$ & Prob. \\
\hline ESOPINC $_{t}$ & + & 0.008 & $0.012 * * *$ & & \\
\hline ESOPINC_ALL $L_{t}$ & + & & & 0.011 & $0.006 * * *$ \\
\hline DIVERSIFICATION $_{t}$ & $?$ & 0.002 & 0.801 & 0.002 & 0.826 \\
\hline DIVERSBTM $_{t}$ & - & 0.054 & $0.003 * * *$ & 0.056 & $0.002 * * *$ \\
\hline FIRMSIZE $_{t}$ & $?$ & 0.012 & $0.007 * * *$ & 0.010 & $0.041 * *$ \\
\hline$G O_{-} E M P L_{t}$ & - & -0.020 & 0.145 & -0.024 & $0.104 *$ \\
\hline
\end{tabular}

Adjusted R-square

0.107

0.110

Segment-year

observations

801

801

This table provides the estimates from a model examining the impact of stock option incentives on the quality of internal capital allocation using $n=801$ firm-level observations. Intercept, year controls, and industry controls are included but not separately reported. ICA_QUALITY proxies the quality of internal capital allocations; it is measured as the standard deviation of the error terms of a benchmark model that distinguishes abnormal capital allocations from those allocations based on economic determinants such as growth opportunities. Model 1 and Model 2 differ in the variable representing equity incentives, using ESOPINC and ESOPINC_ALL, respectively. ESOPINC are the incentives provides by employee stock option plans to all employees but the CEO as in Core and Guay (2001), i.e., the sensitivity of firm-wide option plans to a one percent change in stock price. ESOPINC_ALL is measured as ESOPINC and captures the incentives provided to all employees including the CEO. DIVERSIFICATION is the entropy measure as in Bushman, Indjejikian, and Smith (1995), capturing the firm's degree of diversification. DIVERSBTM is the diversity in growth opportunities of the firm's segments, based on the standard deviation of the segments' imputed book-to-market ratios. FIRMSIZE is the natural logarithm of the firm's total assets. GO_EMPL captures the importance of human capital and is measured as the difference between the firm's market and book value of equity, divided by the number of employees (coefficient multiplied by 1,000). P-values in parentheses are based on heteroskedasticity-robust, firmclustered standard errors (one-tailed for predictions, two-tailed otherwise). $* * *, * *$, and $*$ denote significance at $1 \%, 5 \%$, and $10 \%$, respectively.

EXCESSCAPX is negative and statistically significant $(\mathrm{p}<0.01)$, which implies that there is a negative relationship between the division manager's total pay and the excess allocation of capital. This finding is consistent with the argument that the allocation of internal capital acts as a substitute for increased take-home pay in compensating rent-seeking divisional managers. To specifically test hypotheses 1 and 2, we split excess capital allocation into overallocation (OVERALLOCATION) and underallocation (UNDERALLOCATION) of internal capital. The results of this analysis, also presented in table 2.9 , reveal that overallocation is negative and highly significant $(p<0.01)$, whereas underallocation is not significant $(p=0.79)$. Given that the opportunity costs to rent-seek are too high for non-rent-seeking managers who receive less capital (underallocation), there is no need to compensate these managers 
for their loss in resources. Both the negative significant coefficient for overallocation and the insignificant coefficient for underallocation are consistent with this argument and provide support for hypotheses 1 and 2 .

Regarding the control variables, we find in both models that division manager's total pay ( $\left.L N \_T O T A L P A Y\right)$ is positively associated with the division's level of performance $(R O A)$, the size of the division managed (SIZE), the division's growth opportunities (inverse of $B T M$ ), and the importance of human capital to the firm $\left(G O_{-} E M P L\right)$. All these results are consistent with our expectations.

\subsubsection{Hypothesis 3}

Hypothesis 3 states that equity incentives for employees increase the quality of internal capital allocation. To test this hypothesis, we examine whether the incentives inherent in employee stock option plans are positively associated with our proxy for the quality of internal capital allocation. The results of this analysis, presented in table 2.10, show that stock option incentives for employees (ESOPINC) are significantly positively associated $(\mathrm{p}=0.012)$ with the quality of internal capital allocation (ICA_QUALITY). Including CEO options in employee stock option incentives (ESOPINC_ALL) yields similar results, showing a positive relationship with the quality of internal capital allocation $(\mathrm{p}<0.01)$. Hence, our results strongly support hypothesis 3. In particular, the more employees own options of their firm, the better the quality of internal capital allocation. Employee stock option plans thus help to align incentives of employees with firm objectives.

Regarding the control variables, we find that the quality of internal capital allocation is positively associated with the size of the firm (FIRMSIZE). Contrary to expectations, diversity in divisions' growth opportunities (DIVERSBTM) is positively associated with the quality of internal capital allocation. We examine this unexpected finding further in the next section.

\subsubsection{Robustness checks and additional tests}

Our benchmark model of the division's share of firm capital expenditures includes the lag of the division's share. Although this inclusion logically controls for a lagged effect, it also runs the risk of including division manager rents in the predicted value, if these rents are persistent. That is, we potentially underestimate the extent of misallocation. To examine this potential effect, we run the benchmark model after dropping lagged capital allocation. The explanatory power of the model is still very high (Adjusted R-square $=71.86 \%$ ). Subsequently, we use the residuals of this model and re-run all models and tests discussed above. The results of these analyses show that the inferences drawn in this paper are robust to the exclusion of the lag effect in the benchmark model.

We further check the robustness of our results when we allow the coefficients of our benchmark model to either vary by year or vary by firm-level industry 
Table 2.11

Heckman sample selection correction for availability of EXECUCOMP data

Segment manager's total compensation

\begin{tabular}{|c|c|c|c|c|c|}
\hline Independent variables & $\begin{array}{l}\text { Predicted } \\
\text { sign }\end{array}$ & $\begin{array}{r}\text { Marginal } \\
\text { effect }\end{array}$ & Prob. & $\begin{array}{r}\text { Marginal } \\
\text { effect }\end{array}$ & Prob. \\
\hline$E X C E S S C A P X_{t}$ & - & -0.371 & $0.003 * * *$ & & \\
\hline OVERALLOCATION $_{t}$ & - & & & -0.661 & $0.007 * * *$ \\
\hline UNDERALLOCATION $_{t}$ & $?$ & & & 0.039 & 0.898 \\
\hline$R O A_{t}$ & + & 0.771 & $0.001 * * *$ & 0.761 & $0.001 * * *$ \\
\hline$S I Z E_{t}$ & + & 0.396 & $0.000 * * *$ & 0.393 & $0.000 * * *$ \\
\hline$B T M_{t}$ & - & -0.127 & $0.028 * *$ & -0.125 & $0.029 * *$ \\
\hline$G O \_E M P L_{t}$ & + & 0.400 & $0.038 * *$ & 0.388 & $0.043 * *$ \\
\hline$\lambda_{t}$ & $?$ & 0.380 & $0.002 * * *$ & 0.365 & $0.003 * * *$ \\
\hline Adjusted R-square & & 0.519 & & 0.520 & \\
\hline $\begin{array}{l}\text { Segment-year } \\
\text { observations }\end{array}$ & & 691 & & 691 & \\
\hline
\end{tabular}

\begin{abstract}
This table provides the estimates from a model examining the substitution effect between capital allocation and division manager total compensation after controlling for potential sample selection problems using a Heckman procedure. In the first stage of this procedure, we include the number of divisions in the firm and the relative size of the division as instruments and these variables are individually and jointly significant. Intercept, year controls, and industry controls are included but not separately reported. LN_TOTALPAY is the natural logarithm of the segment manager's total pay, comprising salary, bonus, restricted stock and stock options grants at Black-Scholes (1973) value, longterm incentive payouts, and any other compensation item, e.g. pension contributions. EXCESSCAPX represents excess capital allocations, i.e. is the residual of a benchmark capital allocation model. EXCESSCAPX is used as a determinant in Model 1. In Model 2, EXCESSCAPX is replaced by OVERALLOCATION and UNDERALLOCATION, where OVERALLOCATION (UNDERALLOCATION) equals $E X C E S S C A P X(-1 * E X C E S S C A P X)$ if $E X C E S S C A P X$ is positive (negative) and zero otherwise. $R O A$ is the segment's return on assets, calculated as segment net income divided by segment total assets. SIZE is the natural logarithm of total identifiable segment assets. BTM is the segment's book-to-market ratio, with imputed market values based on matching segments to samples of single-segment firms with corresponding two-digit SIC codes. GO_EMPL captures the importance of human capital and is measured as the difference between the firm's market and book value of equity, divided by the number of employees (coefficient multiplied by 1,000). $\lambda$ is the Inverse Mills Ratio. P-values in parentheses are based on heteroskedasticity-robust, firm-clustered standard errors (one-tailed for predictions, two-tailed otherwise). ${ }^{* *}, * *$, and $*$ denote significance at $1 \%, 5 \%$, and $10 \%$, respectively.
\end{abstract}

classification. In the latter case, data requirements reduce the total sample size of the benchmark model to 2,410 observations, while the number of observations available to test hypotheses 1 and 2 (3) reduces to 684 (775) observations. We also run our benchmark model allowing the intercept to be firm-specific using firm fixed effects. The results for using each of these three alternative specifications are quantitatively similar to those presented in the tables in this paper and thus do not change our inferences. 
As a final robustness check related to the benchmark model, we test whether the predicted divisional shares of the capital budget aggregated at the firm-year level, i.e., $\sum_{i=1}^{n} E\left[C A P X S H A R E_{i j t} \mid x\right]$, is close to 1 . The abundant use of relative measures in the benchmark model should ensure that this is very likely to be the case. Indeed, for approximately $97 \%$ of the firm-years associated with the benchmark model $\sum_{i=1}^{n} E\left[C A P X S H A R E_{i j t} \mid x\right]$ ranges from 0.90 to 1.10 and for more than $90 \%$ it ranges from 0.95 to 1.05 . Despite this observation, we re-run all of our analysis after dropping segment-level and firm-level observations associated with firm-years for which $\sum_{i=1}^{n} E\left[C A P X S H A R E_{i j t} \mid x\right]$ is outside the $0.90-1.10$ or $0.95-1.05$ range. Our results are robust to dropping these observations.

In linking excess capital allocation at the divisional level to the compensation of divisional level managers, we can only include those division managers who are among the five highest paid executives included in EXECUCOMP. This potentially introduces a sample selection problem. To control for this problem, we run a Heckman sample selection model. In particular, we model the probability that the divisional manager is included in EXECUCOMP, where we use the number of divisions within a firm (lower probability) and the relative size of the division (higher probability) as instruments in the first stage to avoid multicollinearity problems in the second stage.

Table 2.11 shows that, although the inverse Mills ratio is significant, the main findings presented in table 2.9 are unaffected. Two noteworthy differences are the following. First, the coefficients for EXCESSCAPX and OVERALLOCATION both become smaller in an absolute sense, but they remain highly significant and keep pointing in the expected direction. Second, the coefficients for ROA and BTM become larger in an absolute sense and the coefficient for BTM also becomes more significant. Overall, our results related to hypotheses 1 and 2 are robust to potential sample selection problems.

Another potential problem, more precisely an endogeneity concern, arises in examining the impact of equity incentives on the quality of internal allocations. Although this concern is valid, the most likely bias that would be introduced is a bias that works against finding the results presented in table 2.10 (see also Stein 2003). For example, reversed causality implies a negative association between equity incentives and the quality of internal capital allocation. This is a direction opposite to that hypothesized and thus most likely works against finding our expected result. Despite this, we run a two-stage-least-squares (2SLS) analysis using four instruments based on the findings from Core and Guay (2001), i.e., idiosyncratic risk, R\&D to sales, number of employees, and a firm's book-to-market ratio. The first-stage exclusion restriction test, partial R-square, and the 
overidentifying restrictions test indicate that these instruments satisfy the relevance and exogeneity criterion. ${ }^{13}$

The results of the 2 SLS analysis, presented in table 2.12, show that equity incentives have a significant positive effect on the quality of internal allocations, consistent with the inferences drawn based on table 2.10. Also consistent with the most likely endogeneity story, the 2SLS coefficient and Hausman test indicate that the bias introduced is significant and works against finding the result presented in table 2.10. More specifically, the 2SLS coefficient for ESOPINC is more than 3 times larger than the OLS coefficient and is also more significant. As a result, the data continue to support hypothesis 3 .

In addition to changes in the coefficient for ESOPINC, there are also changes in the coefficients and significance levels for FIRMSIZE and GO_EMPL. In contrast to the positive and significant coefficient for FIRMSIZE in the OLS model, FIRMSIZE is no longer significant in the 2SLS model. Further, the coefficient for $G O \_E M P L$ remains negative in the 2SLS model, but is larger in magnitude in an absolute sense and now also statistically significant.

Finally, contrary to expectations, we find in both the OLS model and 2SLS model that the quality of internal capital allocation is positively associated with the diversity in divisions' growth opportunities. A potential explanation for this result might be that it is important to rank divisions on a relative basis when allocating a fixed capital budget. Stein (1997) argues that the quality of the ranking of projects depends on the extent of diversification, where a focused strategy, i.e., less diversification, increases this quality. However, to be able to make such a ranking, some diversity in growth opportunities is needed. Thus, although diversity in growth opportunities creates incentives to rent-seek, it also allows a ranking of projects, the benefits of which are higher the lower the level of diversification. To examine whether there is an interaction between the diversity in growth opportunities and diversification on the quality of internal capital allocation, we re-run equation (2.4) after including this interaction.

The results, shown in table 2.13 , indicate that the main effect for the diversity in growth opportunities (DIVERSBTM) is significantly positive, while the interaction effect is significantly negative. To examine the implication of this, we use the estimates from model (1) in table 2.13 to determine the partial derivative of ICA_QUALITY to DIVERSBTM:

$$
\frac{\partial E\left[I C A \_Q U A L I T Y \mid \mathbf{x}\right]}{\partial D I V E R S B T M}=0.099-0.139 \times \text { DIVERSIFICATION }
$$

\footnotetext{
${ }^{13}$ The first-stage exclusion restriction test is significant $(\mathrm{p}<0.01)$ and the partial R-square equals 12 percent, which provides evidence of relevance. The test of the overidentifying restrictions indicates that the null-hypothesis of exogenous instruments cannot be rejected.
} 
Divisional rent-seeking, stock options and the quality of internal capital allocation

Table 2.12

2SLS analysis of the impact of endogenous firm-wide equity incentives

Internal capital allocation quality

(1)

(ICA_QUALITY $)_{t}$

\begin{tabular}{|c|c|c|c|c|c|}
\hline \multirow[b]{2}{*}{ Independent variables } & \multirow[b]{2}{*}{$\begin{array}{l}\text { Predicted } \\
\text { sign }\end{array}$} & & \\
\hline & & $\begin{array}{r}\text { Marginal } \\
\text { effect }\end{array}$ & Prob. & $\begin{array}{r}\text { Marginal } \\
\text { effect }\end{array}$ & Prob. \\
\hline ESOPINC $_{t}$ & + & 0.026 & $0.004 * * *$ & & \\
\hline ESOPINC_ALL $L_{t}$ & + & & & 0.027 & $0.003 * * *$ \\
\hline DIVERSIFICATION $_{t}$ & $?$ & 0.001 & 0.892 & 0.001 & 0.936 \\
\hline DIVERSBTM $_{t}$ & - & 0.057 & $0.003 * * *$ & 0.059 & $0.002 * * *$ \\
\hline FIRMSIZE $_{t}$ & $?$ & -0.007 & 0.539 & -0.006 & 0.565 \\
\hline$G O \_E M P L_{t}$ & - & -0.053 & $0.013 * * *$ & -0.052 & $0.013 * * *$ \\
\hline
\end{tabular}

Adjusted R-square

0.111

0.112

Segment-year

observations

This table provides the 2SLS estimates from a model examining the impact of stock option incentives on the quality of internal capital allocation using $n=797$ firm-level observations. In the first stage, we use idiosyncratic risk, R\&D to sales, number of employees, and a firm's book-to-market ratio as instruments for stock option incentives. The first-stage exclusion restriction test, partial R-square, and the overidentifying restrictions test indicate that these instruments satisfy the relevance and exogeneity criterion. The Hausman test indicates significant endogeneity of stock option incentives in the second stage $(\mathrm{p}<0.05$ two-tailed). Intercept, year controls, and industry controls are included but not separately reported. ICA_QUALITY proxies the quality of internal capital allocations; it is measured as the standard deviation of the error terms of a benchmark model that distinguishes abnormal capital allocations from those allocations based on economic determinants such as growth opportunities. Model 1 and Model 2 differ in the variable representing equity incentives, using ESOPINC and ESOPINC_ALL, respectively. ESOPINC are the incentives provides by employee stock option plans to all employees but the CEO as in Core and Guay (2001), i.e., the sensitivity of firm-wide option plans to a one percent change in stock price. ESOPINC_ALL is measured as ESOPINC and captures the incentives provided to all employees including the CEO. DIVERSIFICATION is the entropy measure as in Bushman, Indjejikian, and Smith (1995), capturing the firm's degree of diversification. DIVERSBTM is the diversity in growth opportunities of the firm's segments, based on the standard deviation of the segments' imputed book-tomarket ratios. FIRMSIZE is the natural logarithm of the firm's total assets. GO_EMPL captures the importance of human capital and is measured as the difference between the firm's market and book value of equity, divided by the number of employees (coefficient multiplied by 1,000). P-values in parentheses are based on heteroskedasticity-robust, firm-clustered standard errors (one-tailed for predictions, two-tailed otherwise). $* * *, * *$, and $*$ denote significance at $1 \%, 5 \%$, and $10 \%$, respectively.

This partial derivative reflects the impact of diversity in growth opportunities on the quality of a firm's internal capital allocation as a function of diversification. It shows that, in the presence of a focused strategy (DIVERSIFICATION $=0)$, the partial derivative is positive (0.099) and more diversity in growth opportunities is thus beneficial in terms of a higher quality of internal capital allocation. The negative coefficient on DIVERSIFICATION in equation (2.12) indicates that this effect diminishes and eventually reverses. In particular, the coefficients predict that, at the average level of diversification observed in the sample, i.e., 
Table 2.13

Interaction between diversity in growth opportunities and diversification

\begin{tabular}{|c|c|c|c|c|c|}
\hline \multirow[b]{3}{*}{ Independent variables } & \multirow[b]{3}{*}{$\begin{array}{c}\text { Predicted } \\
\text { sign }\end{array}$} & \multicolumn{4}{|c|}{$\begin{array}{c}\text { Internal capital allocation quality } \\
\left(I C A \_Q U A L I T Y_{t}\right)\end{array}$} \\
\hline & & \multicolumn{2}{|c|}{$(1)$} & \multicolumn{2}{|c|}{ (2) } \\
\hline & & $\begin{array}{r}\text { Marginal } \\
\text { effect }\end{array}$ & Prob. & $\begin{array}{r}\text { Marginal } \\
\text { effect }\end{array}$ & Prob. \\
\hline ESOPINC $_{t}$ & + & 0.008 & $0.013 * * *$ & & \\
\hline ESOPINC_ALL $L_{t}$ & + & & & 0.010 & $0.007 * * *$ \\
\hline DIVERSIFICATION $_{t}$ & $?$ & 0.035 & $0.039 * *$ & 0.033 & $0.048 * *$ \\
\hline $\begin{array}{l}\text { DIVERSBTM }_{t} \\
\text { DIVERSIFICATION }_{t} \times\end{array}$ & $?$ & 0.099 & $0.000 * * *$ & 0.098 & $0.000 * * *$ \\
\hline DIVERSBTM $_{t}$ & - & -0.139 & $0.015 * *$ & -0.134 & $0.019 * *$ \\
\hline FIRMSIZE $_{t}$ & $?$ & 0.013 & $0.004 * * *$ & 0.010 & $0.026 * *$ \\
\hline$G O_{-} E M P L_{t}$ & - & -0.024 & $0.095 *$ & -0.028 & $0.069 *$ \\
\hline
\end{tabular}

Adjusted R-square

0.113

0.116

Segment-year

observations

801

801

This table provides the estimates from a model examining the impact of the interaction between diversification and the diversity in growth opportunities on the quality of internal capital allocation using $n=801$ firm-level observations. Intercept, year controls, and industry controls are included but not separately reported. $I C A \_Q U A L I T Y$ proxies the quality of internal capital allocations; it is measured as the standard deviation of the error terms of a benchmark model that distinguishes abnormal capital allocations from those allocations based on economic determinants such as growth opportunities. Model 1 and Model 2 differ in the variable representing equity incentives, using ESOPINC and ESOPINC ALL, respectively. ESOPINC are the incentives provides by employee stock option plans to all employees but the CEO as in Core and Guay (2001), i.e., the sensitivity of firm-wide option plans to a one percent change in stock price. ESOPINC_ALL is measured as ESOPINC and captures the incentives provided to all employees including the CEO. DIVERSIFICATION is the entropy measure as in Bushman, Indjejikian, and Smith (1995), capturing the firm's degree of diversification. DIVERSBTM is the diversity in growth opportunities of the firm's segments, based on the standard deviation of the segments' imputed book-to-market ratios. FIRMSIZE is the natural logarithm of the firm's total assets. GO EMPL captures the importance of human capital and is measured as the difference between the firm's market and book value of equity, divided by the number of employees (coefficient multiplied by 1,000). P-values in parentheses are based on heteroskedasticity-robust, firm-clustered standard errors (one-tailed for predictions, two-tailed otherwise). ***,**, and * denote significance at $1 \%, 5 \%$, and $10 \%$, respectively.

DIVERSIFICATION $=0.384$, the partial derivative equals 0.046 , which is close to the coefficient for DIVERSBTM reported in table 2.10. Further, at higher levels of DIVERSIFICATION, i.e., values that range from approximately 0.713 to the maximum of 1.340 , the partial derivative is negative and more diversity in growth opportunities is detrimental in terms of a lower quality of internal capital allocation. In sum, the unexpected result observed in the main analysis can be explained by the fact that there exists an interaction between the level of diversification within the firm and the diversity in divisions' growth opportunities. 


\subsection{Discussion and conclusion}

A large stream of literature compares internal capital markets with external capital markets to assess efficiencies. The peculiarity of internal capital markets is that capital allocations might not only be driven by performance criteria and growth opportunities, but also by the way divisional and executive managers are compensated, an aspect that is still scarcely considered in the empirical literature. In this paper, we examine to what extent firms' resource allocation decisions are affected by the CEOs' response to division-managers' rent-seeking activities and whether equity incentives mitigate this problem.

The results of this study show that compensation and incentives do play an important role in the allocation process of internal capital. Internal capital that is allocated in excess of a benchmark serves as a substitute for increased take-home pay in the overall compensation package of rent-seeking divisional managers. When a capital budget is used to pay rents, less capital is available in other divisions for promising and value-adding investments, which potentially harms firm value. In line with this argument, our results show that misallocations are associated with ex-post inefficiencies.

Further, paying rents indicates that the firm suffers from a two-layer agency problem, i.e., not only divisional managers but also the CEO act opportunistically and create agency costs. Whereas this is a major problem for many (multidivisional) firms, our results show that stock options help to align the incentives of divisional managers, the CEO, and the firm. Providing divisional managers and the CEO with equity incentives via ESOPs penalizes rent-seeking activities and rent payments, while value-adding activities and decisions are rewarded.

These findings have direct implications for the management of diversified firms. A conventional controllability argument is that, in the absence of interdependencies, firms should base compensation of division managers solely on the performance of their respective organizational unit. Such a contract, however, does not prevent divisional rent-seeking. We show that even or maybe especially in the absence of interdependencies in multi-divisional firms, firm-wide incentives are a necessary tool to prevent using the capital budget to compensate rent-seeking managers. Designing compensation contracts beyond standard controllability considerations to include firm-level performance, for example using ESOPs, improves the quality of internal capital allocations and thus investment efficiency.

This study is subject to a number of limitations. First, even though we take great care in developing and validating our benchmark model, and in testing the robustness of the results associated with this model, we cannot rule out that other factors play a role in capital expenditure decisions. Second, we use publicly available disclosures to observe internal capital markets. The reporting environment under SFAS 131, which is part of our study, is a significant improvement over 
SFAS 14, but we still have to rely on circumstantial indicators that point to the existence of and behavior in internal capital markets. Third, we impute growth opportunities of non-listed segments using comparable single-segment listed firms, which is - despite being a widely applied technique - subject to considerable subjectivity.

Despite the above limitations, our study contributes to the literature in several ways. First, by showing that the capital budget acts as a substitute for increased take-home pay of divisional managers, we provide empirical evidence that a twolayer agency problem exists and plays a major role in inefficiencies in internal capital markets. Second, our research design makes a direct link between the use of employee stock option incentives and the quality of internal capital allocations. We provide strong support for the argument that broad-based equity plans mitigate the problem of misallocation and show that ESOPs are used to align the interests of employees with those of the firm. Related to this point, our results indicate that the benefits of firm-level incentives, i.e., measures at a higher level of aggregation than the own division, can be high even when there are few operational interdependencies between divisions. Finally, our study adds to the discussion in the literature whether stock option plans are incentive relevant only for executives or for employees in general. Our findings show that ESOPs do provide important incentives in internal capital markets. 


\title{
Chapter 3
}

\section{Organizational design and the efficiency of internal capital allocations in diversified firms}

\begin{abstract}
Numerous studies document inefficient capital allocations in diversified firms, whereas only little is known about how firms react to counter these misallocations. I argue that changing the divisional structure to reassign decision rights among managers can help to reduce inefficient allocations by altering the incentive to lobby as well as by redistributing bargaining power in the firm. Using a unique database on reconfigurations of the divisional layout, I confirm the hypothesis that firms are reacting to inefficient allocations by adjusting their organizational design. Moreover, results demonstrate that the efficiency of capital allocations as well as shareholder wealth rise considerably following the reassignment of decision rights. Some evidence also suggests that firms are less likely to rearrange their organizational design in response to capital misallocations when the cost of these misallocations is low, but this result does not continue to hold under all robustness tests. The role of divisional reorganizations in relation to misallocations has not been studied empirically in this detail before, contributing to the literature on organizational design and internal capital allocation.
\end{abstract}




\subsection{Introduction}

This paper examines whether diversified firms respond to inefficiencies in the internal allocation of capital among its constituent operating units by changing the organizational layout of the firm. The process of allocating funds in diversified firms - referred to as internal capital markets - is critically studied in an expanding body of literature. This process is also of growing importance for the management of diversified companies in an economy that is more and more characterized by large, multi-divisional firms that internalize transactions that are otherwise organized in external markets between independent parties. A crucial component in managing these diversified operations is an organizational design that appropriately allocates decision rights within the firm, thereby defining the boundaries of authority between its divisions ${ }^{14}$. Setting these boundaries inevitably also influences the internal capital allocations that take place between them, and is bound to affect the efficiency of these transfers. This link between organizational design, more specifically the change to the horizontal scope of authority by divisional reorganizations, and the efficiency of internal capital allocations has not been analyzed thus far.

A recurrent theme in the extant literature on internal capital markets is whether and under what circumstances they deliver net benefits, i.e. if they are more or less efficient than external financing mechanisms (cf. Stein 2003; Maksimovic \& Phillips 2006). Advantages from internal capital markets can arise if units can collectively borrow at lower cost or if internal transfers of funds are subject to lower information asymmetries than between individual units and external providers of capital (Stein 1997; Matsusaka \& Nanda 2002). Conversely, a widely held counterargument proposes that inefficiencies can arise in this process due to influence costs when agents within the firm lobby for a larger allocation than economic performance of their respective unit would justify (Meyer, Milgrom \& Roberts 1992; Scharfstein \& Stein 2000). Inefficient allocations may further arise from internal power struggles within the firm due to uneven distributions of investment prospects between divisions (Rajan, Servaes \& Zingales 2000). A common denominator in these theories is that the profile of a division, as defined by for instance size and performance of all operations in the division, are the root cause of inefficient allocations. For instance, unprofitable operations or large disparities between a firm's divisions provide the division manager with incentives to engage in lobbying and other non-cooperative behavior. Changing a division's profile by reorganizing the portfolio of operations under each division manager's supervision -

\footnotetext{
${ }^{14}$ There is no uniformity in the literature in using the notion of divisions, business units, segments, or investment centers to describe organizational units below corporate level that have distinct fields of operation with specifically assigned management personnel taking investment decisions. To avoid confusion, I refer to these units as divisions throughout this paper.
} 
i.e. changing his decision rights - will therefore influence the efficiency of internal allocations.

Based on this observation, I propose that firms seeking to contain inefficient capital allocations can change the distribution of decision rights among division managers in a way that division managers abstain from lobbying and noncooperative behavior. Major determinants of the extent of non-cooperative activities or lobbying are the relative returns of productive and influence activities in each division (Scharfstein \& Stein 2000) as well as the diversity of these relative returns between divisions (Rajan et al. 2000). A firm can alter these relative returns and their distribution among divisions by changing how decision rights over the firm's operations are bundled in each division such that the firm's aggregate capital allocation efficiency will improve.

As markets expand and shrink, firms do not remain static but adapt to their operating environment, with internal organization following distinct life cycle stages (Harris \& Raviv 2002). While in equilibrium firms are organized perfectly according to their environment, changes in this environment can alter the incentives within the firm for managers to behave non-cooperatively. In consequence, firms readjust their organizational layout in an effort to contain inefficient capital allocations. Firms will only do so once the cost of misallocation exceeds the cost of reorganizing. Hence, organizational adjustments will not take place immediately, providing the opportunity to observe transitory inefficiencies that precede reorganizations.

I provide supporting evidence in this study that diversified firms are indeed more likely to reconfigure their divisions when internal capital allocations are relatively inefficient. I moreover find some evidence that a part of the analyzed firms is less likely to rearrange the organizational layout in reaction to capital misallocations when relatively well endowed with capital, i.e. when the cost of these misallocations is low. This result, however, does not continue to hold under all robustness tests. Lastly, I find that capital is allocated more efficiently following the reorganization of divisions and that shareholder wealth increases, corroborating the notion that firms reorganize to counter inefficient capital allocations.

Prior evidence on the determinants and consequences of divisional reorganizations is scarce, which is largely due to the difficulty of identifying firms that carry out reorganizations of their internal structure. These events are relatively rare to observe and are a far less obvious artifact of organizational change than for instance divestments. I make use of the fact that SFAS 131 (FASB 1997) prescribes firms since 1998 to report their segments according to their internal organizations and identify listed US firms with changes in their segment reporting in the period from 1998 until 2007. I construct a unique dataset by subsequently verifying that these reporting changes are due to reorganizations by reading the respective $10-\mathrm{k}$ 
report sections rather than due to other explanations such as mergers, acquisitions, or divestments.

This study contributes to the body of research on internal capital markets by providing evidence how firms react to inefficient allocations. While extant studies extensively document how these inefficiencies can arise (Stein 2003), only few authors investigate if and how firms consequently react. Investigating the role of reorganizations in this context sheds new light on internal capital markets and furthermore extends the literature on organizational design and delegation in diversified firms. This study shows that resolving inefficient allocations are an additional driver of structuring delegation besides relative expertise in the firm and relative importance of the individual units (Baiman, Larcker \& Rajan 1995) as well as the availability of appropriate performance measures (Moers 2006). Investigating the effects of reassigning decision rights among division managers in this study specifically extends knowledge on the determinants of the horizontal scope of authority, an area that has so far received only limited coverage in the extant literature (Mookherjee 2006).

The subsequent sections of this paper are structured as follows. Section 3.2 provides an overview of related research papers and develops the underlying hypotheses of this study. Section 3.3 describes the data, its collection as well as the models to test the hypotheses, the results of which are presented in section 3.4. Section 3.5 concludes and provides an outlook on potential research avenues.

\subsection{Related research and hypotheses}

The complexity of managing large, diversified firms with several lines of business frequently requires corporate management to structure operations into distinct divisions and to assign immediate oversight responsibilities to division managers. A marked difference between these multidivisional firms and those engaged in a single line of business is the ability of the former to allocate capital among its individual divisions. These intra-company capital transfers can be used to fund operations with cash generated in a different division, thereby complementing or substituting capital raised externally on specialized financial markets.

This process of cross-subsidization, also referred to as an internal capital market, has both advantages and drawbacks. Benefits may for instance arise if the allocating authority, i.e. the CEO, has inside information about the prospects of the firm's divisions that enable him to allocate capital more efficiently than outside investors (Stein 1997; Matsusaka \& Nanda 2002). Conversely, drawbacks from internal cross-subsidization may arise if information provision necessary for internal allocations is costlier than if each division would arrange financial contracts individually with the external capital market. Moreover, capital allocations are 
subject to the CEO's own discretion and may therefore induce division managers to influence the allocation decision in their favor rather than the firm's overall interest, i.e. engage in lobbying (Meyer, Milgrom \& Roberts 1992; Scharfstein \& Stein 2000). Influence activities are harmful to firm performance not only because of the time that division managers spend on lobbying rather than engaging in productive activities but also because of misguided funds that would yield higher returns elsewhere inside or outside the firm. Inefficient allocations can also stem from diversity in performance profiles between divisions (Rajan et al. 2000): Profitable divisions may decide to engage in non-cooperative strategies to prevent having to share their surplus with less profitable divisions. Firm management may then decide to transfer funds between divisions to reduce diversity. Even though these crosssubsidizations may be inefficient themselves, they prevent further inefficiencies arising at otherwise even higher levels of diversity.

The central theories on internal capital markets explain that lobbying and noncooperative behavior of division managers are driven by the division's profile as defined by its assets, profitability, investment prospects, and other economic dimensions. For example, managers of unprofitable divisions in declining markets may reap more benefits from lobbying for capital than managers of prospering divisions that have few problems in attracting capital. However, market conditions of a division's operation naturally fluctuate over time and will in consequence provoke changes in lobbying and non-cooperative behavior. While firms are managed and organized optimally in equilibrium and have weighed up benefits and costs of internal capital markets, division manager behavior may aggravate allocation efficiency due to a changing firm environment to a point that firms have to consider appropriate remedies. Lobbying models with an agency conflict between division managers and CEO vary in the assumption of an additional conflict of interest between CEO and owners of the firm (e.g. Rajan et al. 2000; Scharfstein \& Stein 2000). This distinction is less important in the setting at hand and either CEO or the owners of the firm may administer remedies to align division manager incentives with the firm: Both parties benefit from a higher firm value irrespective of whether interests between them are entirely aligned.

One approach to contain lobbying and resulting inefficient allocations that run counter to firm interests is to partly tie division manager compensation to corporate performance through the provision of firm-level equity and option grants (cf. chapter 2 of this dissertation). However, not all division managers may be willing to accept such a contract since part of their remuneration would be tied to firm-level factors beyond their immediate control. This type of contract may also be too costly for the firm: remunerating division managers partly based on firm performance essentially increases compensation risk (Prendergast 2002) and pay would have to be raised to compensate for this additional risk. In addition, Bernardo, Luo, and Wang (2006) argue that the cost of a division manager's incentive contracts while 
keeping the level of truthful reporting in a diversified firm depends on both level and variance of investment opportunities that the division manager holds. These contracts can therefore turn out to be too costly in some settings to provide incentives to division managers.

Alternatively, remuneration contracts of division managers could be adjusted to include a charge for cost of capital employed by the division. While residual income-based contracts can impede lobbying for money, Wallace (1997) indicates that introducing cost of capital charges in performance evaluation can cause underinvestment if managers turn down positive NPV-projects with deferred future cash inflows if capital charges render earlier periods unprofitable. Exact depreciation schedules with cost of capital estimates for each division (Dutta \& Reichelstein 2002) or multi-period evaluation schemes can prevent this problem, but implementing these mechanisms is bound to be costly and difficult due to the required precision and amount of information on present and future project performance. The incentive problem of lobbying is therefore not necessarily resolved by charging the cost of capital.

Rather than changing performance evaluation contracts to reduce the intra-firm incongruence of incentives, firms can deal with the root cause of diverging interests more directly and alter the way authority is delegated to division managers who cause inefficient capital allocations. Firms are bound to rearrange decision rights when the cost of contractually reducing incentive problems as described above exceeds the cost of changing the delegation of authority. The delegation of decision rights is fundamental for managing diversified operations and a core issue in the literature on organizational design. A central question is how companies decide between centralized and decentralized organization structures when communication between multiple agents is limited and costly (Melumad, Mookherjee \& Reichelstein 1992). Baiman et al. (1995) show that the degree of decentralization by allocating tasks to divisions depends on relative expertise and relative importance of the firm's divisions, whereas Moers (2006) indicates that the choice to delegate depends on the availability of suitable performance measures. Removing the hierarchical layer of division managers and centralizing more would rule out this source of potential inefficiencies. It seems unlikely, however, that diversified firms will reconsider the balance between delegation and centralization when internal capital allocation efficiency declines due to non-cooperative behavior: firms have already chosen to diversify ex ante into distinct operations with specialized information that a central authority is hardly able to process appropriately.

Instead of adjusting the degree of delegation, firms can rearrange how delegated decision rights are bundled within each division, i.e. reorganizing the divisional layout. Research explaining this horizontal span of control of agents in settings of delegated decision rights is still limited (Mookherjee 2006), and this study aims to contribute specifically in this direction. A general conception is that 
those operations should be grouped together in divisions that require joint coordination (Milgrom \& Roberts 1992) and in such a way that operations are supervised by the manager with the best expertise to discover and evaluate interactions among these activities (Harris \& Raviv 2002). One of the few crosssectional empirical studies on divisional reorganizations in general is Brickley and Van Drunen (1990). Similar to the preceding reasoning, they argue that changes in the market conditions and competitive pressure cause firms to adapt their organizational structure. The causal analysis is confined to mainly descriptive evidence, identifying a range of different motives for reorganizations, which broadly imply that firms attempt to increase efficiency. The authors remain silent, however, on the exact nature of these efficiency improvements and consider company reorganizations in general, whereas this study specifically speaks to the effect on capital allocations among divisions as a determinant of how decision rights are allocated in diversified firms.

The central argument of this paper is that changing this bundling of decision rights, i.e. what operations are grouped together in divisions, can improve the efficiency of internal capital allocation: the altered economic profile of the divisions provides its managers with a different set of incentives that can induce them to abstain from lobbying and non-cooperative behavior. Division managers distribute effort over productive and influence activities (Scharfstein \& Stein 2000), their choice depending on the relative returns of both types of activities. Non-cooperative behavior is furthermore increasing if divisions differ in these relative returns (Rajan et al. 2000) with productive divisions unwilling to subsidize weaker ones. Reassigning part of the operations from one division to another changes the aggregate set of investment opportunities under control of each division manager and reduces discrepancies in relative returns of influence and productive activities. A division manager with high incentives to lobby will be less likely to engage in such behavior when a different bundle of decision rights endows him with oversight over better investment projects that render lobbying unattractive vis-à-vis pursuing productive activities. Given that a division manager has the incentive to engage in lobbying, adjusting the composition of operations he supervises can also change the bargaining power of his lobbying efforts, derived from the underlying division's size and other factors such as overall profitability. Assigning operations and assets to different divisions can redistribute bargaining power within the firm and thereby reduce the expected success of lobbying. Lower expected success will consequently reduce the likelihood that division managers decide to engage in such nonproductive behavior ${ }^{15}$.

\footnotetext{
${ }^{15}$ Division managers could oppose organizational changes that would entail giving up bargaining power. Such resistance is less likely to hold, however, if reorganizations offer resisting managers compensating benefits. For instance, the division may shrink but be more profitable after reorganizing.
} 
Reorganizations can improve internal capital allocation efficiency for two additional reasons unrelated to conflicting behavior of division managers. First, the process of allocating internal capital can be streamlined if units that frequently interact through internal fund transfers are regrouped together in the same division. Transferring capital between units of the same division is likely easier to coordinate than if those units are set in separate divisions, similar to the idea that units requiring mutual coordination should be grouped together (Milgrom \& Roberts 1992). Second, firms can reorganize the divisional layout so that a division's subordinate unit is assigned to a different division where management has higher expertise to evaluate its investment proposals. Higher expertise will then feed back into more precise assessments of actual capital requirements of the units and less misallocations, thereby increasing allocation efficiency.

Rearranging decision rights can entail profound changes to the firm that require considerable time and effort to implement, firms will not adjust the bundling of decision rights immediately to counter inefficient internal allocations. Instead, inefficient allocations have to be persistent and costly enough to justify a divisional reorganization. This friction in firm response is bound to allow empirical observation of transitory inefficiencies before reorganizations. The preceding discussion leads to the first hypothesis.

H1: Diversified firms suffering from inefficient internal capital allocations rearrange decision rights of division managers.

Since reorganizing the divisional layout to counter allocation inefficiencies likely is a costly procedure that ties management resources in the reorganization process, firms will only do so after trading off related costs and benefits. Firms may refrain from a costly reorganization when facing low levels of lobbying with negligible misallocations of internal funds. Furthermore, efficient capital allocations will be more important for companies whose access to external capital is limited and costly, an application of the trade-off between internal allocation and external capital proposed in Matsusaka and Nanda (2002). This leads to the second hypothesis.

H2: $\quad$ The probability of an internal rearrangement of decision rights in firms as a reaction to capital misallocations is higher for firms that face external financing constraints.

Brickley and Van Drunen (1990) indicate that the effects of reorganizations may not materialize in the short run. They document a decline in firm performance immediately following divisional reorganizations but propose increases in the longer term. Similarly, improvements in the efficiency of internal capital allocations should 
follow changes to the horizontal scope of decision rights of division managers if this is the initial motivation for the change. Enhancing the efficiency of internal capital allocations should also have reverberations in shareholder wealth, as owners of the firm ultimately profit from more efficient internal company processes. This results in the third and fourth hypothesis.

H3: The efficiency of internal capital allocations increases following the rearrangement of decision rights among divisions.

H4: Shareholder wealth increases following the rearrangement of decision rights among divisions.

\subsection{Data and model}

\subsubsection{Data and sample selection}

To study the preceding hypotheses, I analyze firms that reorganize their divisional structure, being a clearly observable manifestation of the reallocation of decision rights among division managers. I start by obtaining a sample of firms, examining the segment filings in the COMPUSTAT database on all listed firms with more than one operating segment that are incorporated in the US in the period 1998-2007. Consistent with extant literature, I exclude firms with consolidated sales and assets below USD $20 \mathrm{~m}$ as well as groups with one or more segments in the financial or real estate industry. Industry classifications are based on the NAICS rather than the preceding SIC scheme as the latter is phased out and not consistently available at the segment level for years from 2004 onwards. I consider the period starting 1998 to exploit the fact that the introduction of SFAS 131 in that year required firms to align segment reporting with the actual organizational layout of the company. This potentially reduces distortions that may arise if firms strategically (dis-) aggregate divisions to conceal the underlying organizational structure. To find reorganizing firms, I identify firm-years with a change in either the number of segments or in the sum of the individual segment identifier code compared to the preceding firm-year. Considering the sum of segment identifiers ensures capturing reorganizations with changes in the composition rather than the number of segments.

Several reasons apart from reorganizations per se drive changes over time in segment reporting. Examples are transactions such as acquisitions, divestment, mergers, or altered segment reporting in preparation thereof; segment growth or decline around the minimum segment reporting thresholds; or changing the reporting of non-operating segments, e.g. containing corporate unallocated assets or aggregating intercompany transfers for consolidated reporting reasons ${ }^{16}$. To

\footnotetext{
${ }^{16}$ Non-operating segments were excluded from the sample. Their assets were not allocated to other segments, since any method of allocation is bound to introduce an additional element of subjectivity.
} 
distinguish reorganizations from such other reasons of reporting change, I read 1,721 SEC 10-k forms for firm-years exhibiting a different segment structure than in the preceding year. I coded only those years as reorganizations if firms explicitly state to have changed their organizational structure. This rather elaborate procedure has the advantage of vastly reducing the amount of confounding effects that the statistical analysis would otherwise have to control for. For instance, it minimizes the risk of sampling firms that change their disclosure for strategic reasons rather than due to an actual change in their organizational layout: Segment reports are also part of the annual financial audit so that firms that intend to change their segment reports have to provide plausible evidence for doing so and are unlikely to inform about reorganizations unless actual changes take place.

It was argued above that the choice to sample only years that are regulated under SFAS 131 reduces the chance that the observed reporting changes are due to strategic disclosure choices that management intentionally takes to change the representation of segment information to the capital market. A main argument for these information distortions proposed in the literature is that firms may wish to hide proprietary information about profitable operations due to competitive pressure (e.g. Verrecchia 1983; Hayes \& Lundholm 1996; Harris 1998). The inclusion of control variables for performance effects (cf. section "3.3.2 Model and variable construction") serves to additionally reduce the impact of this alternative explanation. Also, it is not clear that managers would unilaterally like to deceive the capital market: Both analytical and empirical research (e.g. Kanodia \& Lee 1998; Berger \& Hann 2003; Bens \& Monahan 2004) shows that firms benefit from increasing the precision of publicly disclosed information that help improve monitoring and reduce the cost of capital, i.e. contributing towards a higher firm value $^{17}$. The following two quotes are examples of the sampled firms that report a reorganization.

\section{LSI Industries, 2004:}

"Effective July 1, 2003, the Company re-aligned its business segments and now operates in the following two business segments: the Lighting Segment and the Graphics Segment. The Company is organized such that the chief operating decision maker (the President and Chief Executive Officer) now receives financial and operating information relative to these two business segments, and organizationally, has a President of LSI Lighting Solutions Plus and a President of LSI Graphics Solutions Plus reporting directly to him."

\footnotetext{
Wherever leaving out non-operating segments lead to a divergence between reported corporate financial figures and segment totals, the latter were used instead.

${ }^{17}$ Further tests in section 3.4 show that the sampled reorganizing firms suffer from relatively higher allocation problems and lower stock market performance prior to reorganization than control firms. It would therefore seem less likely that these firms only pretend to have changed their organization in order to deliberately distort information, which would entail a potential aggravation of their cost of capital.
} 


\section{Oglebay Norton Company, 2001:}

"Effective January 1, 2001, the Company realigned its businesses into three reporting segments, described above, focused on its key markets served. This new segment reporting structure aligns operations which share business strategies, are related by geography and product mix, and reflect the way management evaluates the operating performance of its businesses. In 2001, the Company also announced that it was implementing a new, flatter management structure and consolidating formerly independent business units into an integrated industrial minerals company."

Reorganizations at times coincide with major transactions such as acquisitions of another firm or divestments of a division. I exclude those combined reorganization events since they essentially change the profile of the company, making it difficult to trace effects of reorganizations alone. I also verify that the reorganization is not the result of any transaction in the preceding year using information in the relevant annual reports and on the company websites. This selection procedure leads to the identification of 131 reorganizations among 110 firms, with 938 firm-years and 3,920 segment-years. Two firms change their structure three times, while 17 firms reorganize twice in the sample period. Wherever missing in the COMPUSTAT segment files, I manually added financial data if available in the respective $10-\mathrm{k}$ form or annual report. Table 3.1 gives an overview of the occurrence of reorganizations over the sample period as well as the distribution of firm-year observations of reorganizing firms. The figures illustrate a somewhat elevated occurrence of reorganizations in the years 2001-2003. These reorganizations could in part be reflecting the troubles of the New Economy and the wider economic reverberations, which would however not obstruct these firm observations to qualify for this study.

Part of the subsequent analysis employs a control group of multi-segment firms that did not reorganize. The sampling procedure for this set of non-reorganizing firms is the same as the one described above, similarly excluding firms from the control group that engaged in any other major corporate transaction such as mergers, acquisitions or divestitures of part of their business.

\section{Table 3.1}

Distribution of year observations of reorganizing firms and reorganizations

$\begin{array}{lllllllllll}1998 & 1999 & 2000 & 2001 & 2002 & 2003 & 2004 & 2005 & 2006 & 2007 & \text { total }\end{array}$

\begin{tabular}{lrrrrrrrrrrr}
\hline $\begin{array}{l}\text { Year observations of } \\
\text { reorganizing firms }\end{array}$ & 86 & 97 & 97 & 102 & 105 & 103 & 98 & 90 & 85 & 75 & 938 \\
Reorganization incidents & 0 & 10 & 16 & 20 & 26 & 23 & 7 & 12 & 12 & 5 & $\mathbf{1 3 1}$
\end{tabular}




\subsubsection{Model and variable construction}

Hypothesis 1 posits that diversified firms change their organizational structure as a consequence of inefficient internal capital allocations. Since allocation inefficiencies are unlikely to be the sole determinant of reorganizations, I construct the following probit model on the reorganization likelihood.

$$
\begin{aligned}
\text { REORGANIZATION }_{i, t}= & f\left(I_{C M_{-} E F F_{i, t-n}, \text { DIVERSIFICATION }}{ }_{i, t-n},\right. \\
& \text { DIVERSITY Y,t-n }, \text { DIVISONS }_{i, t-n}, \text { EMPLOYEES }_{i, t-n}, \\
& \text { LEVERAGE } \left._{i, t-n}, \text { ROA }_{i, t-n}, \text { BTM }_{i, t-n}\right),
\end{aligned}
$$

where REORGANIZATION is an indicator variable equal to 1 for firms that alter their divisional structure and 0 otherwise. Firms are indexed with $i$ and the year of divisional reconfiguration with $t$, with $n>=1$ so that all independent observation predate the event year. I use lagged values for all independent variables to model the managerial decision making process on reorganizing the company that is taking place throughout the year on the basis of prior year company characteristics. The main explanatory variable, $I C M \_E F F$, is the Billet and Mauer (2003) measure of internal capital market efficiency, which has been repeatedly used in the literature to capture the efficiency of internal capital markets in multi-divisional firms in various settings (e.g. Bens \& Monahan 2004; Berger \& Hann 2007). ${ }^{18}$ Broadly speaking, the rationale behind ICM_EFF is a comparison between capital expenditures and cash flows of each division. Capital expenditures exceeding the division's cash flows are an indication that intra-firm fund transfers must have taken place to finance that excess investment. These transfers are deemed efficient when the growth opportunities of the division receiving the transfer are above the average level of growth opportunities of all other divisions in that firm. This evaluation takes place for all divisions and is aggregated into a single firm-level measure. I compute this efficiency measure using the ratio of segment book and market values to capture the divisions' individual investment opportunities. Market values for individual divisions are not readily available and therefore imputed using separate industry sales multiples ${ }^{19}$ for each of the sampled years. Industries peers are defined as the group of at least five stock-listed single-segment firms with the same six-digit NAICS industry code. Whenever less than five industry peers are available in the specific year then industries peers are defined at five, four, or on rare occasions three or two digit NAICS levels. Following hypothesis 1, ICM_EFF is expected to be negatively related to the incidence of reorganization.

\footnotetext{
${ }^{18}$ To avoid restrictions on the sample size, the more data-intensive measure on internal capital allocation developed in chapter 2 is applied in section 3.4.3.4 as an alternative robustness test to using $I C M \_E F F$, confirming the results of the main analyses.

${ }^{19}$ I use segment sales figures to estimate market values instead of segment assets as the latter is particularly sensitive to discretionary asset allocation within multi-division firms.
} 
The next four explanatory variables are proxies for the organizational complexity of the firm. DIVERSIFICATION is the Bushman, Indjejikian, and Smith (1995) measure of unrelated diversification, capturing the dispersion of sales across industries that differ on the first three digits of their NAICS code classification, which is largely similar to distinguishing at the two-digit SIC level ${ }^{20}$. DIVERSITY is the Rajan et al. (2000) measure of dispersion of the divisions' growth opportunities $^{21}$. Reorganizations that involve rearranging the responsibilities of division managers and the units that they supervise will be easier the more the firm's different operations require the same management expertise. Similarly, it is likely more problematic to assign a unit to another division for firms with operations in different industries or in different stages of the business life cycle. Conversely, one could also argue that more complex organizations are more likely to reorganize. Due to these contrasting arguments, neither DIVERSIFICATION nor DIVERSITY is expected to exhibit a distinct unidirectional relation with the dependent variable. DIVISIONS is the number of operating divisions, i.e. excluding segments that are disclosed for financial reporting reasons such as corporate overhead expenses. EMPLOYEES is the natural logarithm of the number of employees in the firm. The need to adjust the organizational structure at some point is likely higher for larger firms with more employees and those with more divisions. Both parameters are therefore predicted to be positively related to the occurrence of reorganizations.

Besides organizational complexity, the model also adjusts for three additional firm characteristics. $L E V E R A G E$ is the ratio of long- and short-term debt to total assets. Debt is recurrently argued to reduce various agency costs related to free cash flow by contractual payment commitment (Jensen 1986). Given that debt reduces internal agency problems then LEVERAGE will be inversely related to the regressand. Furthermore, reorganizations are likely dependent on the level of firm performance and growth opportunities. Similarly, Berger and Ofek (1999) argue that these two factors are among the determinants of more severe changes to the organization during corporate refocusing programs, i.e. divestitures of non-core businesses. I capture the effect of firm performance with $R O A$, the earnings before interest and taxes divided by total assets. BTM is the book-to-market ratio of the firm as a conventional proxy of growth opportunities. Reorganizations are likely

${ }^{20}$ The Bushman et al. (1995) measure of unrelated diversification is defined as

$$
\text { DIVERSIFICATION }=\sum_{a=1}^{n} p_{a} \ln \left(1 / p_{a}\right)
$$

with $p_{a}$ being the sales share of industry $a$ in total firm sales.

${ }^{21}$ The Rajan et al. (2000) diversity in growth opportunities measure is defined as

$$
\text { DIVERSITY }=\frac{\sqrt{\sum_{i=1}^{n} \frac{\left(w_{i} q_{i}-\overline{w q}\right)^{2}}{n-1}}}{\frac{\sum_{i=1}^{n} q_{i}}{n}}
$$

where $w_{i}$ is the assets share of division $i$ in total firm assets and $q_{i}$ is the division $i$ 's book-to-market ratio. 
occurring among more mature companies, whereas younger companies are less likely to change their organization already in the outset. To the extent that profitability is higher for more mature businesses with lower equity multiples then $R O A$ and $B T M$ will be positively related to the probability of reorganizations. Including $R O A$ and $B T M$ also controls for the possibility that reorganizations are an indication of changes in the production function of the firm rather than changes in the assignment of decision rights. While less likely to be the case in the sample at hand given the upfront selection procedure (cf. section 3.3.1), the two performance parameters also control for potential competitive pressures that may induce management to change the organizational structure to intentionally distort information. The probit model includes identifier variables for both year and industry as defined at the two-digit NAICS level. Standard errors are corrected for potential clustering at firm level in all specifications.

Hypothesis 2 conjectures that allocation inefficiencies are less likely to initiate reorganizations in firms with comparatively abundant cash flows, i.e. a low cost of inefficient capital allocation. I investigate this moderation effect by augmenting equation (3.1) with an interaction term between the allocation efficiency measure $I C M \_E F F$ and a proxy for the abundance of cash flow, CFABUNDANCE, cf. equation (3.2). CFABUNDANCE is computed using an indicator variable for the lowest quintile across firms and years of the ratio of net cash flows from financing activities scaled by sales. Net financing cash flows increase in the amount of funds raised through either debt or equity and decrease with debt repayments and dividends. Firms in the lowest quintile of the financing cash flow to sales ratio - as indicated through CFABUNDANCE - therefore have ample funds to allow for net outflows and require little additional outside financing, i.e. have sufficient internal funds. Following hypothesis 2 , the interaction term should attenuate the effect of allocation efficiency on the likelihood of reorganizations and is therefore expected to have a positive coefficient. For completeness of the econometric specification I also include $C F A B U N D A N C E$ as an individual regressor, without directional prediction of its coefficient. All other independent variables are the same as in the model for hypothesis 1 . The model for hypothesis 2 similarly includes identifier variables for both year and industry as defined at the two-digit NAICS level. Also, all specifications correct for clustered standard errors at the firm level.

$$
\begin{aligned}
& \text { REORGANIZATION }_{i, t}=f\left(I C M_{-} E F F_{i, t-n},{I C M \_E F F_{i, t-n}}^{*} C F A B U N D A N C E_{i, t-n}\right. \text {, } \\
& \text { CFABUNDANCE } E_{i, t-n}, \text { DIVERSIFICATION }{ }_{i, t-n} \text {, } \\
& \text { DIVERSITY }_{i, t-n}, \text { DIVISONS }_{i, t-n}, \text { EMPLOYEES }_{i, t-n} \text {, } \\
& \text { LEVERAGE } \left.E_{i, t-n}, R O A_{i, t-n}, B T M_{i, t-n}\right)
\end{aligned}
$$

Hypothesis 3 and 4 concern the changes of capital allocation efficiency and shareholder wealth around the date of divisional reorganizations, respectively. I 
investigate hypothesis 3 with $I C M \_E F F$ as described above, and the stock returns of a 12-month buy-and-hold strategy to capture shareholder wealth per firm-year in variable RETURN for hypothesis 4. I compare the level of these variables between the reorganizing firms and an assigned control group that resembles the former but does not reorganize. A frequently used method to arrive at a refined control group is to select firms in the control group by means of two or three dimensions such as year and firm size (e.g. Berger \& Ofek 1999; Wallace 1997). This method proceeds iteratively among the chosen dimensions, where the order in itself introduces an additional element of subjectivity. In an attempt to overcome the deficiencies of traditional methods, propensity score matching models (Rosenbaum \& Rubin 1983) have become increasingly popular in observational studies in recent years and have also started to enter accounting research (e.g. Hogan \& Lewis 2005; Höppe 2009). Among others, they have the considerable advantage that treatment and control group subjects are matched on multiple dimensions simultaneously rather than iteratively and that treatment effect variances are typically lower than in pure random sample matching.

To investigate hypotheses 3 and 4, I select the same control variables as in equation (3.1), the binary response model described for hypothesis 1, as key matching dimensions and proceed in the following four stages. First, I choose to match each reorganizing firm in the year preceding the reorganization event to one control firm that neither reorganizes nor is involved in any transaction such as acquisitions or divestments throughout the sample period. Second, I determine averages of the matching variables for all years preceding the reorganization event. To find comparable matches to these average values among the control firms, I also compute the arithmetic mean among control firms. In particular, I calculate average values in each year over the year itself and all preceding years ${ }^{22}$. This step is taken to reduce potential distortions in matching control firms that may spring from outlier values in the reference year used for matching. Third, I fit a probit propensity score model with nearest neighbor matching to identify matching control firms for all reorganizing firms that do not strictly increase or decrease the number of segments. This method results in a matched control firm for each reorganizing firm in the firm prior to changing the divisional structure. In a fourth step, the control firm years are marked as preceding or following the year of reorganization of the matched reorganizing firm. I then use these years to identify differences in allocation efficiency and shareholder wealth before and after reorganizing a firm's divisions.

\footnotetext{
${ }^{22}$ More specifically, average values used in matching reorganizing and control firms are defined as follows. Let $v_{n t} \in V$ indicate the value of matching variable $v$ for company $n$ in period $t$. Observations preceding a reorganization are indexed with $t<0$ and with $t>0$ or subsequent years, with $\min t_{n}=\underline{t}_{n}$ being the earliest observation in the time series of firm $n$. To obtain averages including the current and all preceding years, but no subsequent years, matrix $V$ is transformed into $\bar{V}$ where

$$
\bar{v}_{n t} \in \bar{V}: \bar{v}_{n t}=\frac{\sum_{t_{n}}^{t} v_{n t}}{t+1-\underline{t}_{n}}
$$
}


Table 3.2

Composition of reorganizing firms

\begin{tabular}{lcc} 
Number of reorganizing firms & 110 & $100 \%$ \\
\hline thereof: & & \\
increasing the number of segments & 40 & $36 \%$ \\
decreasing the number of segments & 34 & $31 \%$ \\
keeping the number of segments & 25 & $23 \%$ \\
firms with multiple reorganizations & 11 & $10 \%$
\end{tabular}

\subsection{Empirical findings}

\subsubsection{Descriptives and univariate statistics}

Table 3.2 categorizes the 110 sampled reorganizing firms depending on whether the firms increase, decrease, or keep the same number of divisions after rearranging their internal structure. The majority of firms increase the number of divisions, either by forming an entirely new segment or by splitting up existing ones. 11 firms change their structure several times during the sample period and do not strictly increase or decrease the number of divisions.

Table 3.3 reports key descriptive statistics for the reorganizing firms in panel A using data from the periods both preceding and following the reorganization event as well as the control group of firms in panel B. The median reorganizing firm has USD $1.1 \mathrm{bn}$ in assets and a return on assets of $8.2 \%$, with three operating segments. Panel B reveals that the control group is characterized by on average smaller firms, with the median firm holding total assets of USD $388 \mathrm{~m}$ and employing 1,800 employees. Despite the size differences, untabulated mean comparison tests show that both groups of firms do not differ significantly in terms of return on assets, book-to-market ratio, nor the measure of excess value of diversified firms. Preceding studies on internal capital allocations frequently make use of the latter construct to compare the sum of all individually valued divisions with that of the actual group equity market value (Berger \& Ofek 1995; Bens \& Monahan 2004). Despite the use of NAICS instead of SIC classifications as in previous studies, I find the average discount to be comparable to preceding studies at $-19 \%$ for the control group and almost similar at $-21 \%$ for the reorganizing firms. The ratio of restructuring costs to consolidated sales is almost identical at on average $1 \%$ for reorganizing firms. This supports the argument that the identified reorganizations address the organization rather than the operations of the company, i.e. do not involve above-average restructurings in the sense of plant closures or large-scale employee dismissals as captured in restructuring costs. 
Table 3.3

Descriptive firm statistics

Panel A - Reorganizing firms

\begin{tabular}{lrrrrrr} 
& Mean & Median & St. dev. & \multicolumn{1}{c}{ Min } & \multicolumn{1}{c}{ Max } & N \\
\hline Total assets (USD mm) & 4,409 & 1,077 & 8,244 & 22 & 60,928 & 934 \\
Total sales (USD mm) & 4,554 & 1,106 & 9,587 & 22 & 101,703 & 934 \\
Employees ('000) & 18.204 & 4.800 & 33.908 & 0.142 & 211.000 & 925 \\
ROA & 0.082 & 0.082 & 0.074 & -0.466 & 0.333 & 934 \\
BTM & 0.603 & 0.511 & 0.457 & 0.000 & 4.104 & 848 \\
LEVERAGE & 0.589 & 0.582 & 0.232 & 0.099 & 1.986 & 934 \\
DIVISIONS & 3.302 & 3.000 & 1.190 & 2 & 7 & 934 \\
DIVERSIFICATION & 0.443 & 0.453 & 0.391 & 0.000 & 1.740 & 934 \\
DIVERSITY & 0.243 & 0.213 & 0.150 & 0.002 & 0.830 & 821 \\
ICM_EFF & 0.004 & 0.000 & 0.191 & -1.747 & 1.750 & 804 \\
EXCESSVALUE & -0.208 & -0.245 & 0.609 & -1.365 & 1.358 & 723 \\
Restructuring costs/total sales & 0.013 & 0.006 & 0.020 & -0.010 & 0.197 & 308
\end{tabular}

Panel B - Control group of firms

\begin{tabular}{lrrrrrr} 
& Mean & Median & St. dev. & \multicolumn{1}{c}{ Min } & Max & \multicolumn{1}{c}{ N } \\
\hline Total assets (USD mm) & 2,395 & 388 & 7,934 & 20 & 242,223 & 11,994 \\
Total sales (USD mm) & 1,908 & 385 & 5,649 & 20 & 137,634 & 11,991 \\
Employees ('000) & 7.740 & 1.800 & 23.199 & 0.100 & 910.000 & 11,578 \\
ROA & 0.047 & 0.068 & 0.147 & -2.698 & 0.333 & 11,935 \\
BTM & 0.714 & 0.533 & 0.675 & 0.001 & 4.104 & 9,877 \\
LEVERAGE & 0.579 & 0.562 & 0.314 & 0.074 & 3.044 & 11,994 \\
DIVISIONS & 2.731 & 2.000 & 0.998 & 2 & 10 & 11,996 \\
DIVERSIFICATION & 0.285 & 0.143 & 0.327 & -0.126 & 1.505 & 11,998 \\
DIVERSITY & 0.336 & 0.300 & 0.201 & 0.001 & 2.129 & 8,937 \\
ICM_EFF & 0.004 & 0.000 & 0.239 & -1.747 & 1.750 & 4,619 \\
EXCESSVALUE & -0.185 & -0.207 & 0.613 & -1.386 & 1.385 & 8,590 \\
Restructuring costs/total sales & 0.022 & 0.007 & 0.102 & -1.186 & 3.404 & 2,561
\end{tabular}

$R O A$ are earnings before interest and taxes divided by total assets. BTM is the book-to-market ratio of the firm as a conventional proxy of growth opportunities. LEVERAGE is the ratio of long- and shortterm debt to total assets. DIVISIONS is the number of operating divisions. DIVERSIFICATION is the Bushman, Indjejikian, and Smith (1995) measure of unrelated diversification. DIVERSITY is the Rajan et al. (2000) measure of dispersion of the divisions' growth opportunities. ICM_EFF is the Billet and Mauer (2003) measure of internal capital market efficiency, based on segment growth opportunities. EXCESSVALUE is the Berger and Ofek (1995) diversification discount measure, based on division sales. 
Table 3.4

Comparative firm statistics before and after reorganizing

\begin{tabular}{|c|c|c|c|c|c|c|}
\hline & $\begin{array}{l}\text { Years } \\
\text { Mean } \\
(1)\end{array}$ & $\mathrm{N}$ & $\begin{array}{c}\text { Years } \\
\text { Mean } \\
(2) \\
\end{array}$ & $\begin{aligned}= & \mathrm{t}^{1} \\
& \mathrm{~N}\end{aligned}$ & $\begin{array}{l}\text { Difference } \\
(1)-(2)\end{array}$ & $\begin{array}{c}\text { t-test } \\
\text { p-value }\end{array}$ \\
\hline $\begin{array}{l}\text { Total assets } \\
\text { (USD } \mathrm{mm})\end{array}$ & 3,372 & 388 & 3,805 & 449 & -433 & 0.330 \\
\hline $\begin{array}{l}\text { Total sales } \\
\text { (USD mm) }\end{array}$ & 3,221 & 388 & 4,930 & 449 & $-1,710$ & $0.009 * * *$ \\
\hline Employees ('000) & 16.514 & 381 & 16.217 & 447 & 0.297 & 0.897 \\
\hline$R O A$ & 0.085 & 388 & 0.076 & 449 & 0.009 & $0.065 *$ \\
\hline BTM & 0.633 & 355 & 0.596 & 396 & 0.037 & 0.285 \\
\hline LEVERAGE & 0.575 & 388 & 0.608 & 449 & -0.033 & $0.046 * *$ \\
\hline DIVISIONS & 3.108 & 388 & 3.334 & 449 & -0.226 & $0.005 * * *$ \\
\hline DIVERSIFICATION & 0.413 & 388 & 0.459 & 449 & -0.046 & $0.080 *$ \\
\hline DIVERSITY & 0.266 & 362 & 0.218 & 375 & 0.048 & $0.000 * * *$ \\
\hline$I C M \_E F F$ & -0.015 & 351 & 0.022 & 372 & -0.037 & $0.014 * * *$ \\
\hline EXCESSVALUE & -0.184 & 290 & -0.240 & 351 & 0.056 & 0.253 \\
\hline Restructuring costs/total sales & 0.015 & 74 & 0.012 & 189 & 0.003 & 0.300 \\
\hline
\end{tabular}

\footnotetext{
${ }^{1}$ The year of reorganization is indicated as year t. Hence, columns (1) and (2) list values for firm years preceding and following a reorganization, respectively.

$R O A$ are earnings before interest and taxes divided by total assets. $B T M$ is the book-to-market ratio of the firm as a conventional proxy of growth opportunities. LEVERAGE is the ratio of long- and shortterm debt to total assets. DIVISIONS is the number of operating divisions. DIVERSIFICATION is the Bushman, Indjejikian, and Smith (1995) measure of unrelated diversification. DIVERSITY is the Rajan et al. (2000) measure of dispersion of the divisions' growth opportunities. ICM_EFF is the Billet and Mauer (2003) measure of internal capital market efficiency, based on segment growth opportunities. EXCESSVALUE is the Berger and Ofek (1995) diversification discount measure, based on division sales. $* * *, * *$, and * identify significant results at the $1 \%, 5 \%$, and $10 \%$ levels (two-tailed).
}

The descriptive statistics in table 3.3 contain all observations before and after the reorganization. For a preliminary analysis of the changes surrounding reorganizations, I split the reorganizing firm year observations into those preceding and following the change in organization layout. Results from mean comparison $\mathrm{t}$ tests of these two sub-samples are depicted in table 3.4. The tabulations indicate an increase in the internal capital market efficiency at a two-sided significance threshold of $1 \%$, pointing at post-reorganization improvements taking place within the organizations. The change in allocation efficiency is investigated in more detail in the analysis on hypothesis 3 . Return on assets declined by $1 \%$ following the reorganization event, statistically significant at $10 \%$. The drop can be interpreted as the transitory decline in performance due to changing the organizational structure. 


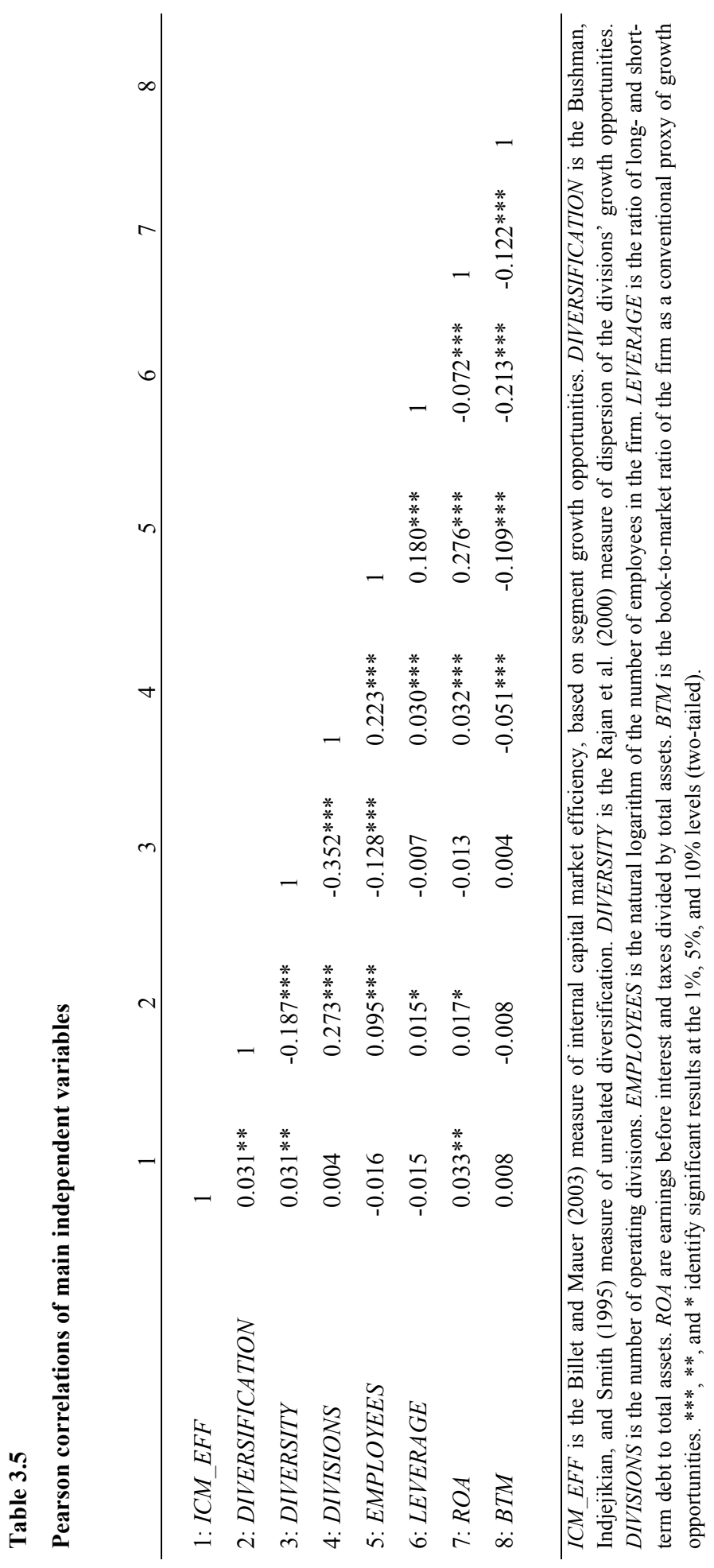


The table further documents a significant increase in both total firm sales as well as the number of operating segments, whereas the total number of employees does not change significantly. Taken together, this substantiates the appropriateness of the initial sample screening procedure to select firms that change the structure of operations of its existing (human) resources, rather than expanding or reducing resources altogether.

Table 3.5 depicts Pearson correlations between the independent variables

\section{Table 3.6}

\section{Probit model of incidence of reorganization on broad sample}

\begin{tabular}{|c|c|c|c|c|c|}
\hline Independent variables & $\begin{array}{c}\text { Predicted } \\
\text { sign }\end{array}$ & $\begin{array}{r}\text { (1) Inc } \\
\text { reorga } \\
R E O R G A \\
\text { Marginal } \\
\text { effect } \\
\end{array}$ & $\begin{array}{l}\text { lence of } \\
\text { lization } \\
\text { IIZATION }_{t} \\
\text { Prob. }\end{array}$ & $\begin{array}{r}\text { (2) Inc } \\
\text { reorga } \\
R E O R G A \\
\text { Marginal } \\
\text { effect }\end{array}$ & $\begin{array}{l}\text { lence of } \\
\text { lization } \\
\text { IIZATION }_{t} \\
\text { Prob. }\end{array}$ \\
\hline$I C M_{-} E F F_{t-n}$ & - & -0.068 & $0.003 * * *$ & -0.052 & $0.016 * *$ \\
\hline DIVERSIFICATION $_{t-n}$ & $?$ & 0.028 & 0.351 & 0.034 & 0.233 \\
\hline DIVERSITY $_{t-n}$ & $?$ & -0.045 & 0.368 & -0.046 & 0.319 \\
\hline$D I V I S I O N S_{t-n}$ & + & 0.000 & 0.486 & 0.000 & 0.488 \\
\hline EMPLOYEES $_{t-n}$ & + & 0.023 & $0.001 * * *$ & 0.023 & $0.001 * * *$ \\
\hline$L E V E R A G E_{t-n}$ & - & -0.034 & 0.195 & -0.050 & 0.129 \\
\hline$R O A_{t-n}$ & + & 0.107 & 0.149 & 0.151 & 0.105 \\
\hline$B T M_{t-n}$ & + & -0.014 & 0.128 & -0.015 & 0.126 \\
\hline Industry controls & & No & & Yes & \\
\hline Year controls & & No & & Yes & \\
\hline Intercept & & Yes & & Yes & \\
\hline Pseudo R2 & & 0.069 & & 0.137 & \\
\hline No. of observations & & 1,411 & & 1,242 & \\
\hline
\end{tabular}

\footnotetext{
Standard errors are corrected for clustering at firm-level. The marginal effect is equal to the partial derivative $\delta \mathrm{E}[\mathrm{y} \mid \mathrm{x}] / \delta \mathrm{x}=\varphi\left(\mathrm{x}^{\prime} \beta\right) \beta$ of the binary response model, evaluated at sample means. REORGANIZATION is an indicator variable equal to 1 for firms that alter their divisional structure and 0 otherwise. ICM_EFF is the Billet and Mauer (2003) measure of internal capital market efficiency, based on segment growth opportunities. DIVERSIFICATION is the Bushman, Indjejikian, and Smith (1995) measure of unrelated diversification. DIVERSITY is the Rajan et al. (2000) measure of dispersion of the divisions' growth opportunities. DIVISIONS is the number of operating divisions. EMPLOYEES is the natural logarithm of the number of employees in the firm. LEVERAGE is the ratio of long- and shortterm debt to total assets. ROA are earnings before interest and taxes divided by total assets. BTM is the book-to-market ratio of the firm as a conventional proxy of growth opportunities. $* * *, * *$, and * identify significant results at the $1 \%, 5 \%$, and $10 \%$ levels (one-tailed for predictions, two-tailed otherwise).
} 
employed in the probit models to document potential multicollinearity problems. None of the correlation factors are so high for multicollinearity to be of discomforting impact. In addition, the variance inflation factors of these variables do not exceed the conventional threshold of 10 with average values of around 3 (untabulated). This corroborates the impression gained from inspecting the correlations in table 3.5 .

\subsubsection{Main analyses}

\subsubsection{Hypothesis 1}

To investigate the determinants of divisional reorganization, I first run the main propensity specification on a sample comparing the control group of firms with all reorganizing firms, regardless of whether they increase, decrease, or keep the same number of segments subsequent to the reorganization event. To investigate the sensitivity of the results to including control variables, I first run specification (1) in table 3.6, excluding year and industry control variables. The results indicate that internal capital market efficiency is negatively related to the occurrence of reorganizations, significant at the $1 \%$ level. Industry and year controls are added in specification (2). The number of observations declines compared to specification (1) as some industry and year indicator variables perfectly predict the dichotomous dependent variable, i.e. exhibit no variation in the latter, so that these industries and years are excluded. Internal capital market efficiency remains significantly negatively related to the incidence of reorganization $(\mathrm{p}=1.6 \%)$ when adding industry and year controls. In other words, the lower the efficiency of internal allocations, the higher the probability of a divisional reorganization. This finding confirms hypothesis 1 . Of the other explanatory variables, only the number of employees relates significantly to changing the organizational structure.

The preceding specifications were estimated using the entire group of reorganizing firms, irrespective whether they increase, decrease or keep the number of divisions after changing their structure. Estimating the model across all reorganizations irrespective of changes in the number of segments is potentially imprecise for three reasons. First, an additional division might rather be the reflection of growth in part of the firm's operations, vice versa for combining a division with another one. Indeed, some companies that increased the number of divisions at times reported in their $10-\mathrm{k}$ form that this was due to the engagement in a growth market. Hence, these firms are potentially changing their production function at the same time that they are changing their organization, which may make it difficult to infer on the effect of the latter alone. Incorporating return on assets and the market-to-book ratio in the preceding probit models can at least to some degree control for such performance- and production-related motives, but may not sufficiently isolate them. Second, changing the number of divisions essentially also 
Table 3.7

Probit model of incidence of reorganization on focussed sample

\begin{tabular}{|c|c|c|c|c|c|}
\hline Independent variables & $\begin{array}{l}\text { Predicted } \\
\text { sign }\end{array}$ & \multicolumn{2}{|c|}{$\begin{array}{c}\text { (1) Incidence of } \\
\text { reorganization } \\
\text { REORGANIZATION }\end{array}$} & \multicolumn{2}{|c|}{$\begin{array}{c}\text { (2) Incidence of } \\
\text { reorganization } \\
\text { REORGANIZATION }\end{array}$} \\
\hline$I C M_{-} E F F_{t-n}$ & - & -0.030 & $0.000 * * *$ & -0.046 & $0.000 * * *$ \\
\hline DIVERSIFICATION $_{t-n}$ & $?$ & -0.004 & 0.644 & -0.013 & 0.317 \\
\hline DIVERSITY $_{t-n}$ & $?$ & -0.023 & 0.113 & -0.040 & $0.029 * *$ \\
\hline$D_{I V I S I O N S} S_{t-n}$ & + & 0.001 & 0.310 & 0.003 & 0.184 \\
\hline$E M P L O Y E E S_{t-n}$ & + & 0.007 & $0.001 * * *$ & 0.012 & $0.000 * * *$ \\
\hline$L E V E R A G E_{t-n}$ & - & 0.012 & 0.144 & -0.006 & 0.378 \\
\hline$R O A_{t-n}$ & + & 0.078 & $0.020 * *$ & 0.127 & $0.009 * * *$ \\
\hline$B T M_{t-n}$ & + & 0.001 & 0.377 & -0.002 & 0.328 \\
\hline Industry controls & & No & & Yes & \\
\hline Year controls & & No & & Yes & \\
\hline Intercept & & Yes & & Yes & \\
\hline Pseudo R2 & & 0.152 & & 0.267 & \\
\hline No. of observations & & 1,326 & & 655 & \\
\hline
\end{tabular}

Standard errors are corrected for clustering at firm-level. The marginal effect is equal to the partial derivative $\delta \mathrm{E}[\mathrm{y} \mid \mathrm{x}] / \delta \mathrm{x}=\varphi\left(\mathrm{x}^{\prime} \beta\right) \beta$ of the binary response model, evaluated at sample means. REORGANIZATION is an indicator variable equal to 1 for firms that alter their divisional structure and 0 otherwise. ICM EFF is the Billet and Mauer (2003) measure of internal capital market efficiency, based on segment growth opportunities. DIVERSIFICATION is the Bushman, Indjejikian, and Smith (1995) measure of unrelated diversification. DIVERSITY is the Rajan et al. (2000) measure of dispersion of the divisions' growth opportunities. DIVISIONS is the number of operating divisions. EMPLOYEES is the natural logarithm of the number of employees in the firm. LEVERAGE is the ratio of long- and shortterm debt to total assets. $R O A$ are earnings before interest and taxes divided by total assets. BTM is the book-to-market ratio of the firm as a conventional proxy of growth opportunities. ***, **, and * identify significant results at the $1 \%, 5 \%$, and $10 \%$ levels (one-tailed for predictions, two-tailed otherwise).

changes the amount of disclosure communicated to the financial market. The impact on disclosure may lead firms to react differently to inefficient internal allocations, e.g. to be more likely to split a segment to reduce information asymmetries. Third, measuring misallocations is likely including a certain degree of measurement error for each division contained in a firm. It follows that changes in measured misallocation may result from changes in the number of underlying divisions and the degree of measurement precision absent any differences in actual misallocations. 
In consideration of these concerns, I restrict the sample of reorganizing firms to those that keep the number of divisions after reorganization or that reorganize several times with no strict increase or decrease in the number of divisions. This subsample contains firms that mostly reassign part of a full division under the auspices of another one and is likely to be a stronger setting to analyze the reassignment of decision rights among division managers compared to studying reorganizations in general that may dilute the analysis with the confounding phenomena described above.

Table 3.7 provides the results from analyzing the refined sample of reorganizing firms. Similar to the entire sample of reorganizations, I start with a reduced model excluding industry and year controls in specification (1), documenting a negative association of allocation efficiency and the incidence of reorganizations and a strong statistical significance below 1\%. Augmenting the model with indicator variables for industry and year in specification (2) further reinforces this relation. Compared to including all types of reorganizations, the association of allocation with reorganizations in the full model in specification (2) is much stronger $(\mathrm{t}$-value $-6.33, \mathrm{p}<1 \%)$. As in the full sample specifications, the number of employees is strongly related to the regressand. According to expectations, reorganizations occur more often for firms with higher return on assets, proxying for more mature companies. Lastly, the Pseudo $\mathrm{R}^{2}$ for the two specifications is persistently higher than in the full sample. The higher joint explanatory power of the independent variables indicates that the antecedents, which the model controls for, have a higher statistical significance in the focused sample.

\subsubsection{Hypothesis 2}

Hypothesis 2 posits that firms are less likely to react to inefficient allocations by changing their organizational design in case of abundant funds at disposal. I augment the specifications shown in table 3.7 with an interaction term between cash flow abundance and the efficiency of internal capital allocations as well as a main effect of cash flow abundance. The results are reported in table 3.8. In specification (2), the main effect of internal capital allocation efficiency is negative and significant at the $1 \%$ level, similar to the original model in table 3.7. The interaction term is positive at a statistical significance of $1 \%$ (t-value $2.97, \mathrm{p}=0.2 \%$ ), showing that cash flow abundance acts as a moderator on the inverse relationship between allocation efficiency and the occurrence of reorganizations. Firms with a relative abundance of cash, i.e. facing few financial constraints, are therefore less likely to react to inefficiencies in the fund allocation process by reorganizing. This makes intuitive sense as an abundance of capital diminishes the marginal cost of capital and thus the marginal cost of capital misallocation, making it more attractive for firms to keep the organizational status quo. The remaining coefficients resemble direction and significance of the original specification in table 3.7, indicating high 
Table 3.8

Probit interaction lag model of incidence of reorganization

\begin{tabular}{|c|c|c|c|c|c|}
\hline Independent variables & $\begin{array}{l}\text { Predicted } \\
\text { sign }\end{array}$ & $\begin{array}{r}\text { (1) Inc } \\
\text { reorg } \\
R E O R G / \\
\text { Marginal } \\
\text { effect }\end{array}$ & $\begin{array}{l}\text { lence of } \\
\text { ization } \\
\text { IIZATION }_{t} \\
\text { Prob. }\end{array}$ & $\begin{array}{r}(2) \text { Inc } \\
\text { reorga } \\
R E O R G A \\
\text { Marginal } \\
\text { effect }\end{array}$ & $\begin{array}{l}\text { ence of } \\
\text { ization } \\
\text { IZATION }_{t} \\
\text { Prob. }\end{array}$ \\
\hline $\begin{array}{l}I C M_{-} E F F_{t-n} \\
I C M E F F_{t-n}\end{array}$ & - & -0.030 & $0.000 * * *$ & -0.048 & $0.000 * * *$ \\
\hline${ }^{*} C F \bar{A} B U N D A N C E_{t-n}$ & + & 0.022 & 0.157 & 0.055 & $0.002 * * *$ \\
\hline$C F A B U N D A N C E_{t-n}$ & $?$ & 0.002 & 0.693 & 0.009 & 0.204 \\
\hline DIVERSIFICATION $_{t-n}$ & $?$ & -0.004 & 0.648 & -0.013 & 0.333 \\
\hline DIVERSITY $_{t-n}$ & $?$ & -0.023 & 0.110 & -0.042 & $0.028 * *$ \\
\hline$D_{I V I S I O N S}$ & + & 0.001 & 0.322 & 0.003 & 0.206 \\
\hline EMPLOYEES $_{t-n}$ & + & 0.007 & $0.001 * * *$ & 0.012 & $0.000 * * *$ \\
\hline$L E V E R A G E_{t-n}$ & - & 0.012 & 0.139 & -0.007 & 0.354 \\
\hline$R O A_{t-n}$ & + & 0.078 & $0.025 * *$ & 0.125 & $0.012 * * *$ \\
\hline$B T M_{t-n}$ & + & 0.001 & 0.370 & -0.002 & 0.331 \\
\hline Industry controls & \multicolumn{3}{|c|}{ No } & \multicolumn{2}{|l|}{ Yes } \\
\hline Year controls & & \multicolumn{2}{|l|}{ No } & \multicolumn{2}{|l|}{ Yes } \\
\hline Intercept & \multicolumn{3}{|c|}{ Yes } & \multicolumn{2}{|l|}{ Yes } \\
\hline Pseudo R2 & \multicolumn{3}{|c|}{0.152} & \multicolumn{2}{|l|}{0.271} \\
\hline No. of observations & \multicolumn{3}{|c|}{1,326} & \multicolumn{2}{|l|}{655} \\
\hline
\end{tabular}

Standard errors are corrected for clustering at firm-level. The marginal effect is equal to the partial derivative $\delta \mathrm{E}[\mathrm{y} \mid \mathrm{x}] / \delta \mathrm{x}=\varphi\left(\mathrm{x}^{\prime} \beta\right) \beta$ of the binary response model, evaluated at sample means. REORGANIZATION is an indicator variable equal to 1 for firms that alter their divisional structure and 0 otherwise. ICM_EFF is the Billet and Mauer (2003) measure of internal capital market efficiency, based on segment growth opportunities. CFABUNDANCE is computed using an indicator variable for the lowest quintile across firms and years of the ratio of net cash flows from financing activities scaled by sales. It indicates the abundance of cash flows in the firm, i.e. the inverse degree of cash constraints. DIVERSIFICATION is the Bushman, Indjejikian, and Smith (1995) measure of unrelated diversification. DIVERSITY is the Rajan et al. (2000) measure of dispersion of the divisions' growth opportunities. DIVISIONS is the number of operating divisions. EMPLOYEES is the natural logarithm of the number of employees in the firm. LEVERAGE is the ratio of long- and short-term debt to total assets. ROA are earnings before interest and taxes divided by total assets. BTM is the book-to-market ratio of the firm as a conventional proxy of growth opportunities. $* * * * *$, and * identify significant results at the $1 \%, 5 \%$, and $10 \%$ levels (one-tailed for predictions, two-tailed otherwise).

orthogonality of the two cash flow abundance terms. Ai and Norton (2003) argue that interaction terms in probit models require transformation before inferences on the significance are possible. In an untabulated test, I apply their method and find that the interaction term remains negative, but insignificant for the majority of the firms with an average z-statistic of 0.76 . However, the standard deviation of this $\mathrm{z}$ statistic at 0.46 and a maximum value at 6.05 indicate that the $z$-statistic for the interaction term surpasses the critical value of 1.96 in some cases. Therefore, 


\section{Table 3.9}

\section{Comparative firm statistics before and after reorganizing}

Panel A - Internal capital market efficiency of reorganizing vs. propensity matched control firms

\begin{tabular}{|c|c|c|c|c|c|c|}
\hline \multirow[b]{2}{*}{ Time } & \multicolumn{2}{|c|}{ Reorganizing firms } & \multicolumn{2}{|c|}{ Control firms } & \multirow{2}{*}{$\begin{array}{c}\text { Difference } \\
\text { (1)-(2) }\end{array}$} & \multirow{2}{*}{$\begin{array}{c}\mathrm{t} \text {-test } \\
\mathrm{n} \text {-value }\end{array}$} \\
\hline & Mean (1) & $\mathrm{N}$ & Mean (2) & $\mathrm{N}$ & & \\
\hline
\end{tabular}

(a) before reorganizing

$\begin{array}{lllllll}I C M_{-} E F F & -0.051 & 88 & 0.040 & 92 & -0.091 & 0.010 * * * \\ \text { (b) after reorganzing } & & & & & & \\ I C M_{-} E F F & -0.004 & 81 & 0.012 & 20 & -0.016 & 0.545\end{array}$

Panel B - Stock returns of reorganizing vs. propensity matched control firms

\begin{tabular}{|c|c|c|c|c|c|c|}
\hline \multirow[b]{2}{*}{ eriod } & \multicolumn{2}{|c|}{ Reorganizing firms } & \multicolumn{2}{|c|}{ Control firms } & \multirow{2}{*}{$\begin{array}{c}\text { Difference } \\
\text { (1)-(2) }\end{array}$} & \multirow{2}{*}{$\begin{array}{c}\text { t-test } \\
\text { p-value }\end{array}$} \\
\hline & Mean (1) & $\mathrm{N}$ & Mean (2) & $\mathrm{N}$ & & \\
\hline
\end{tabular}

(a) before reorganizing

$\begin{array}{lllllll}\text { RETURN } & -0.084 & 81 & 0.061 & 96 & -0.145 & 0.010 * * *\end{array}$

(b) after reorganzing

$\begin{array}{lllllll}R E T U R N & 0.134 & 92 & 0.153 & 50 & -0.019 & 0.854\end{array}$

ICM_EFF is the Billet and Mauer (2003) measure of internal capital market efficiency, based on segment growth opportunities. RETURN is the stock return of a 12-month buy-and-hold strategy to capture shareholder wealth per firm-year. $* * *, * *$, and $*$ identify significant results at the $1 \%, 5 \%$, and $10 \%$ levels (two-tailed).

hypothesis 2 holds at least for some of the sampled firms but the strength of this evidence is obviously limited.

\subsubsection{Hypothesis 3}

Table 3.4 already indicated significant improvements in internal allocation efficiency when comparing the years prior to and after reorganizing in a two-sample t-test. This result, however, considers all types of division reorganizations instead of focusing on those reorganizations where the number of divisions does not change. 
This is likely to be the stronger setting due to fewer potentially confounding events, as argued above. Also, this inter-temporal comparison does not control for other changes in the economic environment that may affect allocation efficiency of all firms. To address both issues, I compare allocation efficiency values of reorganizing firms that keep the number of divisions to the group of control firms determined through propensity matching as described in section 3.3.2. Results are depicted in table 3.9, panel A. The significant difference in allocation efficiencies before reorganization turns insignificant after changing the allocation of decision rights. This is in line with the argument that observed inefficiencies in capital allocation are transitory and that firm reactions reduce inefficiencies. The result confirms hypothesis 3. Additionally, I check for the nonparametric equality of medians between the groups and also run Wilcoxon rank-sum tests. The untabulated results from both alternatives confirm the findings from the two-sample t-tests. Capital allocation efficiencies are significantly lower compared to the control group before reorganizing and this difference vanishes after the change of the organizational layout.

Direct estimations on the dimensions of this improvement are difficult since the underlying measure developed by Billet and Mauer (2003) is an aggregated variable without immediate interpretation. However, the change in the measure before and after reorganization of $0.047(-0.004-[-0.051])$ constitutes $16.5 \%$ of the measure's standard deviation before reorganizing, providing some indication of the benefits of firms reassigning decision rights among division managers.

\subsubsection{Hypothesis 4}

Hypothesis 4 posits that shareholders should ultimately gain from improving the efficiency of the internal allocation process. The analysis for this hypothesis resembles the test of hypothesis 3, substituting the measure of internal capital market efficiency with the 12-month buy-and-hold stock returns as depicted in panel $\mathrm{B}$ of table 3.9. The tests indicate that returns are significantly lower for reorganizing firms compared to their control group for the years preceding the reassignment of decision rights, whereas differences become insignificant in the subsequent years. This confirms hypothesis 4 and corroborates the impression gained when considering capital allocation efficiency in hypothesis 3 that reorganizations reestablish parity with control firms. The same inference is also drawn from the untabulated tests of the nonparametric equality of medians and Wilcoxon rank-sum tests. The diminishing differential between the reorganizing firms and the group of control firms from initially $0.145(0.061-[-0.084])$ to $0.019(0.153-0.134)$ illustrates the considerable effect on shareholder wealth. 
Table 3.10

Probit interaction lag model of incidence of reorganization, specification in changes

\begin{tabular}{|c|c|c|c|c|c|}
\hline \multirow[b]{2}{*}{ Independent variables } & \multirow[b]{2}{*}{$\begin{array}{c}\text { Predicted } \\
\text { sign }\end{array}$} & \multicolumn{2}{|c|}{$\begin{array}{l}\text { (1) Focussed sample } \\
\text { Incidence of } \\
\text { reorganization } \\
\text { REORGANIZATION }\end{array}$} & \multicolumn{2}{|c|}{$\begin{array}{l}\text { (2) Broad sample } \\
\text { Incidence of } \\
\text { reorganization } \\
\text { REORGANIZATION }\end{array}$} \\
\hline & & $\begin{array}{r}\text { Marginal } \\
\text { effect }\end{array}$ & Prob. & $\begin{array}{r}\text { Marginal } \\
\text { effect } \\
\end{array}$ & Prob. \\
\hline$I C M_{-} E F F_{t-n}$ & - & 0.000 & $0.000 * * *$ & -0.001 & $0.041 * *$ \\
\hline DIVERSIFICATION $_{t-n}$ & $?$ & -0.006 & 0.760 & 0.000 & $0.000 * * *$ \\
\hline DIVERSITY $_{t-n}$ & $?$ & 0.015 & 0.282 & 0.066 & $0.025 * *$ \\
\hline DIVISIONS $_{t-n}$ & + & -0.038 & 0.173 & 0.164 & $0.008 * * *$ \\
\hline$E M P L O Y E E S_{t-n}$ & + & 0.018 & 0.239 & 0.019 & $0.062 *$ \\
\hline$L E V E R A G E_{t-n}$ & - & -0.097 & $0.001 * * *$ & -0.144 & $0.015 * *$ \\
\hline$R O A_{t-n}$ & + & 0.014 & $0.049 * *$ & 0.001 & 0.384 \\
\hline$B T M_{t-n}$ & + & -0.028 & $0.061 *$ & -0.003 & 0.405 \\
\hline Industry controls & & Yes & & Yes & \\
\hline Year controls & & Yes & & Yes & \\
\hline Intercept & & Yes & & Yes & \\
\hline Pseudo R2 & & 0.470 & & 0.193 & \\
\hline No. of observations & & 70 & & 253 & \\
\hline
\end{tabular}

\begin{abstract}
Standard errors are corrected for clustering at firm-level. The marginal effect is equal to the partial derivative $\delta \mathrm{E}[\mathrm{y} \mid \mathrm{x}] / \delta \mathrm{x}=\varphi\left(\mathrm{x}^{\prime} \beta\right) \beta$ of the binary response model, evaluated at sample means. All explanatory variables are expressed in percentage changes with respect to the preceding period. REORGANIZATION is an indicator variable equal to 1 for firms that alter their divisional structure and 0 otherwise. ICM_EFF is the Billet and Mauer (2003) measure of internal capital market efficiency, based on segment growth opportunities. DIVERSIFICATION is the Bushman, Indjejikian, and Smith (1995) measure of unrelated diversification. DIVERSITY is the Rajan et al. (2000) measure of dispersion of the divisions' growth opportunities. DIVISIONS is the number of operating divisions. EMPLOYEES is the natural logarithm of the number of employees in the firm. LEVERAGE is the ratio of long- and shortterm debt to total assets. $R O A$ are earnings before interest and taxes divided by total assets. BTM is the book-to-market ratio of the firm as a conventional proxy of growth opportunities. ***, **, and * identify significant results at the $1 \%, 5 \%$, and $10 \%$ levels (one-tailed for predictions, two-tailed otherwise).
\end{abstract}

\title{
3.4.3 Additional analyses and robustness tests
}

\subsubsection{Year-to-year changes}

The binary response model to investigate the effect of internal capital market efficiency on the propensity to reorganize is specified in levels, i.e. inferences are drawn from absolute differences between the reorganizing and control group of 
firms. Alternatively, it is conceivable that variations in changes over time rather than variations in absolute levels of capital allocation efficiency initiate reorganizations. For instance, reorganizing firms may exhibit stronger declines in capital allocation efficiency than control firms. I analyze this alternative by calculating year-to-year percentage changes in the variables and rerun the main probit model from equation (3.1). The disadvantage of this approach is that two consecutive years have to be available to obtain percentage changes. This considerably restricts the number of observations that can enter the analysis. Results are provided in table 3.10. I run the specification using the sample of reorganizing firms that do not change the number of divisions, which was argued to be the stronger setting, in column (1), as well as on the full sample of all reorganizing firms in column (2) to overcome possible disadvantages resulting from the limited number of observations. For both samples, results indicate that firms are more likely to change their divisional organization the stronger internal capital market efficiency declines from year to year. This strengthens the evidence found in the original probit model to support hypothesis 1 .

\subsubsection{Probit regression using propensity score matching}

The main probit models used to investigate hypothesis 1 consider all multi-segment firms in the sample period for comparison with the reorganizing firms to minimize the amount of subjectivity that is inevitably being introduced when selecting a commensurate control group. However, there are various discrepancies in the range of firm characteristics between the sampled reorganizing firms and their control group, as noted before. To ensure that these differences do not introduce systematic bias into the analysis, I run alternative tests using propensity score matching following the same procedure as in the analysis for hypothesis 3 and 4 . After obtaining the propensity matched control group of firms, I run a probit model on the reorganizing and matched control firms to trace the impact of allocation inefficiencies on the probability to reorganize. While obtaining matches for all reorganizing firms, a number of control firms have missing values for the measure of allocation efficiency. This reduces the sample size to $n=102$.

Results are presented in table 3.11. Regressing the measure for internal capital market efficiency on the incidence of reorganization alone in specification (2) does not yield a significant relation at conventional levels. Excluding the variables originally used for propensity matching is suitable in case of close matches so that matching variables should not be significantly related to the regressand. However, differences in the matching dimensions may persist after matching so that it sensible to include the matching variables as regressors, results of which are presented in specification (1). Indeed, the logarithm of the number of employees is significantly related to the regressand and reveals that even after matching differences between the group of reorganizing and control firms persist. Including the matching variables, the measure for internal capital market efficiency is 
Table 3.11

Probit matched sample model of incidence of reorganization

\begin{tabular}{|c|c|c|c|c|c|}
\hline \multirow[b]{2}{*}{ Independent variables } & \multirow[b]{2}{*}{$\begin{array}{c}\text { Predicted } \\
\text { sign }\end{array}$} & \multicolumn{2}{|c|}{$\begin{array}{l}\text { (1) Incidence of } \\
\text { reorganization } \\
\text { REORGANIZATION }\end{array}$} & \multicolumn{2}{|c|}{$\begin{array}{c}\text { (2) Incidence of } \\
\text { reorganization } \\
\text { REORGANIZATION }\end{array}$} \\
\hline & & $\begin{array}{r}\text { Marginal } \\
\text { effect }\end{array}$ & Prob. & $\begin{array}{r}\text { Marginal } \\
\text { effect }\end{array}$ & Prob. \\
\hline$I C M \_E F F$ & - & -0.457 & $0.060 *$ & -0.236 & 0.143 \\
\hline DIVERSIFICATION & $?$ & -0.042 & 0.905 & & \\
\hline DIVERSITY & $?$ & 0.014 & 0.902 & & \\
\hline DIVISIONS & + & 0.059 & 0.285 & & \\
\hline EMPLOYEES & + & 0.039 & $0.029 * *$ & & \\
\hline LEVERAGE & - & -0.014 & 0.477 & & \\
\hline$R O A$ & + & 0.522 & 0.294 & & \\
\hline$B T M$ & + & 0.093 & 0.196 & & \\
\hline Intercept & & Yes & & Yes & \\
\hline Pseudo R2 & & 0.053 & & 0.008 & \\
\hline No. of observations & & 102 & & 102 & \\
\hline
\end{tabular}

Standard errors are corrected for clustering at firm-level. The marginal effect is equal to the partial derivative $\delta \mathrm{E}[\mathrm{y} \mid \mathrm{x}] / \delta \mathrm{x}=\varphi\left(\mathrm{x}^{\prime} \beta\right) \beta$ of the binary response model, evaluated at sample means. REORGANIZATION is an indicator variable equal to 1 for firms that alter their divisional structure and 0 otherwise. ICM_EFF is the Billet and Mauer (2003) measure of internal capital market efficiency, based on segment growth opportunities. DIVERSIFICATION is the Bushman, Indjejikian, and Smith (1995) measure of unrelated diversification. DIVERSITY is the Rajan et al. (2000) measure of dispersion of the divisions' growth opportunities. DIVISIONS is the number of operating divisions. EMPLOYEES is the natural logarithm of the number of employees in the firm. $L E V E R A G E$ is the ratio of long- and shortterm debt to total assets. ROA are earnings before interest and taxes divided by total assets. BTM is the book-to-market ratio of the firm as a conventional proxy of growth opportunities. ***, **, and * identify significant results at the $1 \%, 5 \%$, and $10 \%$ levels (one-tailed for predictions, two-tailed otherwise).

significantly related to the reorganization of decision rights among division managers at $\mathrm{p}=6.0 \%$.

\subsubsection{Geographic segments}

A potential concern of correlated omitted variables in this study stems from other factors that may lead firm management to change their organizational structure and that influence the efficiency of capital allocations at the same time. For instance, a decline in general product market conditions could be the root cause for 
Table 3.12

Geographic segment statistics before and after reorganizing

\begin{tabular}{|c|c|c|c|c|}
\hline & & & Difference & t-test \\
\hline Type of reorganizing firm & $\begin{array}{c}\text { prior } \\
\text { (1) }\end{array}$ & $\begin{array}{l}\text { post } \\
\text { (2) }\end{array}$ & $(1)-(2)$ & n-value \\
\hline
\end{tabular}

(a) Increasing the number of business segments

Number of geographic segments

Diversification

$\begin{array}{llll}2.622 & 3.698 & -1.076 & 0.000 * * * \\ 0.538 & 0.677 & -0.139 & 0.010 * * *\end{array}$

(b) Decreasing the number of business segments

Number of geographic segments

Diversification ${ }^{1}$

$\begin{array}{llll}3.400 & 2.788 & 0.612 & 0.050 * *\end{array}$

$\begin{array}{llll}0.529 & 0.421 & 0.108 & 0.079 *\end{array}$

(c) Keeping the number of business segments

Number of geographic segments

$\begin{array}{llll}3.418 & 3.692 & -0.274 & 0.404\end{array}$

Diversification

$\begin{array}{llll}0.671 & 0.735 & -0.064 & 0.449\end{array}$

Columns (1) and (2) list values for firm years preceding and following a reorganization, respectively.

${ }^{1}$ Diversification is the Bushman et al. (1995) measure of diversification, in this case based on total sales of geographic segments

$* * *, * *$, and * identify significant results at the $1 \%, 5 \%$, and $10 \%$ levels (two-tailed).

reorganizing the firm and for inefficient allocations. Also, the firm may reorganize due to the entering or exiting a product market. I address this issue as much as possible already through control variables as well as through the initial identification of reorganizing firms by excluding various firms where $10-\mathrm{k}$ disclosure hints at external rather than internal reasons for the change in company structure, as described in the sample selection procedure. However, it might still be the case that firms either do not explicitly state that market conditions changed or that the selected control variables do not appropriately filter these effects. For that reason I study geographic segment disclosures to verify that external market conditions remain stable for the selected reorganizing firms.

FASB segment reporting regulation requires firms to disclose revenues and assets by geographic area (SFAS 131, para. 104-107), in addition to disclosure about operating segments. Even though the two forms of segment disclosure may coincide, the latter informs about the actual divisional structure, whereas geographic segment reporting is rather meant to facilitate the assessment of the firm's risk concentration by geographic area ${ }^{23}$. Purely organizational changes to the divisional structure that are the focus of this study should result in a change in business segment reporting alone, whereas geographic segments should remain unaffected

\footnotetext{
${ }^{23}$ An inspection of the dataset yields that geographic and business segment reporting do not coincide for the vast majority of sampled firms, based on a comparison of segment names and alternatively segment sales between the two types of reports.
} 
around the time of reorganization since the company should continue to serve the same markets irrespective of its internal organization. To test the validity of this presumption, I analyze the 110 reorganizing firms with respect to the number of geographic segments reported as well as considering an aggregate corporate measure of the firm's geographic segment sales, the measure of overall diversification as in Bushman et al. (1995) ${ }^{24}$. Table 3.12 reports a significant increase (decrease) in the number of geographic segments and in geographic diversification for firms that increase (decrease) the number of segments after reorganizing. This suggests that not only organizational structure but also underlying operations changed for these types of reorganizations. However, neither number of geographic segments nor geographic diversification changed for the subsample of reorganizing firms that did not alter the number of segments. This supports the choice to focus mainly on these firms in the earlier analyses rather than on the entire sample of reorganizing firms, where changes to operations apart from only reorganizations potentially lower the precision of the analyses.

\subsubsection{Additional model variations}

The previously described binary response models all use probit specifications based on the standard normal cumulative distribution function. The findings are robust to the alternative use of standard normal logistic distribution functions with logit models. The findings are also robust for taking present rather than lagged values for the independent variables in all regression models. Since reorganizations can be lengthy procedures that at times have durations of more than one year, I also vary the event year: Instead of using all firm years up to the point when the reorganization was reported, I omit year t-1 up until year t-3 in separate specifications. The results remain comparable.

As indicated in the analysis on hypothesis 1, firms may also reorganize for reasons unrelated to allocation inefficiencies, for instance due to growth of one of their operations that require separate management supervision. To control for this alternative, I rerun the model based on equation (3.1) in untabulated tests excluding those firms where the $10-\mathrm{k}$ report suggests that the reorganization may be partly linked to expanding the firm's business. I additionally exclude reorganizations that appear to be linked to an earlier financial distress situation, which is the case for 3 of the 110 reorganizing firms. The results using this altered sample remain highly comparable and almost unchanged.

I also vary the test on hypothesis 1 by applying an alternative measure of the quality of internal allocations developed in chapter 2 of this dissertation. The results are depicted in specification (1) of table 3.13. Even though the more extensive data requirements of this alternative proxy considerably restrict the sample size and

\footnotetext{
${ }^{24}$ Since most firms have several industries per geographic segments, measuring unrelated diversification based on geographic segments is not feasible.
} 
require using the broad sample of reorganizing firms, the findings remain very similar to those based on the measure from Billet and Mauer (2003).

To further investigate if firms are more likely to reorganize at low, rather than high levels of allocation efficiency, I recode the main explanatory variable using two indicator variables for observations where efficiency takes on positive values

Table 3.13

Probit interaction lag model of incidence of reorganization

\begin{tabular}{|c|c|c|c|c|c|}
\hline Independent variables & $\begin{array}{l}\text { Predicted } \\
\text { sign } \\
\end{array}$ & $\begin{array}{r}\text { (1) Inci } \\
\text { reorga } \\
R E O R G A \\
\text { Marginal } \\
\text { effect } \\
\end{array}$ & $\begin{array}{l}\text { lence of } \\
\text { ization } \\
\text { IIZATION } \\
\text { Prob. }\end{array}$ & $\begin{array}{r}\text { (2) Inci } \\
\text { reorga } \\
R E O R G A I \\
\text { Marginal } \\
\text { effect } \\
\end{array}$ & $\begin{array}{l}\text { dence of } \\
\text { hization } \\
\text { VIZATION }{ }_{t} \\
\text { Prob. }\end{array}$ \\
\hline Allocation quality $_{t-n}$ & - & -0.510 & $0.019 * *$ & & \\
\hline Medium ICM efficiency ${ }_{t-n}$ & - & & & 0.011 & 0.158 \\
\hline High ICM efficiency ${ }_{t-n}$ & - & & & -0.012 & $0.041 * *$ \\
\hline DIVERSIFICATION $_{t-n}$ & $?$ & 0.055 & 0.112 & -0.010 & 0.521 \\
\hline DIVERSITY ${ }_{t-n}$ & $?$ & 0.056 & 0.316 & -0.044 & $0.034 * *$ \\
\hline$D I V I S I O N S_{t-n}$ & + & -0.004 & 0.383 & 0.004 & 0.174 \\
\hline EMPLOYEES $_{t-n}$ & + & 0.022 & $0.003 * * *$ & 0.012 & $0.001 * * *$ \\
\hline$L E V E R A G E_{t-n}$ & - & -0.059 & 0.154 & -0.023 & 0.214 \\
\hline$R O A_{t-n}$ & + & 0.122 & 0.254 & 0.087 & 0.109 \\
\hline$B T M_{t-n}$ & + & -0.036 & $0.032 * *$ & -0.006 & 0.200 \\
\hline Industry controls & & Yes & & Yes & \\
\hline Year controls & & Yes & & Yes & \\
\hline Intercept & & Yes & & Yes & \\
\hline Pseudo R2 & & 0.214 & & 0.250 & \\
\hline No. of observations & & 384 & & 655 & \\
\hline
\end{tabular}

Standard errors are corrected for clustering at firm-level. The marginal effect is equal to the partial derivative $\delta \mathrm{E}[\mathrm{y} \mid \mathrm{x}] / \delta \mathrm{x}=\varphi\left(\mathrm{x}^{\prime} \beta\right) \beta$ of the binary response model, evaluated at sample means. REORGANIZATION is an indicator variable equal to 1 for firms that alter their divisional structure and 0 otherwise. Allocation quality is the measure of internal capital allocation quality measure developed in chapter 2 of this dissertation. Medium (high) ICM efficiency are indicator variables based on the Billet and Mauer (2003) measure of internal capital market efficiency, $I C M \_E F F$, equal to 1 if $I C M \_E F F=0$ $\left(I C M \_E F F>0\right)$. DIVERSIFICATION is the Bushman, Indjejikian, and Smith (1995) measure of unrelated diversification. DIVERSITY is the Rajan et al. (2000) measure of dispersion of the divisions' growth opportunities. DIVISIONS is the number of operating divisions. EMPLOYEES is the natural logarithm of the number of employees in the firm. LEVERAGE is the ratio of long- and short-term debt to total assets. $R O A$ are earnings before interest and taxes divided by total assets. BTM is the book-to-market ratio of the firm as a conventional proxy of growth opportunities. $* * * * *$, and $*$ identify significant results at the $1 \%, 5 \%$, and $10 \%$ levels (one-tailed for predictions, two-tailed otherwise). 
and where the Billet and Mauer algorithm sets allocation efficiency between positive and negative values at zero. I expect that firms with positive values for allocation efficiency are less likely to reorganize than firms with inefficient allocations. Results in column (2) in table 3.13 confirm these expectations.

In the analysis on hypothesis 2, I construct a new proxy for the level cash constraints within a firm, CFABUNDANCE. To verify my findings, I rerun the analyses in table 3.7 in untabulated tests using a comparable measure as in Core and Guay (2001), which is based on the three year average of common and preferred dividends plus cash flow from investments less cash flow from operations, scaled by total assets. I further indicate high and low values in the resulting variable by applying a median split. Coefficients and levels of significance closely resemble the results in table 3.7 .

I vary the analysis on the inter-temporal effects in hypothesis 3 and 4 by extending the underlying sample from firms that reorganize and keep the number of divisions to all types of reorganizations, i.e. where also the number of divisions changes. The results are comparable to the ones depicted in table 3.9. Stock returns as well as capital allocation efficiency improve at significant levels vis-à-vis the control group of firms.

\subsection{Conclusion}

In this paper, I examine whether diversified firms reassign decision rights among division managers through divisional reorganizations in response to inefficient allocations of internal capital between divisions and find supporting evidence. The effect is persistent across various specifications and robustness checks. A significant increase in the allocation efficiency following the reorganization event additionally documents that reorganizing the divisional structure is effective in containing inefficient internal capital transactions. Moreover, I investigate if firms subject their decision to change the assignment of decision rights to a trade-off between costs and benefits. I specifically analyze whether firms are less likely to reorganize subsequent to inefficient capital allocations when relatively well endowed with cash, i.e. when the cost of misallocations is relatively low. I document some confirming evidence, but this result does not hold under all robustness tests. Lastly, results indicate that stock returns increase following the redistribution of decision rights, illustrating that shareholders benefit from these organizational changes.

This study inevitably faces a number of limitations. Firstly, company reorganizations can be complex processes with numerous antecedents, at times taking place over several years. It is therefore difficult to pin down an exact event date when the reorganization took place since actual implementation may have taken several months or years. This makes it inherently difficult to select the precise 
period during which the reorganization was triggered. Secondly, purely internal reorganizations absent any acquisitions or divestments of part of the firm are very rare events, imposing constraints on the sample size as well as the resulting statistical power. Thirdly, despite their frequent application in various studies, measures of internal capital allocation efficiency remain approximations that have to rely on assumption when and where capital should have been allocated. Imprecision in capturing actual internal transfers is therefore inevitable. Lastly, disclosure about reorganizations in $10-\mathrm{k}$ reports is frequently kept brief with respect to the specific nature of the changes, giving rise to potential coding errors during the manual data gathering process.

Regardless of its limitations, this study contributes to the extant literature in multiple ways. It adds to the growing literature on internal capital markets (cf. Stein 2003) by showing how firms react to inefficient allocations. Moreover, I extend the literature on organizational design offering insights into the determinants of divisionalized firm structures. Baiman et al. (1995) investigate the role of relative expertise within the firm and the relative importance of the business unit, whereas Moers (2006) examines how the firm's choice to delegate depends on the availability of appropriate performance measures. This study adds that internal capital allocations are an additional driver of intra-firm delegation and the allocation of decision rights between division managers. This is of particular interest as only very few prior studies speak to the determinants of the horizontal scope of authority (Mookherjee 2006).

In the light of the scarcity of studies on divisional reorganizations, future research may investigate numerous aspects that were not or only briefly touched upon in this study. One possibility is to focus on the financial market effects of the change in segment reporting that necessarily follow from reconfigurations of the divisional layout due to financial reporting regulation. Future research may additionally use a broader sample over longer time periods to reinforce the evidence provided in this study. 


\section{Appendix 3.A Variable definitions}

\begin{tabular}{|c|c|}
\hline Variable name & Description \\
\hline$B T M$ & $\begin{array}{l}B T M \text { is the book-to-market ratio of the firm as a } \\
\text { conventional proxy of growth opportunities. }\end{array}$ \\
\hline CFABUNDANCE & $\begin{array}{l}C F A B U N D A N C E \text { is computed using an indicator } \\
\text { variable for the lowest quintile across firms and years } \\
\text { of the ratio of net cash flows from financing activities } \\
\text { scaled by sales. It indicates the abundance of cash } \\
\text { flows in the firm, i.e. the inverse degree of cash } \\
\text { constraints. }\end{array}$ \\
\hline DIVERSIFICATION & $\begin{array}{l}\text { DIVERSIFICATION is the Bushman, Indjejikian, and } \\
\text { Smith (1995) measure of unrelated diversification. }\end{array}$ \\
\hline DIVERSITY & $\begin{array}{l}\text { DIVERSITY is the Rajan et al. (2000) measure of } \\
\text { dispersion of the divisions' growth opportunities. }\end{array}$ \\
\hline DIVISIONS & DIVISIONS is the number of operating divisions. \\
\hline EMPLOYEES & $\begin{array}{l}\text { EMPLOYEES is the natural logarithm of the number } \\
\text { of employees in the firm. }\end{array}$ \\
\hline EXCESSVALUE & $\begin{array}{l}\text { EXCESSVALUE is the Berger and Ofek (1995) } \\
\text { diversification discount measure, based on division } \\
\text { sales. }\end{array}$ \\
\hline$I C M_{-} E F F$ & $\begin{array}{l}I C M_{-} E F F \text { is the Billet and Mauer (2003) measure of } \\
\text { internal capital market efficiency, based on segment } \\
\text { growth opportunities. }\end{array}$ \\
\hline LEVERAGE & $\begin{array}{l}L E V E R A G E \text { is the ratio of long- and short-term debt } \\
\text { to total assets. }\end{array}$ \\
\hline REORGANIZATION & $\begin{array}{l}\text { REORGANIZATION is an indicator variable equal to } \\
1 \text { for firms that alter their divisional structure and } 0 \\
\text { otherwise. }\end{array}$ \\
\hline RETURN & $\begin{array}{l}\text { RETURN are stock returns of a } 12 \text {-month buy-and- } \\
\text { hold strategy to capture shareholder wealth per firm- } \\
\text { year. }\end{array}$ \\
\hline$R O A$ & $\begin{array}{l}R O A \text { are earnings before interest and taxes divided by } \\
\text { total assets. }\end{array}$ \\
\hline
\end{tabular}





\title{
Chapter 4
}

\section{Capital budget renegotiations and the adverse consequences of delegating investment decision rights ${ }^{25}$}

\begin{abstract}
A large part of the literature on investment decisions taken within multidivisional firms focuses on investment outcomes whereas relatively little is known about the underlying capital budget process. We analyze these processes, more specifically the effect of information and agency problems on the allocation of capital to individual investment projects with multiple stages, which allow an agent to renegotiate project budgets with the principal. Despite the prevalence of multistage budget processes in practice, prior studies mostly assume only a single negotiation period and provide no clear indication how agents behave in multiperiod settings. Based on capital budget data from a large, multi-divisional firm, we find that agents incorporate more slack into budgets during renegotiations the more the principal delegates investment decision rights to the agent and to a higher extent at the outset of an investment when the principal has less information about the true nature of the investment. We further find that the agent takes advantage of multiperiod budget processes to shift budgetary slack between investment stages of a project, an effect that has not been considered in prior studies. The agent does so to a higher extent the more decision rights are delegated and the less uncertainty the agent faces about his consumption preferences of slack.
\end{abstract}

\footnotetext{
${ }^{25}$ This chapter is based on a working paper co-authored with Frank Moers and Alexander Brüggen.
} 


\subsection{Introduction}

In this paper, we empirically examine the capital budgeting process of a large multidivisional firm and the implications of the dynamics that underlie this process. Although investment decisions are one of the most important decisions made by firms (e.g., Harris \& Raviv 1996), relatively little is known about the capital allocation process that triggers these investment decisions. We examine how information and agency problems affect the allocation of capital to individual investment projects over time, starting from the initial investment proposal moving to subsequent renegotiations.

Most of the literature on within-firm investment decisions is related to the literature on internal capital markets. This literature stresses the agency conflict between division managers and the CEO and how the agent's rent-seeking behavior affects internal capital allocation (e.g., Rajan et al. 2000; Scharfstein \& Stein 2000). One of the main insights from this literature is that rent-seeking results in weaker divisions being cross-subsidized by stronger divisions, which is inefficient (compared to a first-best setting). The studies in this area all focus on investment outcomes rather than the underlying capital budgeting process. Understanding the underlying process, however, allows for more insights into investment outcomes because the characteristics of this process do not only vary between firms but more importantly also between individual investment projects of a single division.

The literature on budgeting in general and capital budgeting in particular offers a more detailed look at how capital budgets can be distorted. Typically in a budgeting context the agent moves first to provide the principal with a limited number of choices (e.g., Bower 1970; Marino \& Matsusaka 2005). Given the existence of information asymmetry between the principal and agent on the exact nature of the investment project, the agent will try to incorporate slack into the budget for private consumption purposes (e.g., Antle \& Eppen 1985). ${ }^{26}$ Even though the principal is aware of the agent's incentive, he is unable to verify with certainty the amount of slack in the budget, resulting in situations of overinvestment.

This is, however, only part of the story. Actual capital budgeting processes have two important features that are underexplored in the (empirical) literature. First, in larger firms, decision rights to allocate capital to investment projects are rarely held by a single principal and some decision rights have to be decentralized. As a result, there are "high delegation" investment projects with little involvement and control by the principal and "low delegation" investment projects with high involvement and control by the principal. Marino and Matsusaka (2005) analytically show that delegation is optimal when agents who have investment projects that the principal would not prefer can pool with agents who have projects that the principal

\footnotetext{
${ }^{26}$ Private consumption should be interpreted broadly here in the sense that it does not only relate to perks or investments in pet projects, but also to not having to put in high effort to efficiently manage costs.
} 
would prefer. The intuition is that, if the principal would require an approval process, i.e., "low delegation", then the former group of agents would strategically "over-propose" so as to mislead the principal, obviously making things even worse for the principal. This implies that (1) slack is more likely to be part of the budget when delegation is high and (2) that this is an equilibrium outcome.

A second important feature is that capital budgeting is a dynamic process. Actual investment processes offer the agent the possibility to renegotiate the allocated budget, as most capital investment projects bear considerable uncertainty concerning the exact costs. This renegotiation is analyzed specifically in this paper. In renegotiating the allocated budget, two types of changes can occur: (1) changes to the total budget of the investment project and (2) changes to the timing of costs within the already allocated budget. We refer to these behaviors as cost escalation and cost shifting, respectively. In addition to occurring for purely operational reasons, we argue that these behaviors are systematically related to delegation and as such (also) occur for opportunistic reasons. In particular, we argue that delegation allows the agent to exploit his information asymmetry and add slack during renegotiations, resulting in cost escalation. Assuming that information asymmetry gradually declines over the course of the investment, we predict that cost escalation is predominately related to delegation during the early stages of the investment process. In contrast, we predict that cost shifting is predominately related to delegation during the more mature stages of the investment process for the following reasons. When an agent with investment decision rights builds slack into the budget, he is uncertain about his consumption preferences during the later periods of the investment project and therefore spreads slack over these periods in an arbitrary fashion (e.g., equal split). Over time, i.e., during the more mature stages of the investment, this uncertainty is resolved and the agent will reallocate his buildin slack according to his revealed consumption preferences, resulting in cost shifting between periods.

In sum, we predict that delegation is systematically related to both cost escalation and cost shifting for reasons of information asymmetry and uncertainty about consumption preferences, respectively. Given that both information asymmetry and uncertainty decrease over the course of the investment, we specifically predict that, for an agent with investment decision rights, cost escalation is the dominant behavior during the early stages of the investment, while cost shifting is the dominant behavior during the more mature stages.

We test our predictions using a unique sample of capital budgeting data of a globally operating, multidivisional firm that is listed in one of the major European market indices. Based on an analysis of data for individual investment projects, we find that requested increases in a project's total investment sum are positively associated with the project's investment decision rights allocated to the agent. We further find that this relationship is predominately present during the early stages of 
the investment, confirming our expectation that information asymmetry is exploited most when it is the highest. Regarding cost shifting, we find that the amount of costs requested to postpone to later periods and/or advance to the current period is positively associated with investment decision rights associated with the project. Consistent with our expectation that uncertainty about consumption preferences resolves over time, we find that the relationship between cost shifting and delegation is especially present during the more mature stages of the investment. Additional analyses and robustness checks all confirm our main results, and overall our results are consistent with expectations.

We contribute to the literature in several related ways. In contrast to most studies in this area, we examine the dynamics of the capital budgeting process instead of the static investment outcomes that result from this process. Examining the dynamics is important because investment projects are typically multi-period in nature and allow the agent to renegotiate during the course of the investment. We first of all show that this renegotiation is nontrivial, as it results in an increase in a project's total investment sum of more than nine percent on average per renegotiation (i.e., per budget round). Understanding this renegotiating process is therefore important because it provides insights into why investment costs escalate. We show that investment costs predominately escalate when the agent can exploit his information asymmetry, i.e., when he has significant investment decision rights. The total investment sum of high delegation investment projects increases by more than 15 percent on average per renegotiation, while that of low delegation projects remains on average the same. We furthermore contribute to the literature by showing that the agent's behavior is itself dynamic in the sense that it changes over the course of the investment project. An agent with investment decision rights will build in slack during the early stages of the investment and as such cost escalation occurs during this period. In later periods, the agent engages in cost shifting so as to reallocate the build-in slack to match his consumption preferences. Finally, we contribute to the literature by examining capital budgeting and capital investments at a greater level of detail than done to date. As a result, our study provides significant insights into the interplay of capital budgeting processes, delegation, and investment outcomes.

The remainder of this paper is structured as follows. In section 4.2, we discuss related research and in section 4.3 we subsequently develop our hypotheses. In section 4.4 and 4.5, we describe our research site and data, respectively. We present our main results, additional analyses, and robustness checks in section 4.6 and we conclude in section 4.7. 


\subsection{Related research}

\subsubsection{Internal capital markets}

Capital investment decisions are among the central elements of managing firms and have a critical influence on the future development of the investing entity. Maintaining control over the investment process is therefore vital but becomes increasingly challenging as firms expand in size and investment volume, requiring a rising number of investment decisions to be decentralized across the firm's hierarchy. This delegation has the benefit of allowing the delegating agent to hold a wider portfolio of operations given benefits to scope and scale. Delegation also allows agents within the firm to specialize on their assigned task. Contrasting these benefits, a continuing stream of research documents the prevalence of the costs of delegation with earlier accounts in Williamson (1967) on the exacerbating loss of control between hierarchies in expanding firms. A related, more recent stream of literature on internal capital markets investigates the loss of control in diversified firms when subordinate holders of investment decision rights use private information to lobby for excess funds during the capital allocation process, typically between division and the firm's headquarters (Rajan et al. 2000; Scharfstein \& Stein 2000). With the exception of Villalonga (2004), empirical studies in this field generally resort to segment reporting to infer on conflicts about capital allocation efficiencies. The choice for studying the conflict at this aggregated level is in part driven by the challenge for any external researchers to obtain sufficiently detailed data below division level that firms typically hold back due to their sensitive nature. Due to this lack of detail, however, the exact process how agents specifically attempt to obtain excess funds during the allocation process remains largely unaddressed.

\subsubsection{Budgetary slack}

Similar to the studies on internal capital market, a main building block in the slack literature is that an agent exploits private information to obtain more resources for perquisite spending (Antle \& Eppen 1985), i.e. attempts to increase slack in investment proposals. The extant literature in this field is predominantly defined by experiments and analytic evidence, typically employing a synthesized two-player setting with superior and subordinate bargaining about the budget with single-period negotiations and investments (e.g. Chow et al. 1988; Arya et al. 2000). Actual investment projects, however, frequently last longer than only one budget period and budget processes typically enable the subordinate to revise budgets even after the start of the investment project. This aspect has received only very little attention in the literature. Even in the few studies that implement multiple budget periods (Antle \& Fellingham 1990) or multiple rounds of renegotiation (Fisher et al. 2002) slack is always introduced prior to the investment period, i.e. neglecting 
renegotiations. Harris \& Raviv (1996) analytically investigate a setting where an agent may request additional funds after being granted a certain spending limit in order to obtain more funds for a project. More recently, Marino \& Matsusaka (2005) analytically show how delegation of investment decision rights affects agents' behavior in terms of budget proposals to the principal. However, no prior study has yet produced detailed empirical evidence how delegation affects adjustments of the initial investment proposal during renegotiation. This paper specifically addresses this issue.

\subsection{Development of hypotheses}

In order to clarify how slack arises throughout the course of an investment project it is instructive to first consider the characteristics of a generic multi-period capital budget process in decentralized firms. This process in which central firm management (the principal) decides how capital is allocated among the investments projects proposed by each of the firm's business units (the agents) can be characterized in five different stages, as illustrated in figure 4.1. The budget request round begins with the agent submitting a project (stage 1) to the principal, specifying its expected duration as well as required funds for each future budget period. In stage 2, the principal then decides how closely the project should be reviewed by delegating decision rights over the projects among different levels of management (cf. Marino \& Matsusaka 2005): more important investments are likely reviewed with more scrutiny at higher management levels. Vice versa, less critical

Figure 4.1 Stylized budget process. Area $A$ signifies the actual investment cost of a project per budget period, area $B$ is the incorporated budgetary slack.

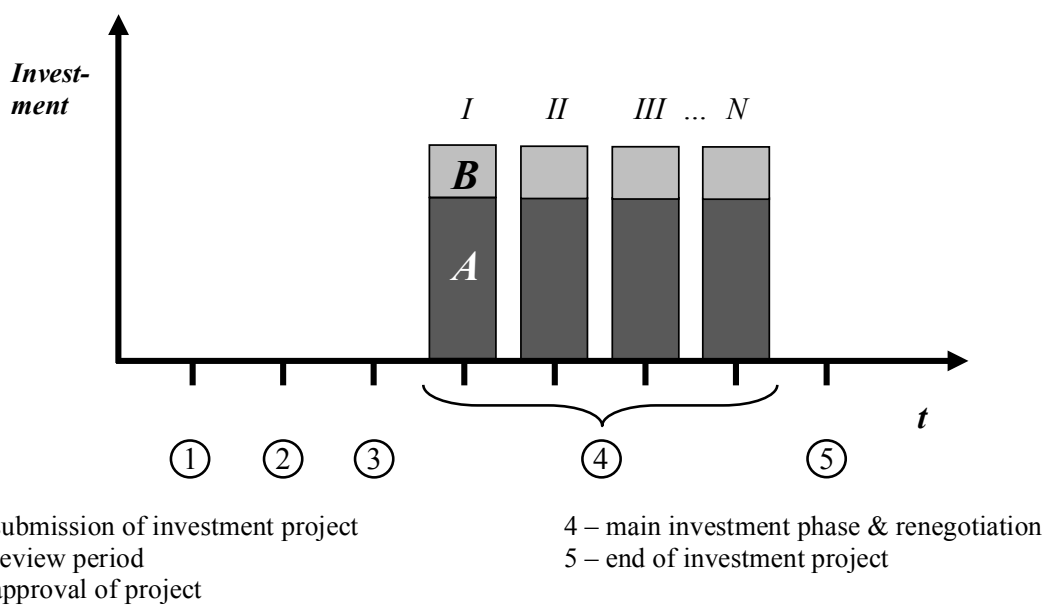

2 - review period

5 - end of investment project 
projects involve fewer top-level managers. Once reviewed, the principal may request changes or turn the submitted project down. In case of acceptance, the principal transfers the requested capital and notifies the agent (stage 3) to commence the main investment. The main investment stage can span up to $\mathrm{N}$ separate investment periods (stage 4), before the project is finished in stage 5 .

At the end of each individual investment period in stage 4 , the principal offers the agent the possibility to renegotiate the project's cost specifications of the following periods. This possibility is offered because the agent is subject to uncertainty at the outset of the project about how the investment will exactly develop. The initial cost planning is therefore only an estimate that may have to be adapted to factors that lie outside the control of the agent. For instance, increasing competition may necessitate building a factory faster than initially planned. Alternatively, raw material price changes may alter construction costs. During budget renegotiations, an agent can therefore request to (1) change the total costs initially granted and/or (2) shift costs between periods, postponing present costs to the future or conversely accelerating future costs to the current period.

These renegotiations can occur for purely operational reasons. However, the agent may also take advantage of this opportunity to modify the budget in a way that serves his own rather than the firm's best interest. Since the agent's interests are not entirely in line with those of the principal, he will prefer a higher capital budget even if this is detrimental to the firm, a view which is consistent with the literature on internal capital markets and budgetary slack. To obtain excess funds for private consumption (Antle \& Eppen 1985), the agent can incorporate slack for each investment period in stage 4 (partition $\mathrm{B}$, figure 4.1) beyond the actual cost of the project per period (partition A, figure 4.1). Two issues are important here: (1) information asymmetry between the principal and agent and (2) agent's uncertainty about his consumption preferences. In the remainder of this section, we will argue that information asymmetry affects the level of slack built in, resulting in cost escalation, while uncertainty about preferences affects the timing of slack consumption, resulting in cost shifting.

For capital budgeting to be a non-trivial problem, information and agency problems need to exist (e.g., Harris \& Raviv 1996, 1998). In general, the agent is assumed to be self-interested and to prefer more capital over less for private consumption purposes. As a result, the agent will try to incorporate slack into the budget. Typically, the principal cannot detect slack and prevent it from occurring since he cannot verify with certainty the difference between the actual and proposed investment cost. This is due to an inherent information asymmetry between the proposing agent and the reviewing principal about the real cost of the project, which only the agent can directly observe. The extent to which the agent can effectively exploit his information asymmetry depends on the extent to which investment decision rights have been allocated to him. If the agent has significant investment 
decision rights, he can use this freedom and request a capital budget that fits his preferences. The question then is why the principal would delegate at all. Marino and Matsusaka (2005) show, in a capital budgeting context, that retaining the right to intervene as a principal can be more costly than delegating investment decision rights. The intuition is that, if the agent has to go through an approval process, then he might distort the information transmitted to the principal even more to gain approval from the principal. When the principal is unable to separate these "distorted" projects from "non-distorted" projects, he is better off delegating investment decision rights to the agent. Following the intuition of Marino and Matsusaka (2005), we assume that the principal delegates optimally and therefore that delegation is high when an approval process would lead to even greater distortions, while delegation is low when distortions are unlikely to occur when the principal can intervene.

Facing the previously outlined budget process, the agent unlikely incorporates all slack already when first submitting the investment for two reasons. Firstly, the agent likely tries to state costs as low as possible upfront to render the project more attractive and increase the chances of acceptance by the principal. Secondly, the agent does not know yet how the principal delegates decision rights on the project during the review phase and thus how closely the project will be reviewed. The difficulty to predict how the principal will delegate is in part due to the delegation decision being a function of the projects that all other agents within the firm submit in the same round, a piece of information that the agent cannot have at the point of submitting. In consequence, the agent rather incorporates slack in the subsequent renegotiation periods once the investment has been approved and the delegation level at which the project is monitored is known. This discussion leads to the first hypothesis.

H1: Budgeted costs escalate in the delegation of investment decision rights.

As argued above, the ability to incorporate slack into the capital budget requires the existence of information asymmetry between principal and agent. As multi-period projects proceed from one investment period to the next, the principal learns more about the actual state of the project. The information asymmetry between agent and principal on the state of the investment project consequently decreases over time, as depicted in figure 4.2. Over the course of the investment phase, it therefore becomes increasingly difficult to incorporate more slack during the renegotiation for the capital budget since the principal is increasingly able to distinguish between budget requests due to changes in actual costs (partition A) or due to slack building (partition B). Hence, when agents are able to exploit their information asymmetry due to high delegation, they will request higher budget 
Figure 4.2 Schematic development of agent uncertainty about future consumption and development of information asymmetry between principal and agent across budget process stages

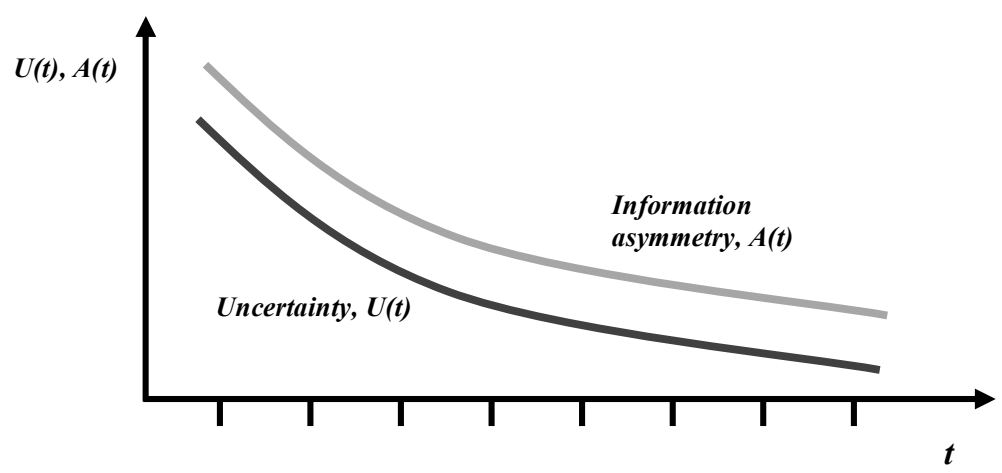

increases in earlier renegotiation periods of a project to take advantage of the higher information asymmetries during these periods. This leads to the second hypothesis.

H2: $\quad$ Budgeted costs escalate in the delegation of investment decision rights to a higher extent in the earlier stages of a project.

As indicated above, budget renegotiations may not only involve total cost changes but also cost shifting between periods. Besides operational reasons such as the need to accelerate a project, an agent may also use a cost shift request to redistribute budget slack that has already been incorporated in the budget previously. In terms of figure 4.1, the agent shifts partition B between the investing periods. Antle and Fellingham (1990) more generally allude to the possibility that agents may choose to shift slack between periods, but the details of this aspect have been mostly left unconsidered in the literature thus far. The agent may wish to reallocate slack because he does not know with certainty how much slack he will desire to consume in subsequent periods when slack is incorporated for the first time. Since multi-period projects can turn out differently than initially expected, the agent may in fact prefer a different level of consumption than the one initially set per period.

The ability to shift slack allows the agent to reduce these differences without having to request adjustments to the overall investment volume of the project. The latter is arguably more difficult to renegotiate with the principal than an interperiodic reallocation of an already granted sum. While shifting costs does not change the overall project budget, it is nevertheless costly to the firm: shifting costs 
reduces the predictability of cash flows required for investments so that the firm has to hold more funds for unforeseen changes in the investment budget.

The extent to which this cost-shifting behavior is observed depends on the agent's ability to incorporate slack in the first place. As a result, similar to requests to change the investment volume of a project, these cost shifts are more pronounced the more the decision rights to supervise a project are delegated to lower management levels, i.e. the less a principal is immediately involved in the review of a project. The third hypothesis follows from this discussion.

H3: The inter-periodic shifting of budgeted costs increases in the delegation of investment decision rights.

Hypothesis 3 argues that agents can resort to cost shifting requests to shift budget between periods to realign differences between actual and desired level of slack. These differences arise because of the inherent uncertainty about consumption preferences. This uncertainty is higher the longer the time between setting and consuming slack, since foreseeing the desired level of slack when first incorporating slack is more difficult for later than for earlier investment periods.

The agent's uncertainty, however, is decreasing as the project evolves, depicted graphically in figure 4.2. With declining uncertainty about consumption preferences, the agent is better able to forecast not only the development of the project but also the according level of slack that he desires himself. Cost shifting requests to realign desired and actual levels of slack will therefore be more pronounced in more mature periods when the agent is better able to align slack with his consumption preferences ${ }^{27}$. This discussion leads to the fourth hypothesis.

H4: The inter-periodic shifting of budgeted costs increases in the delegation of investment decision rights to a higher extent in the later stages of a project.

\subsection{The research site}

The data to investigate the hypotheses put forth in this study were gathered at a large multinational corporation headquartered in Europe. The company is stock-listed and included in one of the main European stock market indices. The unique access to this organization allows for a much more detailed analysis than previous, related studies. The company's internal organization, reporting and control structures

\footnotetext{
${ }^{27}$ An argument could be proposed that with less uncertainty the agent may also align desired and actual level of consumption by requesting a change to the entire project cost, as discussed in hypothesis 1 and 2 . However, decreasing information asymmetry would make it more likely that the principal detects slack. The agent therefore prefers cost shifting, which is arguably a more covert way to manage slack.
} 
closely resemble those used in comparable firms of this size, so that observed effects are unlikely arising from any exceptional characteristics of this research site. The company is diversified into various industrial activities, producing intermediate goods primarily sold to other manufacturers. The various operations are organized in an array of business units, each headed by a business unit director.

The business unit directors are compensated based on similar contracts. The units generally produce for outside customers, with very few internal transfers of products, so that each operates with a certain degree of independence of the firm's other operations. Business units that are more related to each other are grouped together in clusters, which also form the basis for financial segment reporting. Each cluster is assigned a board member with specific responsibility for their operations. The different board members hold closely comparable compensation contracts.

The company operates a sophisticated control system for managing the investment process of its diversified units. The treasury function is entirely centralized and business units cannot contract individually with the external financial market for funding. The budgeting process resembles the one illustrated in figure 1. New capital investment projects are initiated in the business units: they are first screened by the unit director, before submitting the project to the corporate accounting department by means of a standardized form used for requesting capital expenditures. This corresponds to stage (1) in figure 4.1. The projects pertain in almost all cases to only a single unit; joint projects between business units are very rare. Requests for capital expenditures are arranged in two main rounds per year, with proposed investments usually scheduled to begin in the subsequent half-year. Risks of each project are evaluated subjectively and while the internal hurdle rate can change from year to year depending on the general economic situation, it is not risk-adjusted for individual business units or projects.

The corporate accounting department delegates decision rights to approve and follow investment projects to three different levels of authority within the firm's hierarchy, initiating the review stage (2) as in figure 4.1. In the case of high delegation, projects are assigned to the business unit director and a single board member who is appointed to supervise that unit. Under medium delegation, projects require approval by the entire management board in addition to the unit director and the assigned board member. At the lowest level of delegation, i.e. highest centralization, also the supervisory board is involved in inspecting projects in addition to all previously mentioned management ranks. These three delegation levels are set by the head of corporate accounting after all units have submitted their proposals for a budget round. The assignment of these levels is determined by the size of the project as well as subjective factors such as its perceived importance, and the assignment applies during the whole investment project. In addition, the supervisory board can modify projects to be evaluated at their level of authority, i.e. the setting with the lowest delegation. Although business unit managers can expect 
very important projects to be assigned to a higher management level, they cannot foresee the assigned level with certainty prior to the announcement in stage (3) in figure 4.1. This is an important aspect, making it less likely that business units incorporate more slack already in their initial project submission for projects that will be assigned a higher degree of delegation. Instead, they will rather do so after the supervision level has been assigned, introducing more slack for projects the more a project is delegated, i.e. the less it is centrally controlled.

Once decision rights are allocated, the different management levels examine their assigned investment projects. The projects are grouped in three categories according to their progress stage. The first category concerns new investments proposed for approval. The second category contains projects at an intermediary approval stage where the main investments (stage 4, figure 4.1) have not yet started. They are either resubmitted after having been turned down in a preceding budget round, or they have been exceptionally submitted in between budget rounds. In the latter case upfront investments may have already taken place but approval is still needed in the following ordinary budget request period. Projects in the third category have been approved already and are in the main investment phase (stage 4, figure 4.1). Besides deciding on the approval of projects, the budget process is used to examine business unit requests to change the cost structure of all but newly submitted projects. The cost structure is modified when business units seek to obtain additional funds for a project. Smaller cost changes do not need to be explicitly reported but business units need to obtain authorization from their assigned management level for deviations exceeding either ten percent of the project's total investment sum or a predefined threshold amount. The latter criterion is set to prevent excessive cost escalations with larger projects. The cost structure can also change when business units request to alter the initially proposed timing of a project's investment costs. Units can either ask to advance costs that were planned to occur at a later stage to the current budget period, or conversely to postpone costs from the current to subsequent periods. After all decisions on project approvals and cost structure changes are taken, corporate accounting informs all business units about the final outcome. This closes the budget request round.

\subsection{Nature of the data and descriptive statistics}

The analyses of this study are based on data emanating from the budget process described above. More specifically, we obtained budget requests on capital investment projects from business units throughout a period of seven consecutive budgeting rounds, i.e. four calendar years. This time span was selected due its consistency of internal reporting requirements. For all projects business units individually report budgeted investment costs for the current period as well as total 
Table 4.1

Descriptive business unit-level statistics

Panel A - Annually reported data

\begin{tabular}{lrrrrrr} 
& Mean & Median & St. dev. & Min & \multicolumn{1}{c}{ Max } & N \\
\hline SALES & 563 & 409 & 564 & 18 & 2,401 & 63 \\
CAPITAL & 354 & 258 & 424 & 2 & 1,829 & 62 \\
EMPLOYEES & 1,292 & 686 & 1,506 & 5 & 6,384 & 63 \\
CAPEX & 31.975 & 19.400 & 31.611 & 0.100 & 130.700 & 63 \\
ROI & 0.275 & 0.153 & 1.893 & -8.320 & 11.663 & 63 \\
SALESGROWTH & 0.168 & 0.055 & 0.496 & -0.233 & 3.167 & 63
\end{tabular}

$\underline{\text { Panel B - Bi-annually reported data }}$

\begin{tabular}{lrrrrrr} 
Number of: & \multicolumn{1}{c}{ Mean } & Median & St. dev. & Min & Max & N \\
\hline All investment projects & 15.215 & 9 & 16.885 & 0 & 73 & 163 \\
New projects & 3.509 & 1 & 5.267 & 0 & 34 & 163 \\
Early stage projects & 2.865 & 1 & 4.269 & 0 & 22 & 163 \\
Mature stage projects & 6.871 & 4 & 7.610 & 0 & 34 & 163 \\
High delegation projects & 8.896 & 4 & 12.537 & 0 & 56 & 163 \\
Medium delegation projects & 1.227 & 0 & 2.170 & 0 & 11 & 163 \\
Low delegation projects & 0.313 & 0 & 0.899 & 0 & 5 & 163
\end{tabular}

Variables in panel A are all per business unit and calendar year and defined as follows. SALES is sales revenues in million EUR. CAPITAL is the total capital held in million EUR. EMPLOYEES is the number of employees. CAPEX is capital expenditures for investments in million EUR. ROI is the return on investment. SALESGROWTH is the percentage growth in sales revenue. All variables in panel B are based on reported numbers of projects per business unit and per budget submission round.

costs across past and future periods. If the unit seeks to increase the total budgeted investment amount, the project report also states the new amount requested.

Similarly, the report indicates if and what amount the business unit requests to either advance investments costs budgeted for later stages towards the current period - or conversely postpone current investment costs to the future. Each project is reported as either new, early stage or ongoing, i.e. in one of the three aforementioned progress stages. Reports on early stage and ongoing projects also indicate to what hierarchical management level these projects have been assigned. A total of 3,149 reports were retrieved from the company's budget reporting system, 
which were subsequently matched with internal financial statement data of the requesting business units. Projects were assigned a unique identifier to be able to track them over the sample period. We exclude incomplete and inconsistent entries as well as intangible investment projects. The latter follow a different reporting format and are not comparable as such to tangible investments. This procedure leads to a sample of 2,480 project-round observations based on 805 unique investment projects.

On average 23 different business units report each budget period. Although the company largely kept its internal organizational structure, some adjustments took place, e.g. merging and splitting some of the business units. The number of units per budget round ranges between 21 and 26, with a total of 33 distinct business units over the sample period. Information about these units is provided in table 4.1. Panel A presents descriptive statistics on the requesting business units, which is based on annually reported data. The average business unit has sales of EUR 563m and a workforce of 1,292 employees. Average annual capital expenditures of EUR 32m constitute around $9 \%$ of mean capital held, which is conventional for industrial firms that rely on capital investments as an important source of value generation. Panel B informs about the portfolio of investment projects that each business unit reports. These statistics stem from data that is available bi-annually, i.e. for every budget round request. PROJECTS is the number of investment projects reported per business unit in a given budget round. The average business unit report states a portfolio of 15.2 projects. The largest share of 6.9 projects concerns mature-stage investments. Reports on early-stage and new projects account for 2.9 and 3.5 projects on average, respectively. The remainder of the projects not falling in these categories concerns finished or cancelled investments.

An alternative classification is to group projects according to the attributed delegation level (high, medium, or low). Generally, the number of projects per business units increases in the delegation level: On average, 8.9 projects are assigned to the highest level of delegation compared to only 0.3 projects at lowest delegation category. Project observations that do not fall in one of the three delegation categories are new projects that have not been assigned such a level yet.

Descriptive project-level statistics across all business units are given in table 4.2. PROJECTCOUNT indicates how many times a project appears in the budget report of a business unit during the sample period. Including the current budgeting round, the average project is being reported for 2.6 times, with a maximum of 7 rounds, i.e. spanning all budgeting rounds of the sampled years. The average project has a total investment sum, INVTOTAL, of EUR $5.7 \mathrm{~m}$, with investments in the current period, INVCURRENT, of EUR $1.9 \mathrm{~m}$ on average. CHGCOST is the percentage change of a project's total investment amount requested by a business unit. Overall, $27 \%$ of the project reports state a request to change the project's total investment sum, requesting an average increase of $9.3 \%$ compared to the last 
Table 4.2

Descriptive project-level statistics

\begin{tabular}{lcrrrrrr} 
& Mean & Median & St. dev. & \multicolumn{1}{c}{ Min } & \multicolumn{1}{c}{ Max } & N & \multicolumn{1}{c}{$\%$} \\
\hline PROJECTCOUNT & 2.608 & 2.000 & 1.613 & 1 & 7 & 2,480 & 100 \\
INVTOTAL & 5.671 & 2.112 & 12.238 & 0 & 220.000 & 2,160 & 87 \\
INVCURRENT & 1.904 & 0.800 & 3.766 & 0 & 45.631 & 1,731 & 70 \\
CHGCOST & 0.093 & 0.015 & 0.504 & -0.909 & 2.900 & 673 & 27 \\
CHGCOSTXP & 0.092 & 0.003 & 0.530 & -0.949 & 3.000 & 494 & 20 \\
COSTSHIFT & 0.716 & 0.500 & 1.033 & 0.000 & 8.500 & 455 & 18
\end{tabular}

PROJECTCOUNT is a count variable set to 1 for the first report of a project in the sample period and incrementing with 1 for every additional report on that project. INVTOTAL is the total project investment across all budget periods in million EUR. INVCURRENT is the project investment scheduled to take place in the current budget period in million EUR. CHGCOST is the requested percentage change in a project's total investment including the current as well as future budget periods. CHGCOSTXP is the actual, ex-post percentage change in a project's total investment across all budget periods from one budget period to the next, after a request to change costs has been submitted. COSTSHIFT is the requested absolute percentage change in a project's current budget period investment by fully or partly postponing originally scheduled costs to a later period or vice versa advancing future costs to the current period.

period's total investment. CHGCOSTXP is the actual, i.e. ex post, percentage change of a project's total investment from one budget period to the next after a request for a change in the project's investment has been filed. The average actual cost change of $9.2 \%$ is very close to the original request, indicating that change requests on average materialize as asked for. COSTSHIFT is the absolute percentage change of the investment in the current budget period due to requests to shift costs. Cost shifts are either due to postponing costs initially budgeted for the current towards future project periods or vice versa due to advancing costs budgeted for later project stages to the current period. While cost shifts affect the investment in the current period, INVCURRENT, they leave the total investment sum, INVTOTAL, unchanged. These cost shifts result on average in an absolute change of $71.6 \%$ in the investment volume of a project's imminent budget period. Affecting $18 \%$ of the sampled project observations, requests to shift costs occur less frequently than requests to change the entire investment sum of a project.

The sample of project reports was first split in two, according to whether the information asymmetry between principal and agent about these projects is high or low. Low information asymmetry projects are smaller, more standardized investments in for example environmental safety, workplace security, or maintenance of buildings. Information asymmetry is low for these projects because the principal can easily verify the scope and requirements of these investments when submitted by the agent. Incorporating slack in these projects is therefore difficult for 
the agent. Low information asymmetry investments are marked with the dichotomous variable LOWIA. High information asymmetry projects are more difficult to assess so that the degree of delegation is important when determining how much control the principal exercises over a project. As mentioned in the description of the research site, the level of delegation is set by the principal to be low, medium or high. Accordingly, the dichotomous variables $D L O W, D M E D I U M$ and $D H I G H$ identify projects in each of these three delegation levels.

The project-level variables described in table 4.2 are further analyzed at these distinct delegation levels in table 4.3. Comparing averages between the different levels in panel A reveals that the project investment cost (INVTOTAL, INVCURRENT) as well as the number of times a project is occurring in the sampled period (PROJECTCOUNT) strictly decreases in the level of delegation. Panel B indicates that almost all of these differences are statistically significant. Conversely, results for business unit requests to change the total investment amount per project (CHGCOST) or to shift costs (COSTSHIFT) between periods all increase in the extent of delegation. Actual, ex-post total investment cost changes (CHGCOSTXP) follow the same pattern. Most of these differences are significant at the $10 \%$ level. This offers an interim corroboration of hypotheses $\mathrm{H} 1$ and $\mathrm{H} 3$ that cost change and inter-periodic cost shift requests increase in delegation. Taken together with the findings on project size and length, this table illustrates that smaller and potentially less important projects are delegated, at the cost of project cost increases and deviations from the initial timing of outlays. In addition to the delegation levels, panel A lists investment characteristics for low information asymmetry projects (LOWIA). These are on average smaller and of shorter duration than high delegation projects. Untabulated tests confirm these differences to be significant. Additionally, cost shift requests are insignificantly different from high delegation projects, whereas cost change requests are significantly lower.

Pearson correlation statistics for all variables used as explanatory or control variables in the multivariate analysis are given in table 4.4. While most correlations are significant at conventional levels, they remain mostly at relatively small values. Moreover, untabulated tests indicate that variance inflation factors remain always below 2 . Taken together, these results imply that multicollinearity is not of concern for the multivariate models employed in this dataset.

For an indication of the economic impact of the cost change and cost shift requests during the budget process, we sum up the Euro amount for cost change and cost shift requests individually per sampled budget round and scale by the sum of all capital investments in that period. Results are given in table 4.5. Apart from a slight increase of cost change requests, there appears to be no major time trend in request behavior over the sample period. On average, business units request to change 5.4 percent of the investment sum per sampled budget period whereas cost shift requests amount to 9.9 percent. These figures illustrate that cost change as well as cost shift 
requests affect a considerable share of investments and stress the impact of a control problem in the budget process.

\subsection{Results}

\subsubsection{Main analyses}

\subsubsection{Hypothesis 1}

To investigate hypothesis 1 , we construct a multiple regression model with the percentage change of the total project cost, CHGCOST, as dependent variable. The main explanatory variables are DMEDIUM and $D L O W$ that indicate projects with medium and low delegation, using $D H I G H$ as the base level. Both variables are expected to indicate significantly lower levels of cost changes at their respective level of delegation. We include $L O W I A$ to compare high delegation projects with low information asymmetry investments that leave the agent with little leeway to incorporate slack. We expect cost changes to be lower for the latter. The model can be stated as follows.

$\mathrm{CHGCOST}_{p, t}=f\left(\mathrm{DMEDIUM}_{p}, \mathrm{DLOW}_{p t}, \mathrm{LOWIA}_{p}, \mathrm{CONTROLS}_{p, t}\right)$

The indices $p$ and $t$ identify the project and the budget round, respectively. CONTROLS is a vector of several control variables. Two of them are at projectlevel. First, the number of times a project is reported in the sample, PROJECTCOUNT, proxies for the length of a project. Project cost changes arising from uncertainty are likely decreasing the more the project advances, PROJECTCOUNT is therefore expected to be negatively related to the dependent variable. Second, LNINVTOTAL is the natural logarithm of the project's total investment. Since larger and thus more complex projects are more likely subject to unforeseen cost developments, we expect LNINVTOTAL to be positively related to CHGCOST. Three control variables adjust for specificities of the business unit submitting the project: return on investment, $R O I$, year-to-year sales growth of the unit, SALESGROWTH, and size of the unit as the natural logarithm of sales, LNSALES. There are no unidirectional predictions for these variables. Standard errors are corrected for potential clustering at project-level. 


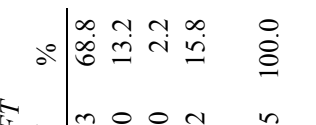

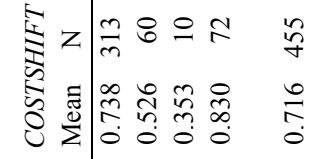

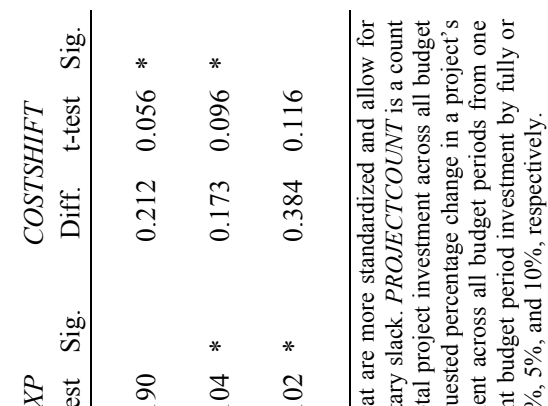

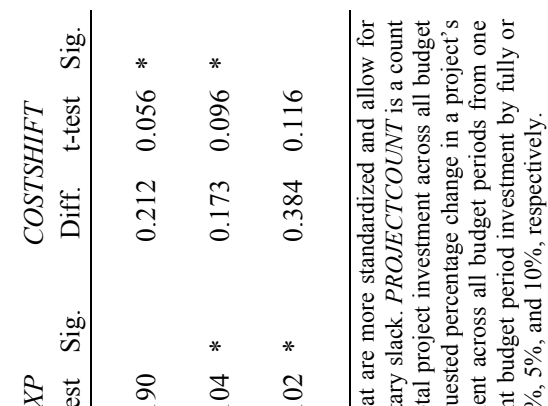

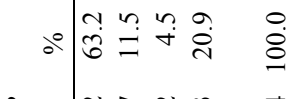

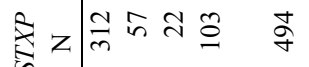

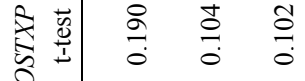

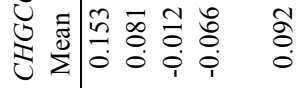

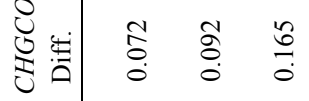

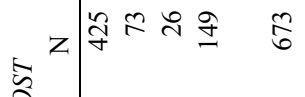

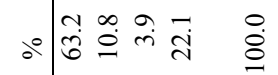

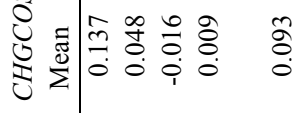

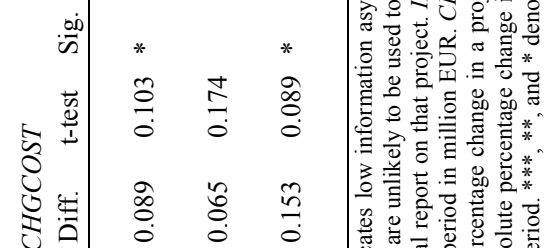

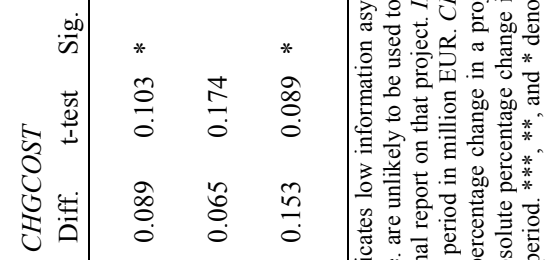

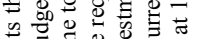

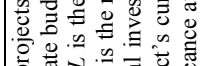

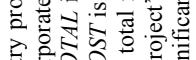

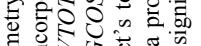

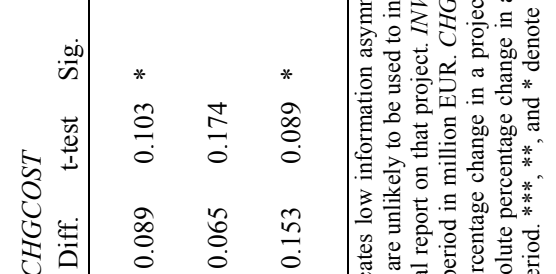

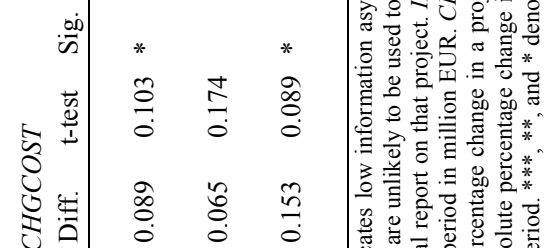

aำ

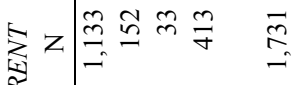

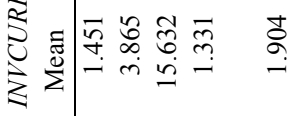

侄范

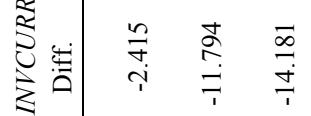

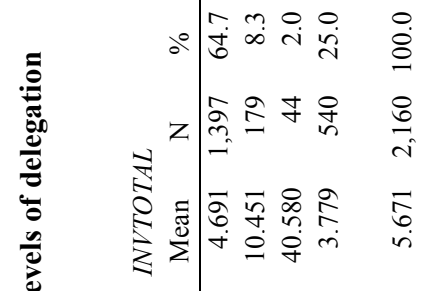

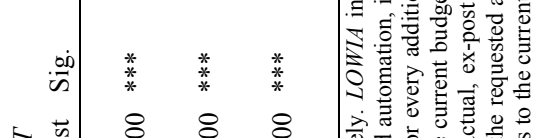

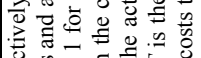

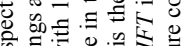

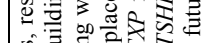

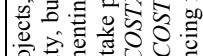

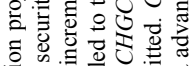

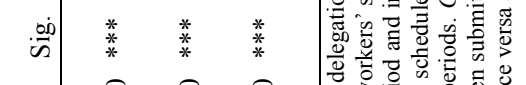

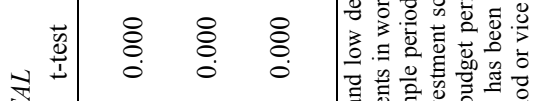

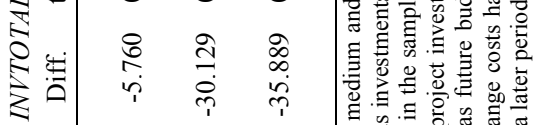

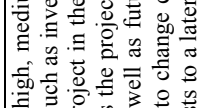

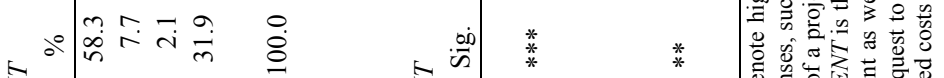

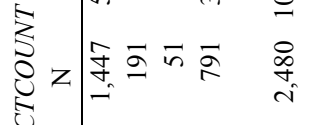

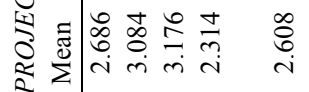

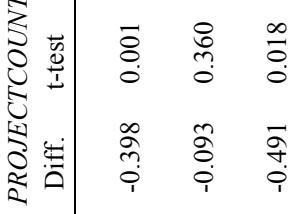

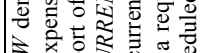

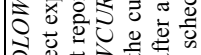

至.

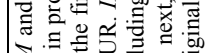

S.

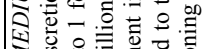




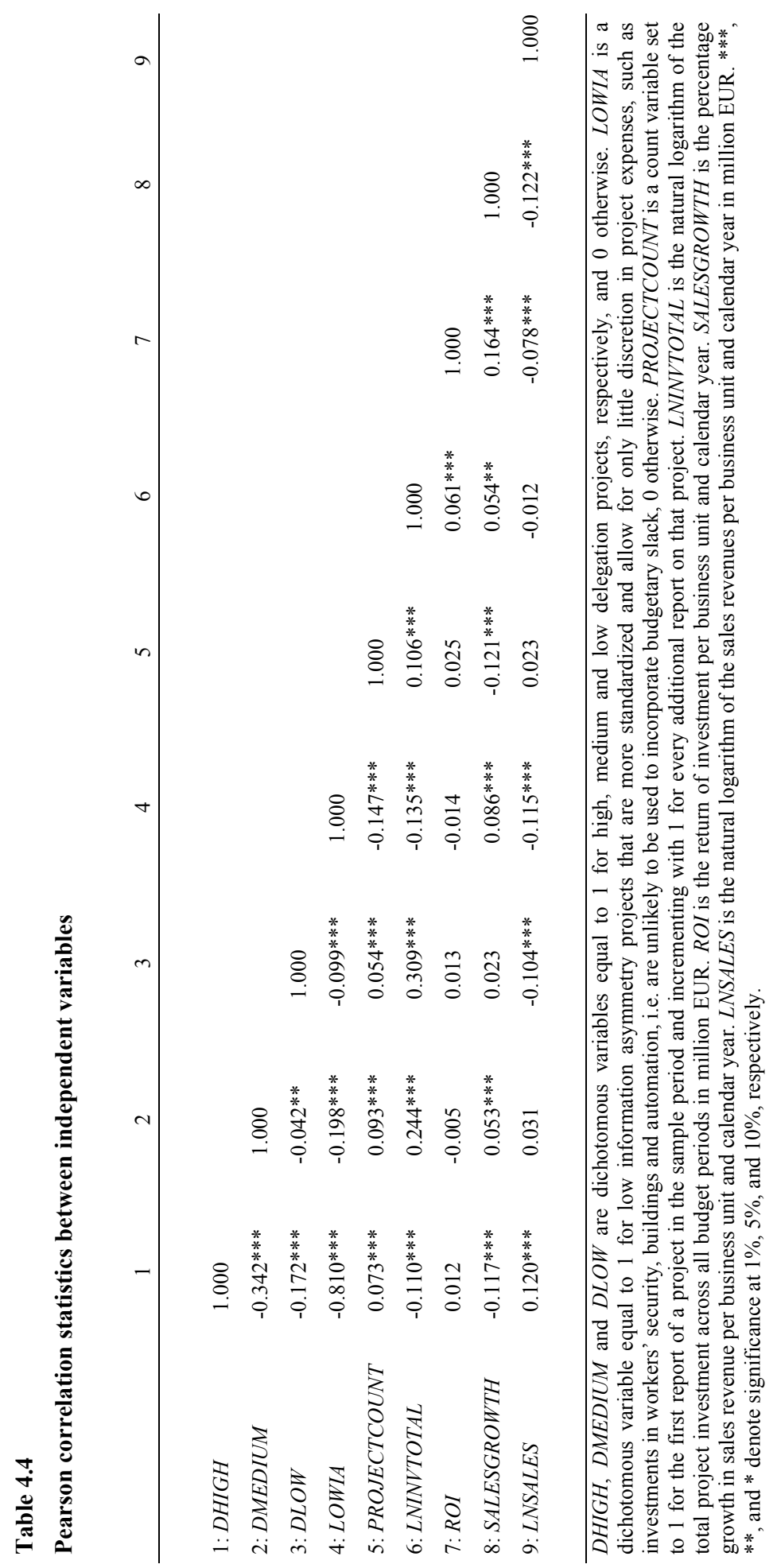


Table 4.5

Investments, cost change and cost shift requests for each sample period

\begin{tabular}{|c|c|c|c|c|c|}
\hline \multirow{2}{*}{$\begin{array}{l}\text { Sample } \\
\text { period }\end{array}$} & \multirow{2}{*}{$\begin{array}{c}\text { Period } \\
\text { investment } \\
\text { (1) Total }\end{array}$} & \multicolumn{2}{|c|}{ Cost change requests } & \multicolumn{2}{|c|}{ Cost shift requests } \\
\hline & & (2) Total & $(2) /(1)$ & (3) Total & $(3) /(1)$ \\
\hline $\mathrm{P} 1$ & 399.0 & 13.0 & 0.032 & 37.8 & 0.095 \\
\hline $\mathrm{P} 2$ & 490.8 & 5.4 & 0.011 & 38.8 & 0.079 \\
\hline P3 & 384.7 & 13.2 & 0.034 & 41.0 & 0.107 \\
\hline P4 & 537.0 & 16.4 & 0.031 & 28.2 & 0.053 \\
\hline P5 & 453.3 & 53.1 & 0.117 & 52.4 & 0.115 \\
\hline P6 & 552.3 & 42.4 & 0.077 & 68.7 & 0.124 \\
\hline P7 & 524.1 & 39.0 & 0.074 & 62.9 & 0.120 \\
\hline Mean P1-7 & 477.3 & 26.1 & 0.054 & 47.1 & 0.099 \\
\hline
\end{tabular}

All amounts in columns 1, 2 and 3 are in million EUR.

Results for hypothesis 1 are presented in table 4.6, first running the model without control variables in specification (1). The coefficients for DMEDIUM and $D L O W$ are significant at the $5 \%$ and $1 \%$ level, respectively. On average, cost change requests at medium delegation level are 9 percentage points lower than at high level. The average level of cost change requests further decreases at low delegation, around 15 percentage points lower than at high level. This evidence documents a continuous decline in cost changes the less investment decision rights are delegated, supporting hypothesis 1 . Cost change requests for low information asymmetry projects are also significantly lower than at high delegation, as predicted. This can be explained by the more standardized nature of these projects that allow for few discretionary changes. Adding control variables in specification (2) reinforces the evidence of the first model. The coefficient of DMEDIUM further increases in significance. Furthermore, the differences in cost change requests for the different delegation levels increase to 15 and 36 percentage points for DMEDIUM and $D L O W$, respectively. This underlines the impact that the delegation of decision rights on investments has on the cost request behavior of the firm's business units. Of the control variables, PROJECTCOUNT is significantly negatively related to requested cost changes $(\mathrm{p}<1 \%)$, documenting that cost change requests are declining in the length of a project. The significant and positive coefficient of LNINVTOTAL 
$(\mathrm{p}<1 \%)$ speaks for higher cost change requests of larger, i.e. more complex, projects.

\subsubsection{Hypothesis 2}

Hypothesis 2 states that requests to change the total scope of an investment project are more pronounced in the early stages of a multi-period investment project. To investigate this issue, we split observations in two groups according to whether they pertain to projects in early or more advanced stages. The company's reporting indicates the project stage, more specifically whether a project is new, has been submitted and some upfront investments have taken place, or whether it is in its main investment phase. For the latter two stages, business units can submit requests to change the total investment sum or to shift costs between periods. We set the dichotomous variable $E A R L Y$ to identify observations on projects that are submitted but where the main investment stage has not started yet. We then add EARLY to the model used for hypothesis 1 and interact this variable with the identifier variables for medium and high delegation levels as well as for low information asymmetry

\section{Table 4.6}

\section{Regression model of cost change requests and levels of delegation}

\begin{tabular}{|c|c|c|c|c|c|}
\hline Independent variables & $\begin{array}{l}\text { Predicted } \\
\text { sign }\end{array}$ & \multicolumn{2}{|c|}{$\begin{array}{l}\text { (1) Cost change } \\
\text { requests }\end{array}$} & \multicolumn{2}{|c|}{$\begin{array}{l}\text { (2) Cost change } \\
\text { requests } \\
C H G \operatorname{COS} T_{p t}\end{array}$} \\
\hline$D_{M E D I U} M_{p}$ & - & -0.089 & $0.054 * *$ & -0.152 & $0.003 * * *$ \\
\hline$D L O W_{p}$ & - & -0.153 & $0.000 * * *$ & -0.364 & $0.000 * * *$ \\
\hline$L O W I A_{p}$ & - & -0.128 & $0.001 * * *$ & -0.147 & $0.001 * * *$ \\
\hline PROJECTCOUNT $_{p t}$ & - & & & -0.044 & $0.000 * * *$ \\
\hline LNINVTOTAL $_{p t}$ & + & & & 0.083 & $0.000 * * *$ \\
\hline$R O I_{p t}$ & $?$ & & & -0.082 & 0.162 \\
\hline SALESGROWTH $H_{p t}$ & $?$ & & & 0.178 & 0.146 \\
\hline$L N S A L E S_{p t}$ & $?$ & & & 0.005 & 0.834 \\
\hline Intercept & & Yes & & Yes & \\
\hline R-Square & & 0.014 & & 0.078 & \\
\hline $\mathrm{N}$ & & 673 & & 616 & \\
\hline
\end{tabular}

Table 4.6 continued next page 
projects. As in the models employed earlier on, standard errors are corrected for clustering at project level.

$$
\begin{aligned}
& \mathrm{CHGCOST}_{p, t}=f\left(\mathrm{DMEDIUM}_{p}, \mathrm{DLOW}_{p}, \mathrm{LOWIA}_{p}, \mathrm{EARLY}_{p, t}\right. \text {, } \\
& D M E D I U M^{*} E A R L Y_{p, t}, D L O W^{*} E A R L Y_{p, t} \text {, } \\
& \left.L O W I A^{*} E A R L Y_{p, t}, \text { CONTROLS } S_{p, t}\right)
\end{aligned}
$$

\begin{tabular}{|c|c|c|c|c|c|}
\hline \multirow[b]{2}{*}{ Independent variables } & \multirow{2}{*}{$\begin{array}{c}\text { Predicted } \\
\text { sign }\end{array}$} & \multicolumn{2}{|c|}{$\begin{array}{l}\text { (3) Cost change requests } \\
C H G C O S T_{p t}\end{array}$} & \multicolumn{2}{|c|}{$\begin{array}{l}\text { (4) Cost change requests } \\
\text { CHGCOST }\end{array}$} \\
\hline & & Coeff. & Prob. & Coeff. & Prob. \\
\hline$D_{M E D I U M_{p}}$ & - & -0.022 & 0.281 & -0.079 & $0.030 * * *$ \\
\hline$D L O W_{p}$ & - & -0.074 & $0.003 * *$ & -0.330 & $0.000 * * *$ \\
\hline$L_{O W I A_{p}}$ & - & -0.043 & 0.128 & -0.056 & $0.097 *$ \\
\hline$E A R L Y_{p t}$ & + & 0.326 & $0.000 * * *$ & 0.273 & $0.000 * * *$ \\
\hline$D M E D I U M^{*} E A R L Y_{p t}$ & - & -0.266 & $0.015 * *$ & -0.279 & $0.006 * * *$ \\
\hline$D L O W^{*} E A R L Y_{p t}$ & - & -0.224 & $0.003 * * *$ & -0.147 & $0.081 *$ \\
\hline$L O W I A^{*} E A R L Y_{p t}$ & - & -0.281 & $0.006 * * *$ & -0.274 & $0.008 * * *$ \\
\hline PROJECTCOUNT & - & & & -0.032 & $0.004 * * *$ \\
\hline LNINVTOTAL $_{p t}$ & + & & & 0.094 & $0.000 * * *$ \\
\hline$R O I_{p t}$ & $?$ & & & -0.056 & 0.304 \\
\hline$S_{A L E S G R O W T H}$ & $?$ & & & 0.151 & 0.194 \\
\hline$L N S A L E S_{p t}$ & $?$ & & & 0.008 & 0.719 \\
\hline Intercept & & Yes & & Yes & \\
\hline R-Square & & 0.069 & & 0.118 & \\
\hline $\mathrm{N}$ & & 673 & & 616 & \\
\hline
\end{tabular}

Table 4.6 continued

\footnotetext{
All standard error are corrected for potential clustering at project level. CHGCOST is the requested percentage change in a project's total investment including the current as well as future budget periods. $E A R L Y$ is a dichotomous variable equal to 1 for budget reports on early stage projects with several upfront investments having taken place but prior to the main investment stage, 0 otherwise. DMEDIUM and $D L O W$ are dichotomous variables equal to 1 for medium and low delegation projects, respectively, and 0 otherwise. LOWIA is a dichotomous variable equal to 1 for low information asymmetry projects that are more standardized and allow for only little discretion in project expenses, such as investments in workers' security, buildings and automation, i.e. are unlikely to be used to incorporate budgetary slack, 0 otherwise. PROJECTCOUNT is a count variable set to 1 for the first report of a project in the sample period and incrementing with 1 for every additional report on that project. LNINVTOTAL is the natural logarithm of the total project investment across all budget periods in million EUR. ROI is the return of investment per business unit and calendar year. SALESGROWTH is the percentage growth in sales revenue per business unit and calendar year. LNSALES is the natural logarithm of the sales revenues per business unit and calendar year in million EUR. ***, **, and * denote significance at $1 \%, 5 \%$, and $10 \%$, respectively.
} 
We expect the main coefficient of $E A R L Y$, identifying early-stage observations for high delegation projects, to be significantly positive, indicating that cost change requests are larger in early investment stages. Furthermore, the interaction terms on medium and low delegation as well as low information asymmetry projects are expected to be significantly negative, i.e. significantly lower than high delegation requests in early project stages.

Specification (3) of table 4.6, excluding control variables, confirms these expectations. Cost change requests of high delegation projects (EARLY) are significantly higher $(\mathrm{p}<1 \%)$ in earlier project stages by 33 percentage points. Requests for medium and low delegation projects are significantly lower than high delegation projects by $27(\mathrm{p}<5 \%)$ and $22(\mathrm{p}<1 \%)$ percentage points in the early stage as compared to the mature stage. The coefficients on the main effect of EARLY as well as all interaction effects remain significant, corroborating the evidence from specification (3). Overall, the findings from both models confirm hypothesis 2.

\section{Table 4.7}

\section{Regression model of cost shifting requests and levels of delegation}

\begin{tabular}{|c|c|c|c|c|c|}
\hline \multirow[b]{2}{*}{ Independent variables } & \multirow{2}{*}{$\begin{array}{l}\text { Predicted } \\
\text { sign } \\
\end{array}$} & \multicolumn{2}{|c|}{$\begin{array}{c}\text { (1) Cost shifting requests } \\
\text { COSTSHIFT }_{p t}\end{array}$} & \multicolumn{2}{|c|}{$\begin{array}{c}\text { (2) Cost shifting requests } \\
\text { COSTSHIFT }_{p t}\end{array}$} \\
\hline & & Coeff. & Prob. & Coeff. & Prob. \\
\hline$D_{M E D I U M_{p}}$ & - & -0.212 & $0.003 * * *$ & -0.260 & $0.009 * * *$ \\
\hline$D L O W_{p}$ & - & -0.384 & $0.001 * * *$ & -0.381 & $0.029 * *$ \\
\hline$L O W I A_{p}$ & - & 0.092 & 0.301 & 0.188 & 0.170 \\
\hline PROJECTCOUNT $_{p t}$ & - & & & -0.003 & 0.471 \\
\hline$L_{N I N V T O T A L_{p t}}$ & + & & & 0.026 & 0.340 \\
\hline$R O I_{p t}$ & $?$ & & & 0.094 & $0.039 * *$ \\
\hline$S_{A L E S G R O W T H}$ & $?$ & & & -0.364 & $0.093 *$ \\
\hline$L N S A L E S_{p t}$ & $?$ & & & 0.182 & $0.013 * * *$ \\
\hline Intercept & & Yes & & Yes & \\
\hline R-Square & & 0.009 & & 0.027 & \\
\hline $\mathrm{N}$ & & 455 & & 419 & \\
\hline
\end{tabular}

Table 4.7 continued next page 


\subsubsection{Hypothesis 3}

To analyze hypothesis 3 on cost shifting behavior, we employ the multiple regression model used to investigate hypothesis 1 and replace the dependent variable with COSTSHIFT, the requested absolute percentage change in the current investment period caused by either postponing part of the current period's investment or by advancing costs initially budgeted for later project periods.

Table 4.7 continued

\begin{tabular}{|c|c|c|c|c|c|}
\hline \multirow[b]{2}{*}{ Independent variables } & \multirow{2}{*}{$\begin{array}{c}\text { Predicted } \\
\text { sign } \\
\end{array}$} & \multicolumn{2}{|c|}{$\begin{array}{c}\text { (3) Cost shifting requests } \\
\text { COSTSHIFT }_{p t}\end{array}$} & \multicolumn{2}{|c|}{$\begin{array}{l}\text { (4) Cost shifting requests } \\
\text { COSTSHIFT }_{p t}\end{array}$} \\
\hline & & Coeff. & Prob. & Coeff. & Prob. \\
\hline$D_{M E D I U M_{p}}$ & - & -0.156 & $0.048 * *$ & -0.252 & $0.030 * *$ \\
\hline$D L O W_{p}$ & - & 0.090 & 0.156 & -0.041 & 0.420 \\
\hline$L O W I A_{p}$ & - & -0.072 & 0.216 & -0.019 & 0.436 \\
\hline$M A T U R E_{p t}$ & $?$ & 0.018 & 0.434 & 0.000 & 0.500 \\
\hline$D_{M E D I U M}^{*} M A T U R E_{p t}$ & - & -0.109 & 0.223 & -0.003 & 0.493 \\
\hline$D L O W^{*} M A T U R E_{p t}$ & - & -0.680 & $0.000 * * *$ & -0.475 & $0.001 * * *$ \\
\hline$L O W I A^{*} M A T U R E_{p t}$ & - & 0.233 & 0.193 & 0.292 & 0.189 \\
\hline PROJECTCOUNT $T_{p t}$ & - & & & -0.001 & 0.487 \\
\hline LNINVTOTAL $_{p t}$ & + & & & 0.022 & 0.367 \\
\hline$R O I_{p t}$ & $?$ & & & 0.090 & $0.050 * *$ \\
\hline SALESGROWTH $H_{p t}$ & $?$ & & & -0.364 & 0.113 \\
\hline$L N S A L E S_{p t}$ & $?$ & & & 0.169 & $0.028 * *$ \\
\hline Intercept & & Yes & & Yes & \\
\hline R-Square & & 0.014 & & 0.031 & \\
\hline $\mathrm{N}$ & & 455 & & 419 & \\
\hline
\end{tabular}

\footnotetext{
All standard error are corrected for potential clustering at project level. COSTSHIFT is the requested absolute percentage change in a project's current budget period investment by fully or partly postponing originally scheduled costs to a later period or vice versa advancing future costs to the current period. MATURE is a dichotomous variable equal to 1 for budget reports on projects in their main investment phase, 0 otherwise. DMEDIUM and DLOW are dichotomous variables equal to 1 for medium and low delegation projects, respectively, and 0 otherwise. LOWIA is a dichotomous variable equal to 1 for low information asymmetry projects that are more standardized and allow for only little discretion in project expenses, such as investments in workers' security, buildings and automation, i.e. are unlikely to be used to incorporate budgetary slack, 0 otherwise. PROJECTCOUNT is a count variable set to 1 for the first report of a project in the sample period and incrementing with 1 for every additional report on that project. LNINVTOTAL is the natural logarithm of the total project investment across all budget periods in million EUR. ROI is the return of investment per business unit and calendar year. SALESGROWTH is the percentage growth in sales revenue per business unit and calendar year. LNSALES is the natural logarithm of the sales revenues per business unit and calendar year in million EUR. ***, **, and * denote significance at $1 \%, 5 \%$, and $10 \%$, respectively.
} 
$\operatorname{COSTSHIFT~}_{p, t}=f\left(\right.$ DMEDIUM $_{p}$, DLOW $_{p}$, LOWIA $_{p}$, CONTROLS $\left._{p, t}\right)$

The results are given in table 4.7, specification (1). Both DMEDIUM and $D L O W$ are significantly negatively related to the dependent variable at a significance level of $1 \%$, as predicted. The coefficients suggest that cost shifting requests are gradually decreasing the less decision rights are delegated and the more the principal retains control. More specifically, cost shifts for medium and low delegation are on average 21 and 38 percentage points lower than at high delegation. This evidence is not altered when adding control variables in specification (2) with coefficients of DMEDIUM and DLOW remaining significant at $1 \%$ and $5 \%$, respectively. The findings from both specifications confirm hypothesis 3 . The results for the control variables in specification (2) furthermore reveal that larger and more profitable units file significantly higher cost shift requests, whereas neither project size nor duration has a substantial impact.

\subsubsection{Hypothesis 4}

Hypothesis 4 states that the increase of cost shifting requests for more delegated projects should be more prominent in later, more advanced stages of an investment project. A similar interaction model as for hypothesis 2 is used to analyze this conjecture, replacing $C H G C O S T$ with COSTSHIFT. Since the focus of hypothesis 4 is on the effects in the later project phase, we replace $E A R L Y$ with the inversely coded, dichotomous variable MATURE that identifies observations on projects in their main investment stage. We also interact the latter with DMEDIUM, DLOW and $L O W I A$ to trace the individual mature-stage behavior of these project types.

$$
\begin{aligned}
& \operatorname{COSTSHIFT~}_{p, t}=f\left(\text { DMEDIUM }_{p}, \text { DLOW }_{p}, \text { LOWIA }_{p}, \text { MATURE }_{p, t}\right. \text {, } \\
& \text { DMEDIUM*MATURE } E_{p, t}, D L O W^{*} M A T U R E_{p, t} \text {, } \\
& \left.L_{O W I A}^{*} \text { MATURE }_{p, t}, \text { CONTROLS } S_{p, t}\right)
\end{aligned}
$$

Following hypothesis 4, the coefficient of MATURE should indicate a significantly higher average level of cost shift requests of high-delegation projects towards later project stages. Ever fewer costs are however available to be shifted between periods as a project progresses. For instance, in the terminal investment period no costs remain that may be accelerated to this period. The extent of cost shift requests is therefore bound to mechanically decline towards the end of projects. This counterbalances the effect of higher costs shifts in mature stages as agents attempt to reallocate slack as a consequence of developments that could not be foreseen at the outset of the project, as posited in hypothesis 4 . The net effect of $M A T U R E$ is thus uncertain and we therefore have no specific sign prediction for this variable. In contrast, the average level of cost shifts for medium- and low-delegation 
projects should be lower than for high-delegation projects in the mature stage. The signs of both interaction coefficients should thus be significantly negative for hypothesis 4 to hold.

Results are provided in specifications (3) and (4) of table 4.7 without and with additional control variables. The average level of cost shift requests is insignificantly different between early and mature stages for high-delegation projects (MATURE). The average medium- and low-delegation cost shift requests both decline compared to high-delegation costs shifts when reaching later project

\section{Table 4.8}

\section{Logistic regression model on the incidence of cost change and shift requests at early and mature project stages}

(1) Incidence of cost

\begin{tabular}{l}
$\begin{array}{l}\text { Independent } \\
\text { variables }\end{array}$ \\
\hline EARLY $_{p t}$ \\
MATURE $_{p t}$ \\
DMEDIUM $_{p}$ \\
DLOW $_{p}$ \\
LOWIA $_{p}$ \\
PROJECTCOUNT $_{p t}$ \\
LNINVTOTAL $_{p t}$ \\
ROI $_{p t}$ \\
SALESGROWTH \\
LNSALES $_{p t}$ \\
Intercept \\
R-Square \\
$\mathrm{N}$
\end{tabular}

shift request
COSTSHIFT_EVENT
COt sign

$?$

$-$

$?$

$?$

$?$

-
+
$?$
$?$
$?$

?
Coeff. Prob.

Coeff. Prob.

$\begin{array}{cc}-0.626 & 0.000 * * * \\ 0.352 & 0.159\end{array}$

$\begin{array}{rl}0.352 & 0.159 \\ -0.736 & 0.092 * \\ -0.583 & 0.001 * * * \\ & \\ -0.248 & 0.000 * * * \\ 0.257 & 0.000 * * * \\ 0.027 & 0.836 \\ -0.359 & 0.155 \\ -0.049 & 0.483\end{array}$

Yes

0.069

1,424
(2) Incidence of cost change request CHGCOST_EVENT $T_{p t}$ Coeff. Prob.

$0.055 \quad 0.697$

$\begin{array}{rl}0.049 & 0.417 \\ 0.204 & 0.286 \\ 0.002 & 0.496 \\ & \\ 0.017 & 0.367 \\ 0.323 & 0.000 * * * \\ -0.057 & 0.463 \\ 0.029 & 0.893 \\ -0.088 & 0.179\end{array}$

Yes

0.035

1,424

\footnotetext{
All standard error are corrected for potential clustering at project level. COSTSHIFT_EVENT is a dichotomous variable equal to 1 when the project observation indicates a cost shift request, 0 otherwise. $E A R L Y$ is a dichotomous variable equal to 1 for budget reports on early stage projects with several upfront investments having taken place but prior to the main investment stage, 0 otherwise. MATURE is a dichotomous variable equal to 1 for budget reports on projects in their main investment phase, 0 otherwise. DMEDIUM and DLOW are dichotomous variables equal to 1 for medium and low delegation projects, respectively, and 0 otherwise. LOWIA is a dichotomous variable equal to 1 for low information asymmetry projects that are more standardized and allow for only little discretion in project expenses, such as investments in workers' security, buildings and automation, i.e. are unlikely to be used to incorporate budgetary slack, 0 otherwise. PROJECTCOUNT is a count variable set to 1 for the first report of a project in the sample period and incrementing with 1 for every additional report on that project. LNINVTOTAL is the natural logarithm of the total project investment across all budget periods in million EUR. ROI is the return of investment per business unit and calendar year. SALESGROWTH is the percentage growth in sales revenue per business unit and calendar year. LNSALES is the natural logarithm of the sales revenues per business unit and calendar year in million EUR. ***, **, and * denote significance at $1 \%, 5 \%$, and $10 \%$, respectively.
} 
stages, the decline in the latter case $\left(D L O W^{*} M A T U R E\right)$ is significant at the $1 \%$ level in both specifications (3) and (4). This confirms hypothesis 4.

\subsubsection{Supplementary analyses}

\subsubsection{Probability of change requests}

The hypotheses of this study specifically concentrate on the extent of project change requests once they have been submitted in relation to varying degrees of delegation. In a supplementary analysis we also investigate the probability that these change requests occur. We argued in the analysis of cost shift requests that they are likely less pronounced towards the end of a project, i.e. in mature project stages, as the amount of remaining project costs evidently declines and thus also the part that can potentially be shifted between periods. Similarly, we expect that the probability of a cost shift requests mechanistically is lower in mature compared to earlier project stages. In contrast, the remaining part of a project should not mechanically affect the probability of requests to change the total costs of an investment. The latter should therefore occur with equal probability between early and mature stages.

We analyze both conjectures with a binary probit model on the incidence of cost change and cost shift requests. CHGCOST_EVENT is a binary variable equal to 1 whenever a project observation reports the filing of a cost change request and is equal to 0 for all other observations. Similarly, COSTSHIFT_EVENT identifies project observations with requests to shift costs. This coding procedure extends the analysis to 1,424 observations, excluding newly submitted investments for which no change requests can be filed. The results of the probit model on the probability of cost shifts and cost changes are provided in specification (1) and (2) of table 4.8, respectively. Standard errors are corrected for potential clustering at the investment project level. The results indicate that the probability of a cost shift request is indeed lower as a project enters later, more mature project stages, whereas cost change requests are equally likely to occur over the course of an investment. We further investigate whether the probability of cost shift and change requests differs between delegation levels. An agent unlikely submits cost shift or change requests solely for the purpose of augmenting or rearranging slack in an investment. It is more likely that the agent takes the opportunity of an operational reason to also manage slack. We therefore spell no specific expectation how the incidence of a cost change or cost shift request is related to the level of delegation. Results show that the incidence of a cost shift request is less likely for low delegation and low information asymmetry projects compared to high delegation projects, at a significance level of $10 \%$ and $1 \%$, respectively. We find no significant differences for cost change requests. The results on early and mature stage probabilities are robust to excluding the indicator variables for the different delegation levels and vice versa. The findings are furthermore unchanged when including indicator variables for individual project rounds of the sample period. 
Table 4.9

Regression model of ex post cost changes and levels of delegation

\begin{tabular}{|c|c|c|c|c|c|}
\hline \multirow[b]{2}{*}{ Independent variables } & \multirow{2}{*}{$\begin{array}{l}\text { Predicted } \\
\text { sign } \\
\end{array}$} & \multirow{2}{*}{\multicolumn{2}{|c|}{$\begin{array}{l}\text { (1) Actual cost change per } \\
\text { project, } C H G C O S T X P_{p, t+1} \\
\text { Coeff. Prob. }\end{array}$}} & \multicolumn{2}{|c|}{$\begin{array}{l}\text { (2) Actual cost change per } \\
\text { project, } C H G C O S T X P_{p, t+1}\end{array}$} \\
\hline & & & & Coeff. & Prob. \\
\hline$D_{M E D I U M_{p}}$ & - & -0.112 & $0.047 * *$ & -0.005 & 0.460 \\
\hline$D L O W_{p}$ & - & -0.296 & $0.000 * * *$ & -0.240 & $0.001 * * *$ \\
\hline$L O W I A_{p}$ & - & -0.196 & $0.000 * * *$ & -0.070 & $0.077 *$ \\
\hline$E A R L Y_{p t}$ & + & & & 0.364 & $0.000 * * *$ \\
\hline$D M E D I U M^{*} E A R L Y_{p t}$ & - & & & -0.386 & $0.003 * * *$ \\
\hline$D L O W^{*} E A R L Y_{p t}$ & - & & & -0.293 & $0.006 * * *$ \\
\hline$L O W I A^{*} E A R L Y_{p t}$ & - & & & -0.370 & $0.004 * * *$ \\
\hline PROJECTCOUNT & - & -0.037 & $0.013 * * *$ & -0.023 & $0.071 *$ \\
\hline LNINVTOTAL $_{p t}$ & + & 0.054 & $0.014 * * *$ & 0.071 & $0.004 * * *$ \\
\hline$R O I_{p t}$ & $?$ & -0.151 & $0.055 *$ & -0.126 & $0.067 *$ \\
\hline SALESGROWTH $H_{p t}$ & $?$ & 0.225 & $0.095 *$ & 0.166 & 0.186 \\
\hline$L N S A L E S_{p t}$ & $?$ & -0.006 & 0.827 & -0.003 & 0.905 \\
\hline Intercept & & Yes & & Yes & \\
\hline R-Square & & 0.059 & & 0.127 & \\
\hline $\mathrm{N}$ & & 473 & & 473 & \\
\hline
\end{tabular}

All standard error are corrected for potential clustering at project level. CHGCOSTXP is the actual, expost percentage change in a project's total investment across all budget periods from one budget period to the next, after a request to change costs has been submitted. EARLY is a dichotomous variable equal to 1 for budget reports on early stage projects with several upfront investments having taken place but prior to the main investment stage, 0 otherwise. DMEDIUM and $D L O W$ are dichotomous variables equal to 1 for medium and low delegation projects, respectively, and 0 otherwise. LOWIA is a dichotomous variable equal to 1 for low information asymmetry projects that are more standardized and allow for only little discretion in project expenses, such as investments in workers' security, buildings and automation, i.e. are unlikely to be used to incorporate budgetary slack, 0 otherwise. PROJECTCOUNT is a count variable set to 1 for the first report of a project in the sample period and incrementing with 1 for every additional report on that project. LNINVTOTAL is the natural logarithm of the total project investment across all budget periods in million EUR. ROI is the return of investment per business unit and calendar year. SALESGROWTH is the percentage growth in sales revenue per business unit and calendar year. LNSALES is the natural logarithm of the sales revenues per business unit and calendar year in million EUR. ***, **, and * denote significance at $1 \%, 5 \%$, and $10 \%$, respectively. 


\subsubsection{Ex post cost change model}

The focus of this study is on requests to change investment projects. However, the principal may still decide to turn down or reduce an agent's initial proposal. A rational agent is unlikely to continue asking the principal to change an investment unless there is a chance that this request will be honored. We nevertheless also analyze how project costs actually develop following a request to change an investment to indicate whether the requested amounts materialize. We rerun the analyses on cost change requests using the ex post change of the total investment sum from the budget period when a cost change request is filed to the subsequent period, CHGCOST_XP. As described before, the descriptive statistics of requested and actual cost changes closely resemble each other. This pattern continues to hold in the multivariate analyses for hypotheses 1 and 2, rerunning the models documented in table 4.6 and replacing CHGCOST with CHGCOST_XP ${ }^{28}$. The results are reported in table 4.9: actual cost changes are more pronounced the more a project is delegated, reconfirming hypotheses 1. Furthermore, EARLY as well as the interaction terms in specification 2 have the same sign and similar significance as the original model reported in table 6 . This reconfirms hypothesis 2 . These results are qualitatively the same when excluding the five control variables on project and business unit characteristics. ${ }^{29}$

\subsubsection{Further robustness tests}

We apply further untabulated modifications to our analyses to test the robustness of our results. First, we alter the way standard errors of our multivariate regression models are corrected, changing from potential clustering at project level to potential clustering at business unit level. Results remain unaffected. Second, the firm's reporting system has a pre-defined indication whether a project is in an early or mature stage, feeding into the analysis of hypotheses 2 and 4 . We modify the distinction between early and mature by reclassifying up to a third of a project's available mature observations as pertaining to the early stages. Hypotheses 2 and 4 continue to hold under this modification. Third, we rerun all multivariate models including indicator variables for the seven budget periods that were sampled. The signs and significances of all main explanatory variables remain unaffected. Fourth, above conclusions on cost change requests in hypotheses 1 and 2 are drawn from inspecting change requests that affect all remaining periods of a project. One could argue that a principal is able to detect attempts to incorporate slack in the current period more easily than in more distant periods if more time is spent to monitor immediate changes. The agent would consequently refrain from incorporating slack

\footnotetext{
${ }^{28}$ The ex post analysis covers less observations than the original model in table 4.6 as some observations subsequent to a request lie outside the sample period.

${ }^{29}$ A comparable ex post analysis is not feasible for cost shift changes, given that total actual cost changes over the entire investment as in CHGCOST_XP are unaffected by additional cost shift requests between periods.
} 
and cost change requests should not escalate in delegation for changes affecting the current period. We test this conjecture by replacing total project cost changes with cost change requests for the current period and find the similar results. The agent is thus equally able to incorporate slack in current as in more distant project periods and the principal's monitoring is not lower in the latter case. Fifth, the variable PROJECTCOUNT increases over a project's lifecycle and is therefore closely related to the project stage identifiers EARLY and MATURE. This may introduce a multicollinearity problem in the analyses for hypotheses 2 and 4 . We therefore rerun the potentially affected specifications leaving out PROJECTCOUNT and obtain closely comparable estimates that confirm both hypotheses. Sixth, we exclude low information asymmetry projects from all main multivariate models and find similar results supporting all four hypotheses. Overall, none of the modifications we applied changed the evidence that the main analyses of this study delivered.

\subsection{Discussion}

The results of this study highlight several adverse consequences of delegating decision rights of multi-period investment projects. First, our findings indicate that additional requests to change the total investment sum of projects are significantly higher the more authority over a project is delegated. We argue that these escalating requests indicate that business units seek to extend budgetary slack by exploiting lower corporate control among projects with higher delegation of investment decision rights. Second, we argue that the information asymmetry between principal and agent on the actual nature of a project is particularly high at the start of an investment. Slack-seeking agents are therefore likely to incorporate more slack in earlier project stages. In support of this argument, our results show that requests to change the total scope of an investment are indeed particularly high at the outset of a project. Third, we propose that business units not only implement more slack but also reallocate this slack to a higher extent between investment periods the more a project is delegated. Business units benefit from reallocating slack between periods as consumption preferences of slack can change over the course of the investment, deviating from the slack incorporated per period when first submitting a multiperiod investment. We find corroborating evidence for this argument as cost shifts increase in the level of delegation. Fourth, we argue that the difference between actually desired slack and initially allocated slack is higher the longer the time span between first incorporating and consuming slack. More mature periods therefore hold a higher difference in actual and desired slack. This induces the agent to resort to higher cost shifting to reduce this difference, which our evidence supports. Several robustness tests reinforce the evidence found for all four hypotheses. 
One of the implications of this study is that the organizational design of decision rights matters in budgeting processes. Companies that intend to delegate decision rights need to be aware of the possible adverse consequences that our results highlight. Although delegation can be an optimal response to avoid possible further distortions (Marino \& Matsusaka 2005), these potential benefits of delegation should be traded off against the deteriorating precision of the investment budget when granting more decision rights to lower hierarchical levels. Another implication concerns the post-auditing of capital budgets to monitor the performance of investment decisions. ${ }^{30}$ Various authors note that only few firms employ sophisticated post-audits (Smith 1993; Pierce \& Tsay 1992; Haka 2007). Firms could, however, considerably improve their budgeting process when using postaudits, as the potential value of post-audits has been repeatedly illustrated in the literature (e.g. Myers et al. 1991; Gordon \& Smith 1992). This study reinforces the evidence on potential gains of post-audits as budget renegotiations that lead to slack escalations can be detected and contained when employing appropriate post-audit procedures.

Our results are subject to several limitations. First, the findings might not be directly representative of other firms since our data emanates from one specific corporate group. However, this concern is alleviated by the fact that the budgeting process implemented in this company is very typical for comparable industrial firms. Second, for some analyses only a limited number of observations are available, especially on the differences of cost shifting requests at early and mature stages. This constrains the array of empirical methods that can be applied to the data and limits the strength of some of our findings. Lastly, operational reasons unrelated to purposeful implementation and reallocation could at least partly drive the business units' requests for cost changes and cost shifts. While it is difficult to see why these reasons would systematically vary with the level of delegation, it may be that the cost request data used in this study only roughly approximates slack, reducing the precision of our results.

In spite of these limitations, we are convinced that our study contributes to the extant literature on capital budgeting, budgetary slack, and the delegation of authority. While prior papers predominantly consider budget processes with slack being incorporated before the actual investment occurs, we analyze a setting where projects span across several budget periods. This setting is of particular interest because multi-period investments offer agents the possibility to renegotiate budgets. In consequence, agents can adjust the amount of slack per period, which previous studies assume to be locked in at the outset of projects. As projects develop over time, agents are bound to update their beliefs of the project and adapt budgetary

\footnotetext{
${ }^{30}$ Note that post-auditing refers to auditing the actual performance of the investment projects after the fact. It does not refer to costly auditing of information transmitted during the capital budgeting process, as for example assumed in the models of Harris and Raviv $(1996,1998)$.
} 
slack accordingly. To the best of our knowledge, we are the first to offer empirical evidence on the consequences of delegating authority in these settings and at this level of detail. A potential avenue for future research is to further investigate the interplay between cost shift and cost change requests at different life-cycle stages of investment projects. Furthermore, it would be interesting to extend the analysis towards the exact trade-off decisions when investment decision rights are delegated, for instance when varying the compensation contracts of the agents involved. 


\section{Appendix 4.A Variable definitions}

\begin{tabular}{|c|c|}
\hline Variable name & Description \\
\hline CAPEX & $\begin{array}{l}\text { Capital expenditures for investments per business unit and } \\
\text { calendar year in million EUR. }\end{array}$ \\
\hline CAPITAL & $\begin{array}{l}\text { Total capital held per business unit and calendar year in million } \\
\text { EUR. }\end{array}$ \\
\hline CHGCOST & $\begin{array}{l}\text { Requested percentage change in a project's total investment } \\
\text { including the current as well as future budget periods. }\end{array}$ \\
\hline CHGCOST_EVENT & $\begin{array}{l}\text { Dichotomous variable equal to } 1 \text { when the project observation } \\
\text { indicates a cost change request, } 0 \text { otherwise. }\end{array}$ \\
\hline CHGCOSTXP & $\begin{array}{l}\text { Actual, ex-post percentage change in a project's total investment } \\
\text { across all budget periods from one budget period to the next, } \\
\text { after a request to change costs has been submitted. }\end{array}$ \\
\hline COSTSHIFT & $\begin{array}{l}\text { Requested absolute percentage change in a project's current } \\
\text { budget period investment by fully or partly postponing originally } \\
\text { scheduled costs to a later period or vice versa advancing future } \\
\text { costs to the current period. }\end{array}$ \\
\hline COSTSHIFT_EVENT & $\begin{array}{l}\text { Dichotomous variable equal to } 1 \text { when the project observation } \\
\text { indicates a cost shift request, } 0 \text { otherwise. }\end{array}$ \\
\hline$D H I G H$ & $\begin{array}{l}\text { Dichotomous variable equal to } 1 \text { for high delegation level } \\
\text { projects (low central supervision), } 0 \text { otherwise. }\end{array}$ \\
\hline$D L O W$ & $\begin{array}{l}\text { Dichotomous variable equal to } 1 \text { for low delegation level projects } \\
\text { (high central supervision), } 0 \text { otherwise. }\end{array}$ \\
\hline DMEDIUM & $\begin{array}{l}\text { Dichotomous variable equal to } 1 \text { for medium delegation level } \\
\text { projects (medium central supervision), } 0 \text { otherwise. }\end{array}$ \\
\hline EARLY & $\begin{array}{l}\text { Dichotomous variable equal to } 1 \text { for budget reports on early } \\
\text { stage projects with several upfront investments having taken } \\
\text { place but prior to the main investment stage, } 0 \text { otherwise. }\end{array}$ \\
\hline EMPLOYEES & Number of employees per business unit and calendar year. \\
\hline INVCURRENT & $\begin{array}{l}\text { Project investment scheduled to take place in the current budget } \\
\text { period in million EUR. }\end{array}$ \\
\hline INVTOTAL & $\begin{array}{l}\text { Total project investment across all budget periods in million } \\
\text { EUR. }\end{array}$ \\
\hline LNINVTOTAL & Natural logarithm of INVTOTAL. \\
\hline LNSALES & Natural logarithm of SALES. \\
\hline
\end{tabular}


LOWIA

MATURE

PROJECTCOUNT

$R O I$

SALES

SALESGROWTH
Dichotomous variable equal to 1 for low information asymmetry projects that are more standardized and allow for only little discretion in project expenses, such as investments in workers' security, buildings and automation, i.e. are unlikely to be used to incorporate budgetary slack, 0 otherwise.

Dichotomous variable equal to 1 for budget reports on projects in their main investment phase, 0 otherwise.

Count variable set to 1 for the first report of a project in the sample period and incrementing with 1 for every additional report on that project.

Return on investment per business unit and calendar year.

Sales revenues per business unit and calendar year in million EUR.

Percentage growth in sales revenue per business unit and calendar year. 


\section{Chapter 5}

\section{Conclusion}

Diversified firms can create considerable value by efficiently allocating capital between business units to internally finance capital investments. Companies that resort to internal capital avoid the regulatory rigidities of external debt and equity markets as well as the inherently higher information asymmetries between the company and its potential investors. In the light of firms increasing in size and complexity over the last decades, the question how to allocate capital efficiently has become both more prominent as well as more difficult to answer. A major factor inhibiting efficient allocations is non-cooperative behavior within the firm, when managers of business units are interested in their own unit's rather than the firm's best interest. Due to this conflict of interests, managers try to obtain additional capital for their own unit even if these funds would have yielded a higher return elsewhere in the firm. Capital allocation efficiency and ultimately firm value suffer from this behavior.

The three studies in this dissertation contribute towards a better understanding of the conditions that induce non-cooperative behavior during capital allocation processes. Furthermore, the results indicate countermeasures that firms can implement to improve allocation efficiency. This chapter provides a summary of the findings of each study, their limitations as well as their implications for diversified firms. An outlook on potential future research in the area concludes this dissertation.

\section{$5.1 \quad$ Summary of results}

The first study, presented in chapter 2, empirically investigates the impact of compensation on the capital allocation efficiency within multi-divisional firms. The CEO cannot verify exactly the investment opportunities in each division and needs to hire division managers. Furthermore, interests of division managers and CEO are not entirely aligned, because division manager incentives are primarily tied to the own division rather than the firm. In this setting, division managers can try to maximize the capital allocation to their division and lobby the CEO for a higher share of the capital budget. Given that the CEO has an interest to maintain the 
composition of divisions within the firm, he cannot simply dismiss lobbying division managers but instead needs to pay quasi-rents to prevent them from leaving the firm. The CEO faces two alternatives how to pay these quasi-rents. He can either raise the share of capital being allocated to that division or more directly increase the division manager's individual remuneration to stop him from lobbying. Scharfstein and Stein (2000) show that the division manager's utility from both options is the same, but that the latter option is less costly for the firm since it does not additionally distort the capital budget.

It would thus be in the best interest of the firm to pay the division manager directly. This payment however reduces corporate funds under control of the CEO, which would not be affected when reallocating the capital budget among divisions instead. Since the CEO reaps personal benefits from larger corporate funds and since also his interests are not necessarily in line with those of the owners of the firm, the CEO will prefer to allocate division managers a larger share rather than paying them directly. The findings in the first study indicate that this is indeed the case: the higher the excess allocation to a division beyond the economically justified level, the lower the division manager's total remuneration. Conversely, underallocations are not associated with remuneration. This stresses that the CEO is able to deprive some divisions of part of the capital budget without having to compensate the division manager for this loss, i.e. that substituting allocations for remunerations between divisions is not a zero-sum game. Diverging interests between division manager and CEO as well as CEO and owners of the firm are underlying the misallocation problem. A potential solution is therefore to tie the personal wealth of managers more closely to that of the firm by issuing firm-wide equity incentives. In support of this argument, allocation quality is shown to increase in the amount of issued equity incentives.

The study presented in chapter 3 of this dissertation analyzes how firms can react to contain inefficient allocations caused by self-interested division managers by reconfiguring the organizational layout of their divisions. The common denominator in the theories on internal allocation efficiency is that non-cooperative division manager behavior is caused by the economic profile of the division, as defined through parameters such as profitability and investment opportunities. For instance, lobbying rather than working on the assigned tasks is particularly profitable for a manager of a division with low investment opportunities. Noncooperative behavior is also more likely among companies with strong differences in investment opportunities between their divisions. Rather than addressing this incentive problem by issuing equity incentives as investigated in chapter 2 , firms can also more directly approach this problem at the root cause, changing the economic profile itself. A division with low investment opportunities and thus high incentives to lobby can for instance be merged with another, high investment opportunity division in a way that the joint investment outlook is sufficiently high 
that lobbying is not attractive enough for the division manager. Also, changes to the organizational layout can be used to smooth economic discrepancies between divisions to reduce the motivation for harmful, non-cooperative behavior. The results show that firms are indeed more likely to reconfigure their organization when prior capital allocation efficiencies are lower than in comparable firms. Measures of capital allocation efficiency as well as shareholder wealth increase subsequent to these reconfigurations, reinforcing the argument that firms reconfigure to improve allocation efficiency. Furthermore, the sample lends some support to the expectation that such reconfigurations are less likely to occur when the cost of misallocating funds internally is relatively low.

Whereas chapter 2 and 3 study the broad effects of capital allocations, chapter 4 considers the budget process underlying capital allocations in more detail. More specifically, the third study investigates the consequences of decentralizing decision rights on the extent of budgetary slack, i.e. excess allocations, in a budgetary setting that allows capital-seeking business unit managers (the agents) to adjust their budget proposal once a multi-period investment is underway. Similar to the two studies in chapter 2 and 3, the CEO, i.e. the principal, cannot observe the actual state of an investment that an agent proposes and therefore cannot disentangle slack from actual project costs. The agent can exploit these conditions and incorporate slack into his proposal during renegotiations to obtain more funds for perquisite consumption. Furthermore, since processing capacity is limited, the CEO cannot decide on all investment projects alone but needs to delegate some of these investment decision rights to lower hierarchical levels, at the expense of losing immediate control over all investment projects. In consequence, one of the predictions is that agents incorporate more slack during renegotiations when the principal delegates more and retains less control over the project. Information asymmetries between principal and agent on the state of the project are particularly high at the outset of projects but decline as the investment proceeds and as actual costs become easier to detect for the principal. The second prediction is therefore that the agent is more likely to incorporate slack into the budget in earlier rather than later project stages to take advantage of higher information asymmetries. The findings strongly support both expectations. The third prediction states that agents not only exploit lower control in order to escalate slack but also to shift slack between periods. The agent may desire to shift slack since the agent cannot perfectly foresee how multi-period projects will exactly develop so that the agent's consumption preference when to consume slack can change during a multi-period investment and deviate from the initial slack allocation. Shifting slack allows the agent to realign actual and desired slack level. In line with the initial prediction, results indicate that slack shifting occurs to a stronger extent for more delegated projects under less control of the principal. Additionally, slack shifting is more pronounced when an agent is more certain about the development of the investment, 
i.e. in later project stages, whereas agents shift less under higher uncertainty during earlier project stages.

\subsection{Limitations}

Considerable attention has been devoted to the empirical research design in order to maximize the validity of the results of all studies presented in this dissertation. Nevertheless, several limitations are in order. In chapter 2, the benchmark model may not capture all factors that play a role during the capital allocation decision despite its high explanatory power. Elaborate validation and testing of the results associated with this model however alleviate this concern.

The studies presented in chapter 2 and 3 share two limitations. First, the two analyses impute growth opportunities of non-listed segments on the basis of listed single-segment firms in the same industry. This can only serve as an approximation of actual, but unobservable growth opportunities. Second, both studies rely on publicly available financial segment data to infer on allocations within the firm, since allocations between divisions are not directly disclosed. Due to the widespread use of these estimation techniques, the two limitations pertain to most studies in the literature on internal capital markets. In order to improve the quality of these estimations, both studies use segment data reported under SFAS 131: this standard requires firms to report more closely according to their actual organizational design and reduces some of the discretion that firms enjoyed under the preceding standard SFAS 14.

Investigating changes to the divisional layout of firms in chapter 3 is complicated by the fact that these reconfigurations may span a time period of several months. This makes it difficult to determine an exact event date. Additionally, disclosure on these reconfigurations is very limited so that they can at times only be identified when comparing detailed changes between two consecutive segment reports. In addition, the lack of disclosure makes it difficult to discriminate organizational changes to a finer extent than presented in this dissertation. Divisional reorganizations in absence of other potentially diluting event that change the organization such as acquisitions or divestments are also relatively rare and not straightforward to detect. This limits the sample size and thus also the range of applicable statistical analyses.

The more detailed internal data in chapter 4 allows circumventing some of the imputation problems inherent in the other two cross-sectional studies. The advantage of more detailed data comes at the possible costs that the findings may not be immediately generalizable. This concern can largely be dispelled by the fact that the budgeting system and also the other organizational arrangements in the analyzed industrial group are very similar to those found in comparable firms. 
Another potential limitation is that operational reasons unrelated to budgetary slack may drive requests to renegotiate budgets, so that using cost request data only roughly approximates slack. While unobservable operational reasons can undoubtedly affect requests to change project budgets, it is difficult to see how these would be systematically linked to the level of delegation. Analyzing differences of cost requests between delegation levels therefore largely filters out confounding effects of unobservable factors. A final limitation stems from the available sample size. The analyzed industrial group did not always adhere to the same format of their budgeting reports, so that only those budget period reports could enter the analysis that followed a comparable format. This puts an inevitable limit to the sample size and also the range of suitable statistical tests.

\subsection{Implications and recommendations for future research}

Various implications follow from the results of this dissertation. Parties that can profit from these insights include not only academic scholars but also management and shareholders of multi-divisional firms, as well as financial market intermediaries.

The study on internal allocation quality and compensation in chapter 2 stresses that the internal investment efficiency in multi-divisional firms can suffer from multiple agency problems between shareholders and top management, but also between different layers of management. The study shows that shareholders and management can resort to firm-wide equity incentives to at least partly resolve these agency problems and improve the allocation efficiency as managers refrain from influence activities when the resulting costs are affecting their personal wealth. This indicates that compensating employees below top management level with stock options not only increases retention but also has immediate incentive effects, inducing employees to act more in the interest of the firm. This result also shows that compensation contracts of division managers should not only be based on considerations of operational interdependence between divisions. This more conventional controllability argument states that division managers should only be compensated on the performance of the entire firm if inter-divisional dependencies allow a division manager to affect the performance of other units. Firm-based remuneration is otherwise argued to only increase noise, exposing division managers to unnecessary compensation risk. The study shows, however, that division managers may also engage in influence activities when there are few or no operational links between the units of a firm. To prevent this behavior and to improve internal investment efficiency, firms should therefore consider compensating division managers on firm performance even in the absence of interdependencies between divisions. Furthermore, the presence of incentive 
packages can also serve as a signal to analysts in the external financial market to better estimate the extent of allocation problems within the firm. This is of particular interest because the relatively opaque nature of information about the constituents of multi-divisional firms frequently leads external analysts to value these companies at a discount.

This dissertation indicates that firms can - apart from adjusting the compensation structure - also change the organizational layout of the firm to reduce influence activities of division managers surrounding the capital allocation process. The study presented in chapter 3 shows that firms can reduce the incentives of a division manager to engage in non-cooperative behavior by adjusting the economic profile of their divisions. To do so, firms do not necessarily have to engage in largescale, costly reorganizations. Instead, changes to the economic profile of a division can also be achieved by adjusting the composition of operations that a division manager supervises, which entails a change in reporting and the way decision rights are partitioned rather than a physical change in the actual operations. The results of this study stress that firms should not only devise their internal organization in the light of operational practicalities but also with respect to potential non-cooperative behavior that the internal structure may provoke. The results also show that external analysts and other intermediaries in the financial market can use disclosures surrounding divisional reorganizations to infer on the efficiency of internal capital allocations and in how far companies attempt to improve the latter. The data gathering process for this study however demonstrated that these disclosures are still relatively limited so that firms that wish to unmistakably signal the benefits of their organizational changes could potentially profit from extending the information disclosed to the financial market.

In chapter 4 , this dissertation documents the costly consequences of delegating authority over investment project decisions in capital budgeting processes. More specifically, budgets are shown to be less precise as self-interested managers incorporate more slack and reallocate more excess funds between periods the higher the level of delegation of an investment project. These findings underline that firms that have to deal with a multitude of investment proposals from their business units should consider two aspects. First, delegating investment decisions has certainly several benefits, for instance freeing up management resources of the delegating party to be used elsewhere in the firm. However, the results in this dissertation indicate that costs can escalate with non-trivial amounts the more budget authority is delegated. Firms should therefore not delegate investment decisions without thoroughly trading off the benefits of delegation with the costly loss of control in the guise of budgetary slack. Second, firms that are already delegating investment decision rights or those that plan to do so should be aware of the importance of appropriate internal reporting systems. These systems can help reducing information asymmetries between the budget-requesting and budget-granting party, thereby ex 
ante lowering the potential implementation of slack. These systems also facilitate the post-auditing of budgets. While elaborate post-audits are still rarely used in practice, this dissertation indicates that they can be of considerable value to track and prevent the escalation and inter-periodic reallocation of slack over the course of multi-period investment projects.

A multitude of research possibilities exist to extent this dissertation and other studies in the field of internal capital allocation. Kuppuswamy and Villalonga (2010) remark that only very few studies have attempted to explain causal relationships in internal capital markets. Aiming in this direction, chapters 2 and 3 contribute to the literature by analyzing the role of compensation contracts and organizational design to contain non-cooperative behavior in allocation processes. However, future research could address potential additional approaches that firms take to counter inefficient allocations. For instance, it is not yet profoundly studied if rotating management reduces non-cooperative behavior of division managers, as indicated in Stein (2003), and how these schemes specifically work. Concerning chapter 3, the annual reporting cycle for segment reports as well as the extreme scarcity of related, supplemental information in other publications and news sources led to a time window of one year within which the event took place. Future research could try to narrow this time span to more precisely measure allocation efficiencies that surround divisional reconfigurations. Chapter 3 investigates the possibility that firms are less likely to change their divisional structure to counter inefficient allocations when misallocations are less costly. Firms certainly also take additional trade-off decisions before deciding to reorganize divisions and more research is needed to clarify this decision making process.

The extant literature on capital allocation problems is largely resorting to segment disclosures in annual reports. In the light of the inevitable limitations of segment data, further insights are more likely to spring from the use of internal allocation data. The limited prior research on budget renegotiations studied in chapter 4 illustrates that internal data, while harder to obtain, can allow for a host of new analyses that could help to better understand capital allocation processes. This dissertation intends to extend knowledge in academia and practice on internal capital allocation processes, which are at the heart of managing multi-divisional firms. Many of the mechanisms in this area however still remain unknown. Internal capital allocation research therefore continues to be a challenging field of study that has the potential to contribute valuable insights into the nature and economics of the firm. 



\section{References}

Ai, C. and E.C. Norton. "Interaction terms in logit and probit models". Economics Letters 80 (2003): 123-129.

Alchian, A.A., 1969. "Corporate management and property rights.” In: Manne, H. (Ed.). Economic Policy and the Regulation of Corporate Securities. Washington, DC: American Enterprise Institute.

Antle, R., and G.D. Eppen. "Capital rationing and organizational slack in capital budgeting." Management Science 31, 2 (1985): 163-174.

Antle, R., and J. Fellingham. "Resource rationing and organizational slack in a twoperiod model." Journal of Accounting Research 28, 1 (1990): 1-24.

Arya, A., J. Fellingham, J. Glover, and K. Sivaramakrishnan. "Capital budgeting, the hold-up problem, and information system design.” Management Science 46, 2 (2000): 205-216.

Baiman, S., D.F. Larcker, and M.V. Rajan. "Organizational design for business units." Journal of Accounting Research (Autumn 1995): 205-229.

Bens, D.A., and S.J. Monahan. "Disclosure quality and the excess value of diversification." Journal of Accounting Research (September 2004): 691-730.

Berger, P.G., and R.N. Hann. "The impact of SFAS No. 131 on information and monitoring." Journal of Accounting Research 41 (2003): 163-223.

Berger, P.G., and R.N. Hann. "Segment profitability and the proprietary and agency cost of disclosure." Accounting Review 82 (2007): 869-906.

Berger, P.G., and E. Ofek. "Diversification's effect on firm value." Journal of Financial Economics 37 (1995): 39-65.

Berger, P.G., and E. Ofek. "Causes and effects of corporate refocusing programs." Review of Financial Studies 12 (Summer 1999): 311-345.

Bernardo, A.E., J. Luo, and J.J.D. Wang (2006). "A theory of socialistic internal capital markets.” Journal of Financial Economics 80 (2006): 485-509.

Billett, M.T., and D.C. Mauer. "Cross-subsidies, external financing constraints, and the contribution of the internal capital market to firm value." Review of Financial Studies 16 (2003): 1167-1201.

Black, F., and M. Scholes. "The pricing of options and corporate liabilities." Journal of Political Economy 81 (1973): 637-654.

Bower, J. Managing the resource allocation process: a study of corporate planning and investment. Harvard University, Division of Research, Graduate School of Business Administration. Boston, MA: Harvard Business School Press: 1970. 
Brickley, J.A., and L.D. van Drunen. "Internal corporate restructuring." Journal of Accounting and Economics 12 (1990): 251-280.

Bushman, R.M., R.J. Indjejikian, and A. Smith. "Aggregate performance measures in business unit manager compensation: The role of intrafirm interdependencies." Journal of Accounting Research 33 supplement (1995): 101-128.

Campa, J.M., and S. Kedia. "Explaining the diversification discount." Journal of Finance 55 (August 2002): 1731-1762.

Chow, C.W., J.C. Cooper, and W.S. Waller. "Participative budgeting: Effects of a truth-inducing pay scheme and information asymmetry on slack and performance.” Accounting Review 63, 1 (1988): 111-122.

Corbett, J., and T. Jenkinson. "How is investment financed? A study of Germany, Japan, the United Kingdom and the United States." The Manchester School Supplement (1997): 69-93.

Core, J.E., and W.R. Guay. "Stock option plans for non-executive employees." Journal of Financial Economics 61 (2001): 253-287.

Dutta, S., and S. Reichelstein. "Controlling investment decisions." Review of Accounting Studies 7 (2002): 253-281.

Fauver, L., J. Houston, and A. Naranjo. "Capital market development, international integration, legal systems, and the value of corporate diversification: A crosscountry analysis.” Journal of Financial and Quantitative Analysis 38 (March 2003): 135-157

Financial Accounting Standards Board (FASB). "Disclosure about segments of an enterprise and related information." Statement of Financial Accounting Standards No. 131. Norwalk, CT: FASB, 1997.

Fisher, J.G., L.A. Maines, S.A. Peffer, and G.B. Sprinkle. "Using budgets for performance evaluation: Effects of resource allocation and horizontal information asymmetry on budget proposals, budget slack, and performance." Accounting Review 77, 4 (2002): 847-865

Gerakos, J.J., C.D. Ittner, and F. Moers. "Compensation objectives and non-cash pay: An investigation of benefits and broad-based equity grants." Working paper (2007), available at SSRN: http://ssrn.com/abstract=1316434.

Gordon, L.A., and K.J. Smith. "Postauditing capital expenditures and firm performance: The role of asymmetric information." Accounting, Organizations and Society 17, 8 (1992): 741-757

Grossman, S.J., and O.D. Hart. "The costs and benefits of ownership: A theory of vertical and lateral integration.” Journal of Political Economy 44 (1986): 691719.

Haka, S. "A review of the literature on capital budgeting and investment appraisal: Past, present and future musings." In: C.S. Chapman, A.G. Hopwood, and 
M.D. Shields, Handbook of Management Accounting Research Volume 2. Elsevier, 2007.

Harris, M.S. "The association between competition and managers' business segment reporting decisions." Journal of Accounting Research 36 (1998): 111-128.

Harris, M., and A. Raviv. "The capital budgeting process: Incentives and information." Journal of Finance 51, 4 (1996): 1139-1174

Harris, M., and A. Raviv. "Capital budgeting and delegation." Journal of Financial Economics 50, 3 (1998): 259-289.

Harris, M., and A. Raviv. "Organization design." Management Science 48 (July 2002): 852-865.

Hayes, R.M., and R. Lundholm. "Segment reporting to the capital market in the presence of a competitor." Journal of Accounting Research 34 (1996): 261279.

Hogan, C.E., and C.M. Lewis. "Long-run investment decisions, operating performance, and shareholder value creation of firms adopting compensation plans based on economic profits." Journal of Financial and Quantitative Analysis 40 (December 2005): 721-745.

Höppe, F. "The incentive and signaling effects of annual bonus schemes: evidence from firm innovation." Working paper, Maastricht University School of Business and Economics, 2009.

Jensen, M.C. "Agency costs of free cash flow, corporate finance, and takeovers." American Economic Review 76 (May 1986): 323-329.

Kanodia, C., and D. Lee. "Investment and disclosure: The disciplinary role of periodic performance reports.” Journal of Accounting Research 36 (1998): 3355 .

Khanna. T., and K. Palepu. "The future of business groups in emerging markets: Long-run evidence from Chile." Academy of Management Journal 43 (June 2000): 268-285.

Kuppuswamy, V., and B. Villalonga. "Does diversification create value in the presence of external financing constraints? Evidence from the 2008-2009 financial crisis." Working Paper 10-101, Harvard Business School Working Paper, 2010.

Lang, L.H.P., and R. Stulz. "Tobin's q, corporate diversification, and firm performance.” Journal of Political Economy 102 (1994): 1248-1280.

Lins, K., and H. Servaes. "International evidence on the value of corporate diversification.” Journal of Finance 54 (1999): 2215-2239.

Maksimovic, V., and G. Phillips. Conglomerate firms and internal capital markets. Handbook of Corporate Finance, 1: Empirical Corporate Finance, ed. by B.E. Eckbo, 2007. 
Marino, M., and J.G. Matsusaka. "Decision processes, agency problems, and information: an economic analysis of capital budgeting procedures." Review of Financial Studies 18 (2005): 301-325.

Matsusaka, J.G., and V. Nanda. "Internal capital markets and corporate refocusing." Journal of Financial Intermediation 11 (2002): 176-211.

Melumad, N., D. Mookherjee, and S. Reichelstein. "A theory of responsibility centers.” Journal of Accounting and Economics 15 (1992): 445-484.

Meyer, M., P. Milgrom, and J. Roberts. "Organizational perspectives, influence costs, and ownership changes." Journal of Economics \& Management Strategy 1 (Spring 1992): 9-35.

Milgrom, P., and J. Roberts. Economics, organization and management. Englewood Cliffs, NJ: Prentice Hall, 1992.

Moers, F. "Performance measure properties and delegation." Accounting Review 81 (2006): 897-924.

Mookherjee, D. "Decentralization, hierarchies, and incentives." Journal of Economic Literature 44 (June 2006): 367-390.

Myers, M., L.A. Gordon, and M.M Hamer. "Postauditing capital assets and firm performance: An empirical investigation." Managerial and Decision Economics 12, 4 (1991): 317-327

Oyer, P. "Why do firms use incentives that have no incentive effects?" Journal of Finance 59 (2004): 1619-1649.

Oyer, P., and S. Schaeffer. "Why do some firms give stock to all employees? An empirical examination of the alternative theories." Journal of Financial Economics 76 (2005): 99-133.

Pierce, B.J., and J.J. Tsay. "A study of the post-completion audit practices of large American corporations: Experience from 1978 and 1988." Journal of Management Accounting Research 4, (Fall 1992): 131-155.

Prendergast, C. "The tenuous trade-off between risk and incentives." Journal of Political Economy 110 (2002): 1071-1102.

Rajan, R., H. Servaes, and L. Zingales. "The cost of diversity: The diversification discount and inefficient investment." Journal of Finance 55 (2000): 35-80.

Ramsey, J.B. "Tests for specification errors in classical linear least-squares analysis." Journal of the Royal Statistical Association B 71 (1969): 350-371.

Rosenbaum, P.R., and D.B. Rubin. "The central role of the propensity score in observational studies for causal effects." Biometrika 70 (April 1983): 41-55.

Scharfstein, D.S., and J.C. Stein. "The dark side of internal capital markets: divisional rent-seeking and inefficient investment." Journal of Finance 55 (2000): 2537-2564.

Servaes, H. "The value of diversification during the conglomerate merger wave." Journal of Finance 51 (1996): 1201-1225. 
Smith, K.J. "Investment monitoring systems, abandonment of capital assets, and firm performance." Journal of Management Accounting Research 5 (Fall 1993): 281-299.

Stein, J.C. "Internal capital markets and the competition for corporate resources." Journal of Finance 52 (1997): 111-133.

Stein, J.C. "Agency, information and corporate investment." In: Constantinides, G.M., Harris, M., Stulz, R. (Eds.). Handbook of the Economics of Finance. Amsterdam, The Netherlands: North-Holland, 2003.

Stowe, J.D., and X. Xing. "Can growth opportunities explain the diversification discount?” Journal of Corporate Finance 12 (2006): 783-796.

Verrecchia, R.E. "Discretionary disclosure." Journal of Accounting and Economics 5 (1983): 179-194.

Villalonga, B. "Does diversification cause the 'diversification discount'?" Financial Management 33(2) (2004): 5-27.

Wallace, J.S. "Adopting residual income-based compensation plans." Journal of Accounting and Economics 24 (1997): 275-300.

Whited, T. "Is it inefficient investment that causes the diversification discount?" Journal of Finance 56 (2001): 1667-1691.

Williamson, O.E. "Hierarchical control and optimum firm size." Journal of Political Economy 75, 2 (1967): 123-138.

Williamson, O.E. Markets and hierarchies: Analysis and anti-trust implications. New York, NY: Free Press, 1975.

Wooldridge, J.M. Econometric analysis of cross section and panel data. Cambridge, MA: MIT Press, 2002.

Wulf, J. "Internal capital markets and firm-level compensation incentives for division managers.” Journal of Labor Economics 20 (2002): s219-s262. 



\section{Summary in Dutch (Nederlandse samenvatting)}

De wereldwijde economische activiteit en interactie is de afgelopen decennia sterk toegenomen. Een gevolg van deze economische groei is niet alleen een toename in het aantal, maar ook in de omvang van bedrijven. Naarmate een bedrijft groeit, worden degelijke management structuren, die de steeds complexere organisatie kunnen steunen, belangrijker. In productiebedrijven zijn daarbij vooral procedures voor de efficiënte interne allocatie van kapitaal voor investeringen in vaste activa cruciaal. Immers, deze vaste activa bepalen de toekomstige productie en productiviteit van het bedrijf. Dit proefschrift bestudeert deze allocatiemechanismen, de inefficiënties die hierbij kunnen optreden en de stappen die bedrijven kunnen nemen om deze inefficiënties te beperken of op te lossen.

Het eerste hoofdstuk geeft een inleiding in het onderzoeksgebied en een overzicht van de hoofdaspecten van interne kapitaalallocatie. Vooral binnen gediversifieerde ondernemingen met meerdere divisies of business units zijn deze allocaties van belang. Bij deze concerns vormt het hoofdkantoor de enige link naar de externe kapitaalmarkt. Verder bundelt het hoofdkantoor het kapitaal dat de divisies genereren. Op basis van investeringsaanvragen door de divisies beslist dan het hoofdkantoor hoe het extern en intern kapitaal binnen het bedrijf verdeeld wordt. Voorstanders van kapitaalallocatie binnen gediversifieerde bedrijven tonen aan dat de interne allocatie efficiënter is dan een directe financiering van een investeringsproject door de externe kapitaalmarkt. De reden hiervoor is vooral dat het hoofdkantoor een beter inzicht heeft in hoe rendabel de investeringen zijn dan kapitaalverstrekkers in de externe markt, dat wil zeggen dat beslissingen onder minder informatie asymmetrie genomen worden. Verder is interne financiering van voordeel om minder afhankelijk van de externe kapitaalmarkt te kunnen opereren, in het bijzonder bij structurele marktproblemen zoals in opkomende markten of in meer ontwikkelde economieën tijdens de recente kredietcrisis. Tegenstanders argumenteren dat interne kapitaalallocaties vaak een subjectieve beslissing van het hoofdkantoor zijn. Dit geeft managers, die investeringen aanvragen, de mogelijkheid om de besluitvorming in hun eigen voordeel te beïnvloeden om zodoende meer kapitaal dan het economisch optimum te ontvangen. Dit non-coöperatieve gedrag van managers resulteert in inefficiënties omdat het kapitaal niet meer altijd het beste investeringsproject bereikt.

Gezien de potentiële inefficiënties van interne allocaties, is het opmerkelijk dat de bestaande literatuur weinig aandacht besteedt aan de manieren waarop bedrijven 
inefficiënties kunnen voorkomen of tenminste beperken. Dit is het startpunt van het onderzoek in hoofdstuk 2. Het uitgangspunt voor deze studie is dat divisie managers voorrang geven aan de doelen van hun eigen divisie in plaats van die van de gehele onderneming; anders gezegd, dat er een conflict in incentives bestaat. Daardoor proberen deze managers tijdens de kapitaalallocatie meer middelen te krijgen, ongeacht het betere potentieel van projecten in andere divisies. Dit is ten eerste mogelijk omdat het hoofdkantoor, vertegenwoordigd door de CEO, beïnvloedingsactiviteiten niet helemaal kan onderscheiden van rechtvaardige investeringsaanvragen door informatie asymmetrie tussen divisie en hoofdkantoor. Ten tweede is het door deze informatie asymmetrie en de specificiteit van taken noodzakelijk te delegeren. Door deze afhankelijkheid kan de CEO de beïnvloedingactiviteiten niet negeren, omdat de divisie managers anders kunnen dreigen het bedrijf te verlaten.

De CEO heeft twee keuzes om hierop te reageren. Aan de ene kant kan hij direct meer aan de beïnvloedende manager uitbetalen en zijn salaris verhogen. Alternatief kan de CEO ook beslissen om de divisie manager meer kapitaal voor investeringen toe te wijzen, op kosten van een verlaging van het budget van alle andere divisies. De divisie manager beschouwt zowel directe uitbetaling als ook (over-) allocatie als substituten. De directe uitbetaling levert minder kosten voor de onderneming op dan de reallocatie van kapitaal, die de investeringsefficiëntie van het hele bedrijf verlaagt. Echter het direct verhogen van het salaris verlaagt het hoeveelheid kapitaal onder de controle van de CEO, hetgeen indruist tegen zijn streven om zo veel mogelijk kapitaal te controleren. In zoverre de incentives van de CEO niet helemaal parallel lopen met de doelen van de onderneming, zal de CEO de reallocatie van het budget prefereren boven directe uitbetaling. De verwachting is dus dat kapitaalallocatie naar een divisie en salaris van de divisie manager als substituut negatief gerelateerd zijn en dat excessieve allocaties de efficiëntie van interne investeringen verlagen. Een oplossing voor dit probleem, dat gedreven wordt door afwijkende prikkels tussen divisie manager, CEO en eigenaar van het bedrijf, is het belonen middels aandeel-gebaseerde beloningscontracten aan alle betrokken partijen, oftewel "firm-wide equity incentives". Hierdoor merkt een manager, die beslissingen neemt die de efficiëntie van kapitaalallocatie verlagen, dit direct in zijn beloning. De verwachting is dus dat de kwaliteit van interne kapitaalallocaties positief gerelateerd is aan de uitgave van equity incentives.

Deze verwachtingen worden getest op basis van de segmentrapportage van een streekproef van beursgenoteerde bedrijven in de VS in de jaren 1998 tot 2004, in combinatie met handmatig verzamelde data over bezoldigingsstructuren. De resultaten bevestigen de verwachting dat inefficiënte, excessieve kapitaalallocaties negatief gerelateerd zijn aan het salaris van de directe divisie manager. Allocatie en directe compensatie zijn dus substituten. Verder tonen de resultaten aan, dat de 
kwaliteit van kapitaalallocatie stijgt, als er meer equity incentives uitgegeven worden.

Terwijl hoofdstuk 2 het effect van beloningscontracten op de efficiëntie van kapitaalallocaties bestudeert, richt hoofdstuk 3 zich op veranderingen in de organisatiestructuur als alternatief om de efficiëntie van deze allocaties te verhogen. Meerdere theoretische studies argumenteren dat het economisch profiel van een divisie de hoofdreden voor non-coöperatief gedrag van divisie managers is, wat als gevolg inefficiënte interne kapitaalallocatie heeft. Een manager besteedt bijvoorbeeld meer tijd aan lobbyen als de verwachte rendementen van productieve activiteiten lager zijn dan van lobbyen. Verder kunnen sterke verschillen in investeringsmogelijkheden tussen divisies ertoe leiden dat beter presterende divisies suboptimaal investeren omdat zij niet bereid zijn om zwakkere divisies door het kapitaal van de optimale investering mede te financieren. Reallocaties van kapitaal door een interventie van de CEO kunnen de investeringsefficiëntie verbeteren maar zijn meer een teken dan een oplossing van niet-coöperatief gedrag.

In het equilibrium kiezen bedrijven voor de optimale organisatiestructuur die, gegeven alle andere markt factoren, de kosten van niet-coöperatief gedrag omtrent de kapitaalallocatie zo laag mogelijk houdt. Omdat markten zich verschillend kunnen ontwikkelen, veranderen de economische profielen van de individuele divisies en daarmee ook de prikkels voor inefficiënt gedrag en lobbyen naar meer kapitaal door de divisie manager. Om deze inefficiënties tenminste voor een deel te voorkomen, is een mogelijke oplossing het veranderen van het economisch profiel van de divisie, aangezien dit de oorspronkelijke reden van inefficiënte kapitaalallocaties is. Het profiel van een divisie kan veranderd worden door een nieuwe samenstelling van de activiteiten die in iedere divisie gebundeld zijn. In plaats van alleen sterk presterende activiteiten in een divisie en zwakkere in een andere kunnen bijvoorbeeld sterke en zwakke activiteiten in een divisie onder het toezicht van een, in plaats van twee divisie managers gebundeld worden. Dit verlaagt de diversiteit van divisieprestaties en daarmee het niet-coöperatief gedrag bij de kapitaalallocatie. Hieruit resulteert de hypothese dat bedrijven met minder efficiënte kapitaalallocaties meer geneigd zijn om hun divisies opnieuw te structureren. Verder wordt verwacht dat de efficiëntie van kapitaalallocaties na een herstructurering van divisies stijgt.

De hypotheses van de tweede studie worden onderzocht met behulp van een streekproef van gediversifieerde bedrijven uit de VS in de jaren 1998 tot 2007. Segmentrapportage in deze periode valt, zoals in de eerste studie van dit proefschrift, onder het reglement van SFAS 131. Veranderingen in de organisatiestructuur leiden daarom ook tot een verandering in de segmentrapportage. Dit maakt het mogelijk om veranderingen in de organisatiestructuur op te sporen. Om andere redenen voor een verandering in de segmentverslaggeving, zoals acquisities of deelverkoop van de onderneming, uit te sluiten, werden 10-k 
rapportages van de SEC gelezen. Bedrijven geven in deze rapportages de reden voor veranderingen in de verslaggeving aan. Op die manier kunnen daadwerkelijke reorganisaties geverifieerd en andere evenementen uitgefilterd worden. Deze groep van reorganiserende bedrijven wordt in de analyse vergleken met soortgelijke bedrijven die niet van organisatiestructuur veranderen. De resultaten tonen aan dat bedrijven met minder efficiënte kapitaalallocaties een grotere kans hebben om hun organisatiestructuur te veranderen. Verder stijgen de efficiëntie van kapitaalallocaties en de ondernemingswaarde voor aandeelhouders als gevolg van deze herstructureringen.

De twee studies in hoofdstuk 2 en 3 gebruiken extern gerapporteerde data om de efficiëntie van interne kapitaalallocaties te meten, zoals de meerderheid van gerelateerde studies in dit onderzoeksgebied. Een reden hiervoor is dat bedrijven meestal terughoudend zijn met het beschikbaar stellen van interne data. Echter, het gebruik van externe data limiteert de precisie en de omvang van de mogelijke analyses. Ten gevolge van deze beperkingen blijven veel vragen over het allocatieproces op basis van publiek beschikbare data onbeantwoord.

De derde studie van dit proefschrift gaat op deze beperkingen in en bestudeert kapitaalallocaties direct met behulp van een interne dataset over het investeringsproces van een gediversifieerd concern. De focus van de analyse ligt op "budgetary slack", dat wil zeggen: het gedeelte van een kapitaalallocatie dat een aanvragend agent (de divisie manager) boven de daadwerkelijk benodigde som van de principaal (de CEO) ontvangt. Het aanvragen van een bovenmatige allocatie is voordelig voor de agent omdat hij hiervan een persoonlijk voordeel in vorm van hogere eigen consumptie, oftewel "perquisites", haalt. Slack verlaagt de efficiëntie van kapitaalallocaties en wordt bevorderd door een informatie asymmetrie tussen aanvragend agent en kapitaal gevend principaal, die het de principaal onmogelijk maakt om daadwerkelijke kosten van slack te onderscheiden. De meeste studies onderzoeken budget slack in een een-periode model terwijl investeringsprojecten vaak meerdere periodes beslaan en de agent de kans geven om in de loop van het project de aangevraagde kosten opnieuw te onderhandelen. De derde studie analyseert of deze heronderhandelingen door de agent voor het verkrijgen van meer slack meer gebruikt worden als een principaal projecten meer delegeert en minder, als de principaal meer controle over het project uitoefent. Verder wordt onderzocht of agenten minder controle door de principaal ook gebruiken om slack voor hun eigen voordeel binnen de looptijd van een project voor consumptie op een eerder of later tijdstip dan oorspronkelijk gepland te verschuiven. Verschuivingen kunnen optreden omdat ook de agent door onverwachte ontwikkelingen bij langdurende investeringen niet precies kan voorspellen wanneer hij slack wil consumeren. Terwijl deze verschuivingen niet het budget verhogen, veroorzaken ze wel kosten omdat zij de zekerheid voor de principaal verminderen wanneer hij financiële middelen nodig heeft om alle projecten te kunnen financieren. 
De budget data voor deze analyse hebben betrekking op de investeringsaanvragen en -beslissingen van een wereldwijd opererend concern. Het budgetteringsproces is vergelijkbaar met soortgelijke processen in bedrijven van vergelijkbare omvang. De resultaten bevestigen dat agenten meer slack in de loop van investeringsprojecten toevoegen als de principaal meer delegeert en daardoor minder directe controle uitoefent. Dit effect is bijzonder sterk bij meer informatie asymmetrie tussen principaal en agent, hetgeen het ontdekken van slack lastiger maakt. Verder geven de resultaten aan dat agenten meer slack tussentijds verschuiven als de principaal meer delegeert. Agenten verschuiven meer slack zodra zij beter kunnen plannen wanneer zij slack willen gebruiken.

De drie studies in dit proefschrift geven veelvoudige inzichten in de werking van kapitaalallocaties in diversifieerde bedrijven. De eerste studie in hoofdstuk 2 toont aan dat beloning op basis van aandelen in het geval van divisie managers kan bijdragen aan een verbetering in de efficiëntie van kapitaalallocaties. Vaak worden dergelijk beloningen alleen gebruikt om samenwerking te bevorderen tussen divisies in markten die onderling afhankelijk zijn. Deze studie laat zien dat deze contracten ook van waarde zijn als divisies minder operationeel afhankelijk van elkaar zijn om samenwerking bij de kapitaalallocatie te bevorderen. De eerste studie introduceert verder een nieuwe methode voor het meten van de kwaliteit van interne allocaties. Anders dan de meeste bestaande maatstaven is deze methode gebaseerd op meerdere meetfactoren en daardoor minder afhankelijk van de sensitiviteit en veronderstellingen van een meetfactor. De tweede studie in hoofdstuk 3 laat zien dat niet alleen veranderingen in de beloning- maar ook in de organisatiestructuur tot een verbetering van kapitaalallocaties kunnen leiden. Dit aspect is tot op heden niet gedocumenteerd. De derde studie in hoofdstuk 4 laat de gevolgen zien als een bedrijf door delegatie van investeringsprojecten minder controle over de kosten uitoefent. De analyse maakt duidelijk dat door het opnieuw aanvragen van kosten gedurende een project de kosten meer stijgen als het hoofdkantoor meer delegeert en dus minder controle uitoefent. De rol van nieuwe onderhandelingen in budget processen is tot nu nog niet gedocumenteerd en maakt duidelijk dat de post-audit van budgets, hoewel weinig gebruikt in de praktijk, een belangrijke rol kan spelen om budgetcontrole te behouden. Deze en verdere conclusies en aanbevelingen worden in hoofdstuk 5 weergegeven. Ten slotte gaat dit proefschrift in op de vraag hoe de bevindingen in toekomstig onderzoek verder uitgebreid kunnen worden. 



\section{Summary in German (Deutsche Zusammenfassung)}

Weltweit haben über die letzten Jahrzehnte Wirtschaft und Handel bislang unerkannte Ausmaße erreicht. Infolgedessen haben nicht nur die Anzahl der hieran beteiligten Unternehmen sondern auch deren durchschnittliche Größe zugenommen. So hat seit Mitte der Neunziger Jahre die an Umsatz und Bilanzsumme gemessene Größe der US-basierten Firmen außerhalb des Finanzsektors, die in der COMPUSTAT-Datenbank geführt werden, bis zum Jahr 2009 im Durchschnitt um $136 \%$ bzw. $110 \%$ zugenommen. Trotz zunehmender Automatisierung ist im gleichen Zeitraum auch die durchschnittliche Mitarbeiterzahl um 67\% gestiegen. Ein Ende dieses Aufwärtstrends ist vorerst nicht absehbar.

Eine wichtige Voraussetzung für dieses Wachstum sind leistungsfähige Managementstrukturen zur Unterstützung der internen Organisation des Unternehmens. Dabei nehmen insbesondere Steuerungsprozesse für Kapitalanlageentscheidungen, z.B. für den Neubau einer Fabrik, eine besondere Rolle ein: Corbett und Jenkinson (1997) zeigen, dass von 1970 bis 1994 zwischen 70\% und 96\% aller Neuinvestitionen im Vereinigten Königreich, Japan, Deutschland und den USA durch interne Mittel finanziert wurden. Darüber hinaus verdeutlicht die noch auslaufende Kreditkrise, welche zu einer bedeutenden Verknappung externer Finanzierungsmöglichkeiten geführt hat, die Bedeutung effizienter Innenfinanzierung. Das zentrale Thema dieser Dissertation sind diese internen Kapitalallokationsmechanismen, welche Faktoren zu Ineffizienzen dieser Prozesse führen und wie diesen Ineffizienzen entgegengewirkt werden kann.

Das erste Kapitel dieser Dissertation gibt eine kurze Einleitung in das Forschungsgebiet der internen Kapitalallokationen. Vor allem in diversifizierten Unternehmen mit organisatorisch von einander getrennten Geschäftsbereichen sind diese Allokationen von Bedeutung, da kapitalgenerierende Bereiche durch Querfinanzierungen kapitalschwächere Bereiche unterstützen können. Diese Querfinanzierungen werden zumeist durch die Konzernzentrale gesteuert, die zudem auch zusätzliche Mittel am externen Kapitalmarkt, z.B. durch Banken oder die Wertpapierbörse, aufnehmen und in den internen Allokationsprozess einfließen lassen kann. Ein Vorteil dieser internen Allokation in diversifizierten Unternehmen ist, dass die Konzernzentrale sehr viel geringerer Informationsasymmetrie ausgesetzt ist als ein externer Investor, der beabsichtigt direkt in einen Unternehmensteil zu investieren. Zudem unterliegt ein Unternehmen durch Innenfinanzierungsmechanismen weniger den Umständen und Anforderungen des externen Kapitalmarktes. Dies 
ist zum einen von offensichtlichem Vorteil in Ländern mit schwach entwickelten Kapitalmarktstrukturen, zum anderen aber auch in Wirtschaftszonen mit ausgebildeten Finanzmärkten, wenn etwa wie in der jüngsten Kreditkrise systematische Risiken die Fremdmittelaufnahme erschweren. Demgegenüber darf jedoch nicht außer Acht gelassen werden, dass die Konzernzentrale einen subjektiven Ermessensspielraum bei der internen Kapitalallokation besitzt. Dadurch haben Geschäftsbereichsleiter, die für Investitionen in ihrem Bereich Kapital anfragen, den Anreiz, die Verteilungsentscheidung zu ihren Gunsten zu beeinflussen um über das ökonomische Optimum hinaus mehr Kapital zu erhalten. Dieses unkooperative Verhalten verringert die Allokationseffizienz, da das Kapital innerhalb des Unternehmens nicht mehr unbedingt der besten Investitionsmöglichkeit zufließt.

Ein Großteil der bestehenden Studien zu diesem Fragenkomplex analysiert, ob interne Kapitalallokationen durchschnittlich ineffizient oder effizient arbeiten. Hingegen ist die Frage, wie Unternehmen auf Ineffizienzen reagieren um diese zu begrenzen bisher nur in Ansätzen untersucht worden. Dies ist Gegenstand der ersten Studie dieser Dissertation in Kapitel 2. Im Zentrum steht dabei der Anreizkonflikt zwischen Geschäftsbereichsleitern und Gesamtkonzern, welcher daraus resultiert, dass sich die Bereichsleiter zuerst dem Wohlergehen ihres Firmenzweiges und erst nachrangig dem des Gesamtunternehmens verpflichtet fühlen. Durch diesen Interessenkonflikt versucht der Bereichsleiter mitunter Kapital zu erhalten, welches innerhalb des Konzerns an anderer Stelle besser investiert wäre, indem er die Konzernleitung in seiner Entscheidungsfindung zu seinen Gunsten zu beeinflussen versucht. Die Konzernleitung steht dabei vor dem Problem, dass sie aufgrund von Informationsasymmetrien die von den Geschäftsbereichen vorgestellten Investitionsprojekte nicht vollständig auf deren tatsächliche Parameter hin überprüfen kann. Beeinflussungsaktivitäten können daher nicht grundsätzlich durchschaut und verhindert werden. Darüberhinaus kann die Konzernleitung selbst bei Erkennen von Beeinflussungsaktivitäten die Anfragen der Geschäftsbereichsleiter nicht einfach ignorieren, da letztere sonst drohen, die Firma zu verlassen.

Da der Konzern aber auf den Erhalt der Unternehmensstruktur bedacht ist, bieten sich zwei Möglichkeiten, auf Beeinflussungsaktivitäten zu reagieren. Zum einen kann der Konzern dem Geschäftsbereich mehr Investitionskapital zuweisen, wodurch die Budgets anderer Bereiche, denen Mittel entzogen werden, verzerrt werden. Zum anderen kann die Konzernleitung dem Geschäftsbereichsleiter direkt mehr Gehalt auszahlen, womit keine Budgetverzerrungen auftreten. Insgesamt verursacht die direkte Auszahlung weniger Kosten für das Unternehmen und ist daher im Sinne der Anteilseigner. Allerdings werden durch letztere Variante die der Konzernleitung selber zur Verfügung stehenden Mittel vermindert, welche der Konzernleitung von direktem, persönlichen Nutzen sind, etwa durch ,perquisite spendings“. Wenn die Konzernleitung nicht vollständig im Interesse der Anteilseigner sondern auch zum eigenen Vorteil handelt, wird sie sich eher für eine Umverteilung des 
Investitionsbudgets entscheiden, anstatt die eigenen Mittel zu kürzen. Durch diese Abwägungsentscheidung zwischen Erhöhung des Gehalts des Bereichsleiters oder alternativ einer übermäßigen Investition in dessen Bereich folgt die Hypothese, dass Gehalt und Allokation Substitute und somit negativ korreliert sind. Ferner ist zu erwarten, dass die Entscheidung, in den Kapitalallokationsprozess einzugreifen, dessen Effizienz vermindert. Das Grundproblem dieser Fehlallokationen liegt in dem zweifachen Anreizkonflikt zwischen Bereichsleiter und Konzernleitung sowie der Konzernleitung und den Anteilseignern. Eine Möglichkeit diesem Problem entgegenzuwirken ist die Ausgabe von auf dem Firmenwert beruhenden Leistungsgehältern, z.B. in Form von Aktien oder darauf beruhenden Derivaten. Hieraus resultiert die Hypothese, dass die interne Allokationseffizienz mit dem Ausmaß derartiger Leistungsgehälter steigt.

Die Hypothesen dieser Studie werden auf Basis der Segmentberichterstattung im Jahresabschlussbericht von börsennotierten, diversifizierten Unternehmen in den USA im Zeitraum von 1998 bis 2004 untersucht. Diese Daten wurden erweitert durch einen eigens aufgebauten Datensatz über Entlohnungsstrukturen auf der Grundlage von 10-k Formularen der amerikanischen Börsenaufsicht SEC. Die Auswertung dieser Daten bestätigt die Erwartung, dass Kapitalallokation und Gehalt der Bereichsleiter als Substitut fungieren und übermäßiger Gebrauch von Allokationen zu einer Verminderung der Gesamtallokationseffizienz des Unternehmens führt. Weiterhin zeigen die Ergebnisse, dass die Allokationsineffizienzen zurückgehen, je stärker die Bereichsleiter und die Konzernleitung unternehmenswert-basierte Gehälter beziehen.

Im Gegensatz zu den in Kapitel 2 behandelten Effizienzsteigerungen durch Anpassungen der Gehaltsverträge liegt der Fokus der zweiten Studie dieser Dissertation in Kapital 3 auf Modifizierungen der Organisationstruktur als alternativem Mittel zur Verminderung von Allokationsineffizienzen. Mehrere theoretische Arbeiten verweisen darauf, dass nicht-kooperatives Verhalten von Bereichsleitern in diversifizierten Unternehmen auf das durch ökonomische Kennzahlen ergebende Profil wie etwa der Wirtschaftlichkeit des ihnen unterstehenden Bereiches im Verhältnis zu den anderen Unternehmensbereichen zurückzuführen ist. So wird unter anderem angeführt, dass ein Bereichsleiter zwischen produktivem und beeinflussendem Verhalten aufgrund des relativen Ertrags beider Tätigkeiten wählt. Ein relativ leistungsschwächerer Unternehmensbereich wird daher eher zu nicht-kooperativem Verhalten führen.

Kapitel 3 erläutert, dass starke Differenzen in Ertrag und Wachstumsmöglichkeiten der Bereiche zu ineffizientem Verhalten der Bereichsleiter führen können. Im ökonomischen Equilibrium legen Unternehmen die organisatorischen Grenzen zwischen ihren Geschäftsbereichen so fest, dass das daraus resultierende nichtkooperative Verhalten so niedrig wie möglich gehalten wird. Da sich die einzelnen Märkte der Unternehmensbereiche jedoch im Laufe der Zeit unterschiedlich entwi- 
ckeln können, bleiben die durch das Leistungsprofil der Bereiche hervorgerufenen Anreize zu ineffizientem Verhalten nicht zwangsläufig dieselben. Um den daraus resultierenden Fehlallokationen vorzubeugen, können Unternehmen die Organisation der Geschäftsbereiche neu einteilen, um dadurch die ökonomischen Profile der Bereiche zu verändern, womit die Anreize zu ineffizientem Verhalten eingedämmt werden. Unternehmen können derartige Umorganisationen durch Neuzusammenstellung des Portfolios der diversen Geschäftstätigkeiten pro Bereich erreichen. Beispielsweise können ein starker und ein schwacher Unternehmensteil in einen gemeinsamen Bereich überführt werden, um dessen durchschnittliche Wirtschaftlichkeit den restlichen Unternehmensbereichen anzupassen. Die Wahrscheinlichkeit einer Umstrukturierung der Geschäftsbereiche sollte daher höher bei Firmen sein, deren Kapitalallokationen relativ ineffizient sind. Darüberhinaus ist zu erwarten, dass die interne Kapitalallokationseffizienz nach derartigen Organisationsveränderungen steigt.

Diese Hypothesen werden mit einem Datensatz US-amerikanischer, börsengelisteter Firmen mit mehreren Geschäftsbereichen in dem Zeitraum 1998-2007 untersucht. Wie in Kapitel 2 macht sich diese Studie dabei zunutze, dass die Rechnungslegungsvorschriften in diesen Jahren eine Anpassung der Berichtssegmente an die tatsächliche Organisationsstruktur vorschreiben. Veränderungen in dieser Struktur machen sich daher in einer veränderten Präsentation der Berichtssegmente bemerkbar. Um sicher zu gehen, dass es sich bei diesen Veränderungen tatsächlich um Neuorganisationen der Bereiche und nicht um anderweitige Ereignisse wie z.B. Veräußerungen oder Fusionen handelt, wurden die 10-k Formulare der SEC herangezogen, da hier die Gründe der Veränderungen in der Segmentberichterstattung genannt sind. Der sich aus dieser Prozedur ergebende Datensatz untermauert die Hypothesen dieser Studie. Erstens haben Firmen mit niedrigerer Allokationseffizienz eine höhere Wahrscheinlichkeit, ihre Geschäftsbereiche neu zu gliedern. Zweitens verbessern sich sowohl die Effizienz der internen Kapitalverteilung als auch die Wertentwicklung des von den Anteilseignern investierten Vermögens in den Folgejahren dieser Neugliederungen.

Der Großteil der akademischen Untersuchungen zur internen Kapitalallokationseffizienz basiert auf Daten der externen Rechnungslegung statt auf tatsächlichen internen Kapitaltransferdaten. $\mathrm{Zu}$ einem Großteil liegt dies an der Zurückhaltung vieler Firmen, interne Daten zu Forschungszwecken freizugeben. Dies führt allerdings dazu, dass zum einen die internen Kapitalallokationen zumeist nur näherungsweise bestimmt werden können. Zum anderen müssen so viele Fragestellungen in Bezug auf den zu Grunde liegenden Allokationsprozess unbeantwortet bleiben. Durch die Kooperation mit einem börsengelisteten Konzern und die direkte Auswertung von Daten des Investitionsbudgetprozesses unterliegt die dritte Studie dieser Dissertation in Kapitel 4 nicht diesen Einschränkungen. 
Der Fokus der dritten Studie liegt dabei auf dem Auftreten von Budgetanfragen, die den tatsächlichen Kapitalbedarf eines Investitionsprojekts übersteigen. Geschäftsbereichsmanager nutzen diese überhöhten Anfragen um mehr Kapital für ihren Geschäftsbereich zu erhalten. Diese Budgetüberschüsse können auftreten, wenn die kapitalbewilligende Stelle, d.h. der Prinzipal, den exakten Kapitalbedarf des anfragenden Bereichsleiters, d.h. des Agenten, nicht genau überprüfen kann. Vielfach werden in den bisherigen Arbeiten dabei vereinfachte Budgetprozesse mit nur einer Verhandlungsrunde zwischen Agent und Prinzipal untersucht. Erstens umfassen jedoch reale Budgetprozesse zumeist mehrere Investitionsperioden, zu denen der Agent das angefragte Budget neu verhandeln kann. Diese Möglichkeit wird dem Agenten eingeräumt, da sich ein Investitionsprojekt während seiner Laufzeit anders als ursprünglich vom Agent vorhersehbar entwickeln kann. Zweitens wird in den meisten Studien eine vereinfachte Delegationsstruktur angenommen, bei der ein Agent Projekte anfragt und ein Prinzipal die Bewilligungsrechte hält. In tatsächlichen Budgetprozessen gestaltet sich die Bewilligungsstruktur zumeist differenzierter: Nicht alle Projekte werden zentral von einem Prinzipal begutachtet, sondern je nach Projekt auch in Abstufungen in tieferen Managementebenen. Kapitel 4 widmet sich speziell dem Zusammenspiel dieser beiden Aspekte. Eine der untersuchten Hypothesen besagt dabei, dass Agenten die Nachverhandlungsoption stärker ausnutzen, um nach Bewilligung eines Projektes zusätzliche, überhöhte Kapitalforderungen zu ihrem eigenen Nutzen zu stellen je mehr der Prinzipal die Bewilligungsrechte delegiert, d.h. je weniger direkte Kontrolle er über das Investitionsprojekt ausübt. Eine weitere Hypothese ist, dass der Agent stärker versucht, die Budgetüberschüsse innerhalb eines Projektes zwischen den Investitionsperioden vorzuverlegen oder zu verzögern je mehr die Bewilligungsrechte delegiert werden. Dem Agent nutzen diese intertemporalen Verschiebungen, falls sich Investitionsprojekte nicht gemäß seinen Erwartung entwickeln und der Agent die ursprüngliche zeitliche Verteilung von Budgetüberschüssen seinen Konsumpräferenzen neu anpassen möchte.

Zur Untersuchung dieser Hypothesen greift Kapitel 4, wie weiter oben erwähnt, auf Daten des Budgetprozesses eines weltweit agierenden, börsengelisteten Konzerns zurück. Die Resultate bestätigen, dass Bereichsleiter stärker überschüssiges Budget für ihren Geschäftsbereich nachverhandeln und mehr dieser Überschüsse zu ihrem Vorteil intertemporal verschieben, je mehr die Konzernleitung die Bewilligungsrechte $\mathrm{zu}$ Investitionsprojekten delegiert, d.h. je weniger direkte Kontrolle ausgeübt wird. Die Ergebnisse zeigen darüberhinaus, dass angefragte Budgetüberschüsse vor allem in der Anfangsphase von Projekten höher ausfallen, wenn es für die Bewilligungsstelle besonders schwierig ist, die Anfragen zu überprüfen. Ein weiterer Befund ist, dass Agenten Budgetüberschüsse zu dem Zeitpunkt ausgeprägter verschieben, wenn sie selber ihre eigenen Konsumpräferenzen von Budgetüberschüssen besser einschätzen können. 
Die drei Studien dieser Dissertation liefern diverse Erkenntnisse über die Kapitalallokationsprozesse in diversifizierten Unternehmen, die sowohl für Theorie als auch Praxis relevant sind. Die erste Studie in Kapitel 2 zeigt, das aktienbasierte Gehaltsverträge für Geschäftsbereichsleiter für eine Verbesserung der Kapitalallokationseffizienz sorgen können. Konventionell werden derartige Verträge jedoch nur angewendet, wenn die Geschäftsfelder des Unternehmens einander beeinflussen, um somit die Kooperation im operativen Geschäft der Bereichsleiter zu fördern. Diese Dissertation zeigt, dass derartige Verträge auch von Vorteil sind, um innerbetriebliche Kooperation nicht nur im operativen Bereich sondern auch in Finanzierungsfragen zu fördern. In der ersten Studie wird weiterhin eine neue Methode entwickelt, um die Allokationseffizienz zu messen. Im Gegensatz zu bestehenden Verfahren greift diese Methode u.a. auf mehrere Messfaktoren zurück und ist dadurch weniger abhängig von der Sensitivität einer einzelnen Bezugsgröße. Die zweite Studie in Kapitel 3 zeigt, dass nicht nur Veränderungen in der Gehaltsstruktur sondern auch in der Zusammenstellung der Geschäftsfelder je Unternehmensbereich zu einer Verbesserung der Kapitalallokationseffizienz führen können. Der Effekt von Organisationsstrukturen auf die Allokationseffizienz ist in der bisherigen Literatur noch nicht berücksichtigt worden. Die Studie verdeutlicht, dass Unternehmen nichtkooperatives Verhalten der Bereichsleiter durch Neuordnung der Geschäftsfelder verbessern können, ohne zu drastischeren Maßnahmen wie der Veräußerung von Bereichen greifen zu müssen. Die dritte Studie in Kapitel 4 legt dar, dass sich die Delegierung von Bewilligungsrechten über Investitionsprojekte nachteilig auf die Kostenentwicklung auswirken und zu überschüssigen Budgetanfragen und Budgetverschiebungen führen kann. Die Rolle von Neuverhandlungen bei Budgetanfragen ist in der bisherigen Literatur noch nicht eingehend untersucht worden. Weiterhin zeigt diese Studie, dass eine umfassende Budgetkontrolle auch die Kostenentwicklung der vergangenen Perioden einschließen sollte. Häufig werden Budgetentwicklungen jedoch nur von der laufenden zur nächsten Periode kontrolliert, wodurch z.B. akkumulierende Kostenneuanfragen nicht direkt identifiziert und verhindert werden können. Diese und weitere Schlussfolgerungen dieser Dissertation werden in Kapitel 5 behandelt. Kapitel 5 schließt mit Empfehlungen, wie die Forschungsergebnisse dieser Arbeit in Anschlussuntersuchungen ausgeweitet werden können. 


\section{Curriculum Vitae}

Julius Frédéric André was born on the $14^{\text {th }}$ of October 1980 in Hamburg, Germany. From 2001 to 2006 he studied business administration at Maastricht University, The Netherlands, and at HEC Lausanne, Switzerland. After graduation, he joined the Department of Accounting and Information Management at Maastricht University as a $\mathrm{PhD}$ candidate. He conducted part of his research as a Visiting Scholar at the Wharton School, University of Pennsylvania, USA, in 2009. His work was presented and discussed at various universities and international conferences in Europe and the US. 